MARCELO HILÁRIO GALLARO DOS SANTOS

\title{
DESENVOLVIMENTO DE TRANSDUTORES PIEZELÉTRICOS DE ULTRASSOM PARA FORMAÇÃO DE IMAGENS
}


MARCELO HILÁRIO GALLARO DOS SANTOS

\section{DESENVOLVIMENTO DE TRANSDUTORES \\ PIEZELÉTRICOS DE ULTRASSOM \\ PARA FORMAÇÃO DE IMAGENS}

Dissertação apresentada à Escola

Politécnica da Universidade de

São Paulo para obtenção do

Título de mestre em Engenharia

São Paulo

2010 
MARCELO HILÁRIO GALLARO DOS SANTOS

\section{DESENVOLVIMENTO DE TRANSDUTORES PIEZELÉTRICOS DE ULTRASSOM PARA FORMAÇÃO DE IMAGENS}

Dissertação apresentada à Escola Politécnica da Universidade de São Paulo para obtenção do Título de mestre em Engenharia

Área de Concentração:

Engenharia Mecatrônica

Orientador:

Prof. Dr. Julio Cezar Adamowski

São Paulo

2010 
Este exemplar foi revisado e alterado em relação à versão original, sob responsabilidade única do autor e com a anuência de seu orientador.

São Paulo, de julho de 2010.

Assinatura do autor

Assinatura do orientador

\section{FICHA CATALOGRÁFICA}

Santos, Marcelo Hilário Gallaro dos

Desenvolvimento de transdutores piezelétricos de ultrassom para formação de imagens / M.H.G. dos Santos. -- ed.rev. -- São Paulo, 2010.

p.78

Dissertação (Mestrado) - Escola Politécnica da Universidade de São Paulo. Departamento de Engenharia Mecatrônica e de Sistemas Mecânicos.

1.Transdutores piezelétricos de ultrassom (Modelagem; Fabricação I.Universidade de São Paulo. Escola Politécnica. Departamento de Engenharia Mecatrônica e de Sistemas Mecânicos II.t. 


\section{AGRADECIMENTOS}

Ao Professor Dr. Julio Cezar Adamowski, pela orientação e pelo constante estimulo transmitido durante todo o trabalho.

Aos professores do departamento, em especial ao Prof. Dr. Flávio Buiochi e Emílio Carlos Nelli Silva pelas sugestões.

Aos amigos do laboratório de ultrassom que colaboraram direta ou indiretamente na execução deste trabalho, em especial ao doutores Nicolás Péres e Marco Aurélio Brizzotti Andrade, aos mestres Timoteo Francisco de Oliveira, João Eduardo Maeda, David Julio da Costa, Nilson Noris Franceschetti, Mario Luis Carneiro e aos engenheiros Alan Tavares de Souza e Eduardo Bonci Cavalca.

Ao senhor Raimundo Izidro pela atenção e responsabilidade.

A Petrobras/ANP e ao CNPq pelo apoio financeiro para realizar esse trabalho.

A minha esposa Maria Trindade e a minha filha Marcella Concettina, nascida na época que eu iniciei o mestrado, por elas me darem motivação para vida e novas responsabilidades. 


\section{RESUMO}

Este trabalho visa o desenvolvimento de um processo de fabricação para a produção de pequenos lotes de transdutores piezelétricos de ultrassom. O comportamento destes transdutores é estudado através de modelos matemáticos e verificações experimentais, com o objetivo de obter especificações de projeto para seleção de cerâmicas piezelétricas, dimensionamento da camada de retaguarda e da camada de casamento de impedância acústica. Utilizando as equações constitutivas dos materiais piezelétricos e a solução da equação de onda, o transdutor é modelado como um produto de matrizes, sendo cada matriz correspondente a uma camada do transdutor. As relações entre os parâmetros de entrada e saída das camadas analisadas do modelo são utilizadas para determinar as funções características de interesse no projeto de transdutores específicos. O processo de fabricação foi desenvolvido visando diminuir o tempo de montagem e aumentar a confiabilidade de funcionamento, melhorando a qualidade de soldagem das conexões elétricas, da colagem e da vedação, e aumentando a precisão de posicionamento dos componentes do transdutor. Assim objetiva-se obter lotes homogêneos em relação às especificações de projeto, com repetitividade no comportamento dos transdutores produzidos. Utilizando o processo de fabricação desenvolvido, um lote de 133 transdutores de $5 \mathrm{MHz}$ foi produzido, com cerâmicas piezelétricas de $10 \mathrm{~mm}$ de diâmetro para suportar pressões de até $500 \mathrm{~atm}$. Os transdutores foram testados individualmente e os resultados mostram uma grande repetitividade do processo desenvolvido. 


\begin{abstract}
This work aims the development of a manufacturing process for the production of small batches of piezoelectric ultrasonic transducers. The behavior of these transducers is studied by means of mathematical models and experimental tests, in order to get the design specifications for the piezoelectric ceramics selection, scaling the backing and matching layers. Using the constitutive equations of piezoelectric materials and the wave equation solution, the transducer is modeled as a product of matrices, each matrix corresponding to a layer of the transducer. The relationship between input and output parameters of transducer layers is used to determine the characteristic functions of specific transducers. The manufacturing process was developed for small production batches of transducers and aim decrease assembly time and increase reliability operation, improving the quality of welding of electrical connections, bond and seal, and increasing the positioning accuracy of the transducer components. So the objective is to obtain homogeneous batches regarding to design specifications, with repeatability in the behavior of the manufactured transducers. Using the process manufacturing developed, a 133-transducers batch of $5 \mathrm{MHz}$ was produced, with $10 \mathrm{~mm}$ diameter piezoelectric ceramics, to withstand pressures up to $500 \mathrm{~atm}$. The transducers are individually tested and the results show a high repeatability of the manufacturing process.
\end{abstract}




\section{SUMÁRIO}

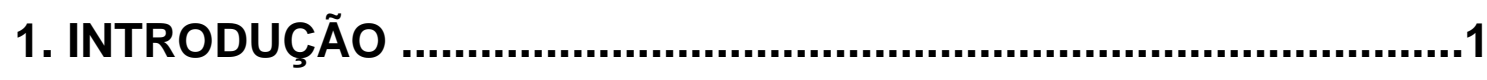

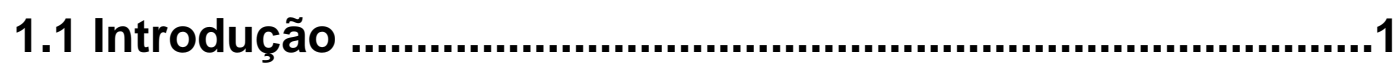

1.2 Objetivos do trabalho .............................................................

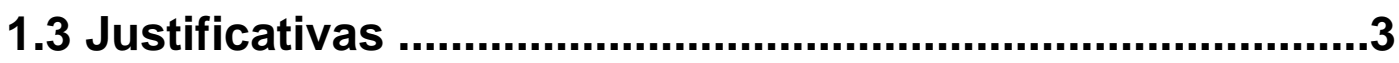

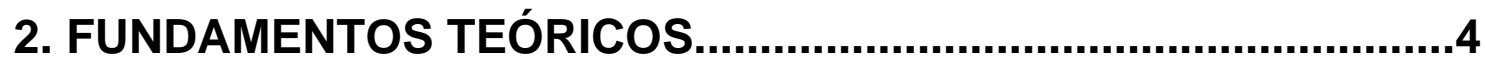

2.1 Transdutor de ultrassom.........................................................

2.2 Material piezelétrico...............................................................

2.3 Frequências de ressonância e de anti-ressonância

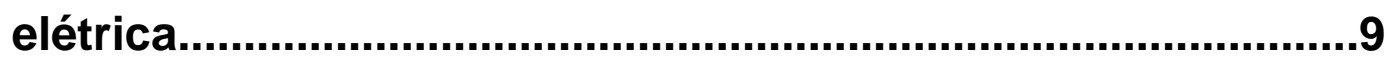

2.4 Impedância acústica ………….......................................11

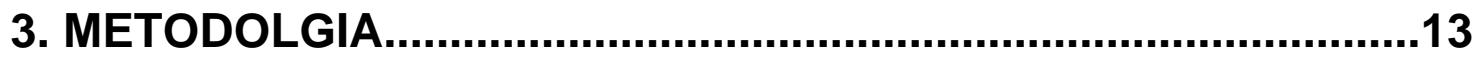

3.1 Introdução........................................................................13

3.2 Modelo matemático do transdutor piezelétrico de

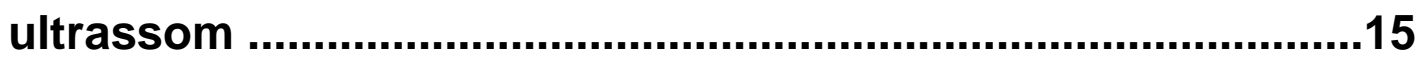

3.2.1 Descrição do modelo .................................................................15

3.2.2 O modelo da cerâmica piezelétrica................................................15

3.2.3 Camadas de acoplamento acústico ............................................. 25

3.3 Algoritmo de cálculo e resultados numéricos.........................30

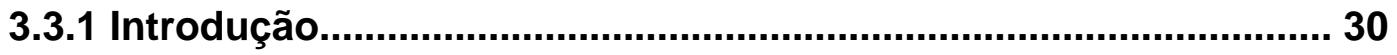

3.3.2 Funções características do transdutor........................................ 30

3.3.3 O programa de cálculo............................................................... 38

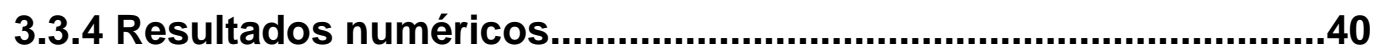

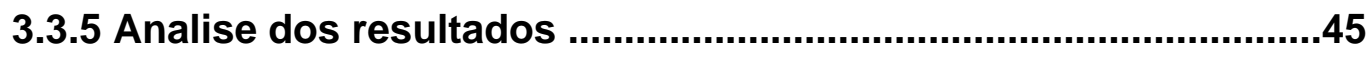

3.4 Fabricação de transdutores..............................................46 
3.4.1 Processo de fabricação e montagem dos componentes dos transdutores.

3.4.2 Materiais utilizados para constituição das camadas passivas..56

3.4.3 Análise do processo de fabricação. 59

3.5 Resultados experimentais. .62

3.6 Comparação entre o sinais teórico e experimental 67

4 CONCLUSÕES. 74

REFERÊNCIAS BIBLIOGRÁFICAS........................................76

BIBLIOGRAFIA COMPLEMENTAR............................................78 


\section{INTRODUÇÃO}

\subsection{Introdução}

Este trabalho visa o desenvolvimento de um processo de fabricação para a produção de pequenos lotes de transdutores piezelétricos de ultrassom monoelementos e também o estudo do comportamento desses transdutores através de modelos matemáticos e verificações experimentais feitas em protótipos de transdutores, com o objetivo de obter especificações de projeto para fabricação de transdutores.

Para cada aplicação especifica existe um tipo de transdutor mais adequado. Para formação de imagens as características importantes de um transdutor são a resolução axial e a resolução lateral. A resolução axial quantifica a capacidade do transdutor de detectar pontos próximos na direção do seu eixo e está relacionada com a frequência de operação e a largura do pulso ultrassônico. Frequências altas e pulsos estreitos melhoram a resolução axial. Definida a frequência de operação, pode-se diminuir a largura do pulso de um transdutor evitando reverberações internas, fazendo com que uma das camadas do transdutor, a camada de retaguarda, absorva adequadamente os sinais dentro do transdutor e a outra camada, a camada de casamento de impedância acústica, transmita o máximo da energia dos sinais para o meio, aumentado a eficiência. A resolução lateral quantifica a capacidade de distinção de pontos próximos na direção perpendicular ao eixo do transdutor e é determinada, além do mecanismo de movimentação lateral, pela diretividade do feixe acústico do transdutor, que relaciona a potência irradiada numa determinada direção com a potência total irradiada pelo transdutor. Neste trabalho, são otimizados transdutores para obter uma boa resolução axial, ou seja, são construídos e modelados transdutores de banda larga.

A aplicação do lote de transdutores produzidos neste trabalho é na inspeção preventiva de oleodutos e gasodutos utilizando pig ultrassônico, a qual assume uma 
importância estratégica na indústria de petróleo para evitar vazamentos, assegurar a produtividade operacional e evitar a contaminação do meio ambiente. O pig ultrassônico (OKAMOTO,1999) utilizado nessas inspeções preventivas para detectar pontos de corrosão ao longo de dutos é um equipamento impulsionado pelo próprio fluido da tubulação, que possui vários transdutores piezelétricos de ultrassom para detectar a extensão e a profundidade dos defeitos com precisão de décimos de milímetros. Através da técnica de pulso-eco são medidas as distâncias dos transdutores de ultrassom até as paredes interna e externa do oleoduto, obtendo-se dessa forma uma medida indireta das perdas em espessura da parede, possibilitando quantificar a corrosão interna e externa. Devido à grande demanda de transdutores piezelétricos de ultrassom com características específicas para atender as empresas que montam os pigs, este trabalho apresenta o desenvolvimento de um processo para a produção de lotes de transdutores de ultrassom de banda larga para operação em ambientes sujeitos a altas pressões (até 500 bar).

O processo de fabricação foi desenvolvido visando diminuir o tempo de montagem, melhorar a qualidade da colagem e vedação, e aumentar a precisão de posicionamento dos componentes do transdutor. Assim, objetiva-se ter um lote homogêneo em relação às especificações de projeto, com repetitividade no comportamento dos transdutores produzidos.

Utilizando as equações constitutivas dos materiais piezelétricos e a solução da equação de onda, o transdutor é modelado como um produto de matrizes, sendo cada matriz correspondente a uma camada do transdutor (modelo de matriz distribuída). Através dos modelos matemáticos que descrevem a vibração de um elemento de material piezelétrico e de materiais não piezelétrico, avalia-se o comportamento de um transdutor de ultrassom monoelemento que vibra no que é conhecido como modo de espessura (thickness mode). Então, utilizam-se as relações entre os parâmetros de entrada e saída das camadas analisadas do modelo para determinar as funções características de interesse no projeto de transdutores específicos. 


\subsection{Objetivos do trabalho}

Os objetivos deste trabalho se resumem em:

- Aplicar o modelo de matriz distribuída para simular a resposta pulso-eco de transdutores piezelétricos de ultrassom.

-Desenvolvimento de um processo de fabricação de transdutores piezelétricos de ultrassom monoelemento.

-Fabricação e caracterização de um conjunto de transdutores para verificar repetitividade do processo de fabricação.

-Comparar os resultados teóricos com verificações experimentais de transdutores através da medição do sinal de reflexão (modo pulso-eco).

\subsection{Justificativa}

A repetitividade dos comportamentos elétrico e mecânico dos transdutores de ultrassom estão principalmente relacionados aos processos de fabricação dos materiais passivos que compõem os transdutores e do processo de montagem de transdutores. Os modelos matemáticos são essenciais para uma análise do comportamento dos transdutores e uma boa compreensão desses modelos é necessária para o desenvolvimento de transdutores específicos.

Este trabalho visa o estudo do comportamento de transdutores de ultrassom através de modelos matemáticos e verificações experimentais e a verificação de processos de fabricação que reproduza a repetitividade de comportamento de transdutores. 


\section{FUNDAMENTOS TEÓRICOS}

Para um maior entendimento do tipo de transdutor que trata este trabalho é descrito um transdutor de ultrassom, as propriedades dos materiais piezelétricos e os fenômenos relacionados à impedância acústica.

\subsection{Transdutor de ultrassom}

O transdutor de ultrassom converte energia elétrica em energia mecânica na forma de vibrações, e vice-versa. Aplicando uma tensão elétrica nos terminais do transdutor é emitida uma onda acústica no meio, e quando uma onda acústica é recebida, ou seja quando ocorrem variações de pressão na superfície frontal do transdutor, é obtida nos terminais elétricos uma tensão.

Um transdutor de ultrassom monoelemento de banda larga é mostrado na fig. 2.1 e uma foto dos transdutores construídos na figura 2.2. Os componentes principais do transdutor são o elemento piezelétrico ativo em formato de disco cerâmico , uma camada de retaguarda e uma camada de casamento de impedância acústica.

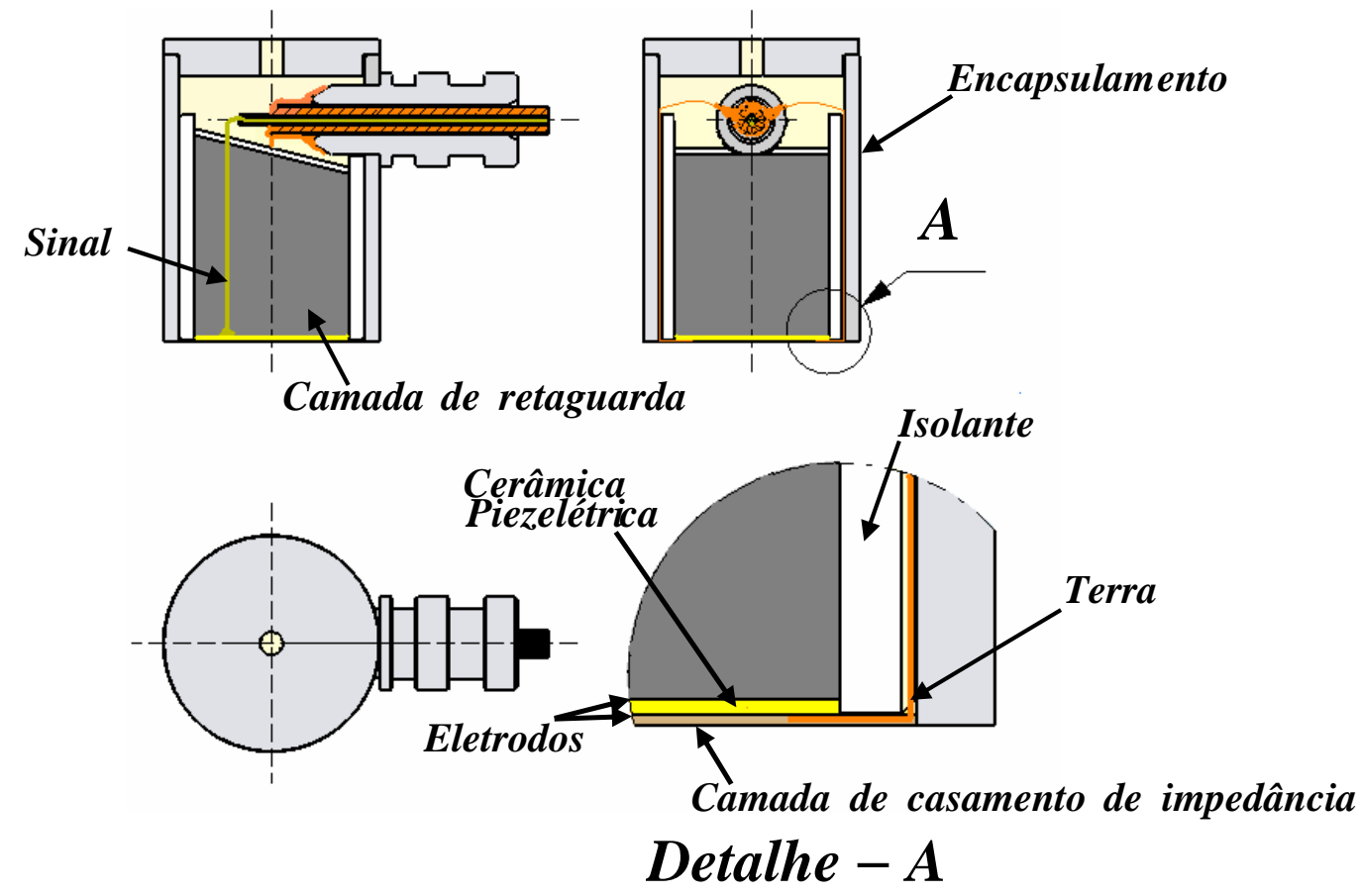

Figura 2.1: Típica construção de um transdutor de ultrassom monoelemento. 


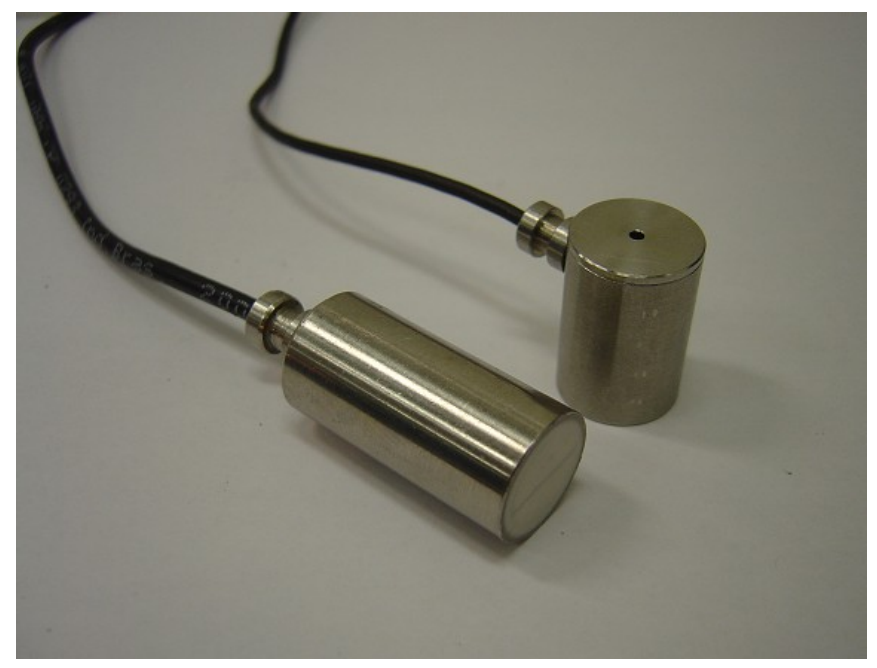

Figura 2.2: Transdutores de ultrassom monoelementos construídos no laboratório

O elemento ativo no transdutor que realiza a transdução de energia é a cerâmica de material piezelétrico, material que sob ação de um campo elétrico produz deformação mecânica e quando sofre deformação mecânica produz um campo elétrico.

A camada de retaguarda (backing) tem a função de absorver as vibrações produzidas pela cerâmica piezelétricas, as quais se propagam para trás do trandutor, evitando reflexões indesejadas. Para que isso ocorra, o material da camada de retaguarda deve ter impedância acústica próxima da impedância acústica da cerâmica, para minimizar a reflexão. Além disso, deve ter altas perdas para absolver a onda que se propaga pelo material da camada de retaguarda, minimizando a amplitude das ondas refletidas na superfície posterior desta camada. Cuidados adicionais, como manter a superfície posterior da camada de retaguarda não paralela à superfície da cerâmica, pode ser implementado na fabricação do transdutor mantendo uma inclinação durante o processo de cura.

A camada de casamento de impedância acústica (matching layer) além de proteger o material piezelétrico tem a função de fazer o casamento de impedância acústica entre a cerâmica e o meio. Para que haja máxima transmissão possível de energia do 
material piezelétrico, ou seja, transmissão total entre a cerâmica e o meio, a espessura da camada de casamento acústico deve ser dimensionada com um quarto do comprimento de onda da frequência central do transdutor e sua impedância acústica deve ser dada por (KINO, 1987):

$$
Z_{m}=\left(Z_{1} Z_{2}\right)^{1 / 2}
$$

sendo que

$Z_{m}=$ Impedância da camada de casamento acústico

$Z_{1}=$ Impedância da cerâmica piezelétrica

$Z_{2}=$ Impedância do meio

Contudo para um transdutor de banda larga que tem uma única camada de casamento de impedância acústica a equação (2.1) pode ser modificada para (Shung et al.,1996):

$$
Z_{m b}=\left(Z_{1} Z_{2}^{2}\right)^{1 / 3}
$$

sendo que

$Z_{m b}=$ Impedância acústica da camada de casamento acústico para transdutor de banda larga

$Z_{1}=$ Impedância acústica da cerâmica piezelétrica

$Z_{2}=$ Impedância acústica do meio

Na seção 3.3.4 são mostrados os resultados de simulações desses dois modelos de camadas de casamento de impedância acústica. Verificou-se que os dois modelos apresentam resultados muito próximos, sendo que o modelo dado pela equação (2.2) fornece um sinal ligeiramente mais amortecido. Apesar disso, considerando-se também as propriedades mecânicas da camada de casamento de impedância, foi utilizado o modelo dado pela equação (2.1). 


\subsection{Material piezelétrico}

Um material piezelétrico sofre deformação sob a ação de um campo elétrico, e gera um campo elétrico quando é deformado. Diferentemente de um material elástico que a tensão mecânica depende somente da deformação, e de um material dielétrico que o deslocamento elétrico depende somente do campo elétrico, em um material piezelétrico, a tensão depende da deformação e também do campo elétrico, e o deslocamento elétrico depende do campo elétrico e da deformação. Assim as equações constitutivas do efeito piezelétrico são dadas por (GALLEGO JUÁRES, 1989) .

$$
\begin{aligned}
& T=c^{E} S-e^{t} E \\
& D=e S+\varepsilon^{S} E .
\end{aligned}
$$

sendo que:

$T=$ vetor das tensões mecânicas

$S=$ vetor das deformações mecânicas

$D=$ vetor deslocamento elétrico

$E=$ vetor campo elétrico

$e=$ Matriz dos coeficientes piezelétricos

$\varepsilon^{s}=$ matriz de permissividades elétricas medidas com deformação constante

$c^{E}=$ matriz de rigidez elástica obtida com campo elétrico constante

$t=$ matriz transposta

O material piezelétrico utilizado neste trabalho possui classe de simetria $6 \mathrm{~mm}$ (AULD,1990), tendo simetria no plano $x y$. Considerando estas características as equações 2.3 e 2.4 são reescritas como: 


$$
\begin{aligned}
& {\left[\begin{array}{c}
T_{1} \\
T_{2} \\
T_{3} \\
T_{4} \\
T_{5} \\
T_{6}
\end{array}\right]=\left[\begin{array}{cccccc}
c_{11}^{\mathbf{E}} & c_{12}^{\mathbf{E}} & c_{13}^{\mathbf{E}} & 0 & 0 & 0 \\
c_{12}^{\mathbf{E}} & c_{11}^{\mathbf{E}} & c_{13}^{\mathbf{E}} & 0 & 0 & 0 \\
c_{13}^{\mathbf{E}} & c_{13}^{\mathbf{E}} & c_{33}^{\mathbf{E}} & 0 & 0 & 0 \\
0 & 0 & 0 & c_{44}^{\mathbf{E}} & 0 & 0 \\
0 & 0 & 0 & 0 & c_{55}^{\mathbf{E}} & 0 \\
0 & 0 & 0 & 0 & 0 & c_{66}^{\mathbf{E}}
\end{array}\right]\left[\begin{array}{l}
S_{1} \\
S_{2} \\
S_{3} \\
S_{4} \\
S_{5} \\
S_{6}
\end{array}\right]-\left[\begin{array}{ccc}
0 & 0 & e_{31} \\
0 & 0 & e_{31} \\
0 & 0 & e_{33} \\
0 & e_{15} & 0 \\
e_{15} & 0 & 0 \\
0 & 0 & 0
\end{array}\right]\left[\begin{array}{l}
E_{1} \\
E_{2} \\
E_{3}
\end{array}\right]} \\
& {\left[\begin{array}{l}
D_{1} \\
D_{2} \\
D_{3}
\end{array}\right]=\left[\begin{array}{cccccc}
0 & 0 & 0 & 0 & e_{15} & 0 \\
0 & 0 & 0 & e_{15} & 0 & 0 \\
e_{31} & e_{31} & e_{33} & 0 & 0 & 0
\end{array}\right]\left[\begin{array}{l}
S_{1} \\
S_{2} \\
S_{3} \\
S_{4} \\
S_{5} \\
S_{6}
\end{array}\right]+\left[\begin{array}{ccc}
\varepsilon_{11}^{\mathbf{s}} & 0 & 0 \\
0 & \varepsilon_{11}^{\mathbf{s}} & 0 \\
0 & 0 & \varepsilon_{33}^{\mathbf{s}}
\end{array}\right]\left[\begin{array}{l}
E_{1} \\
E_{2} \\
E_{3}
\end{array}\right]}
\end{aligned}
$$

Nesse trabalho considera-se que a direção de polarização da cerâmica é na direção z, ou seja na direção 3. 


\subsection{Frequência de ressonância e de anti-ressonância elétrica.}

O circuito elétrico equivalente de uma cerâmica piezelétrica que tem direção de vibração paralela à direção de excitação elétrica (modo de espessura) e vibra próxima a sua frequência de ressonância (MOREIRA, 2008) pode ser visto na fig. (2.3).

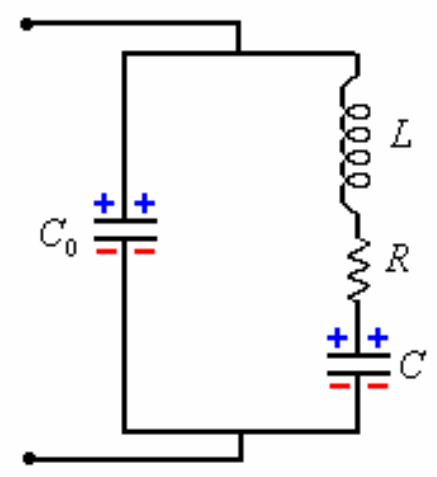

Figura 2.3: Circuito equivalente de uma cerâmica piezelétrica próximo à ressonância fundamental.

A parte elétrica do circuito equivalente da cerâmica é representada pelo ramo do circuito que possui o capacitor $C_{0}$ e a parte mecânica, no outro ramo do circuito, é representada por um indutor de indutância $L$ que corresponde à massa, por um resistor de resistência $R$ que corresponde ao amortecimento e por um capacitor de capacitância $C$ que corresponde à constante elástica. No circuito equivalente ocorre uma interação da ressonância mecânica com a parte elétrica devido ao efeito piezelétrico.

Na frequência de ressonância elétrica $\left(f_{r}\right)$, os valores de $L$ e $C$ são tais que, as reatâncias $X_{L}$ e $X_{c}$ se anulam por serem opostas em sinais e iguais em magnitude, conforme equações (2.8), (2.9) e (2.10). Resultando, no ramo em série, apenas a resistência elétrica $R$ que é pequena (condições de curto circuito). Assim na curva do modulo da impedância elétrica, figura (2.4), a frequência de ressonância elétrica corresponde a frequência de mínima impedância. 


$$
\begin{gathered}
X_{L}=2 \pi f_{r} L \\
X_{C}=\frac{1}{2 \pi f_{r} C} \\
X_{L} \approx X_{C}
\end{gathered}
$$

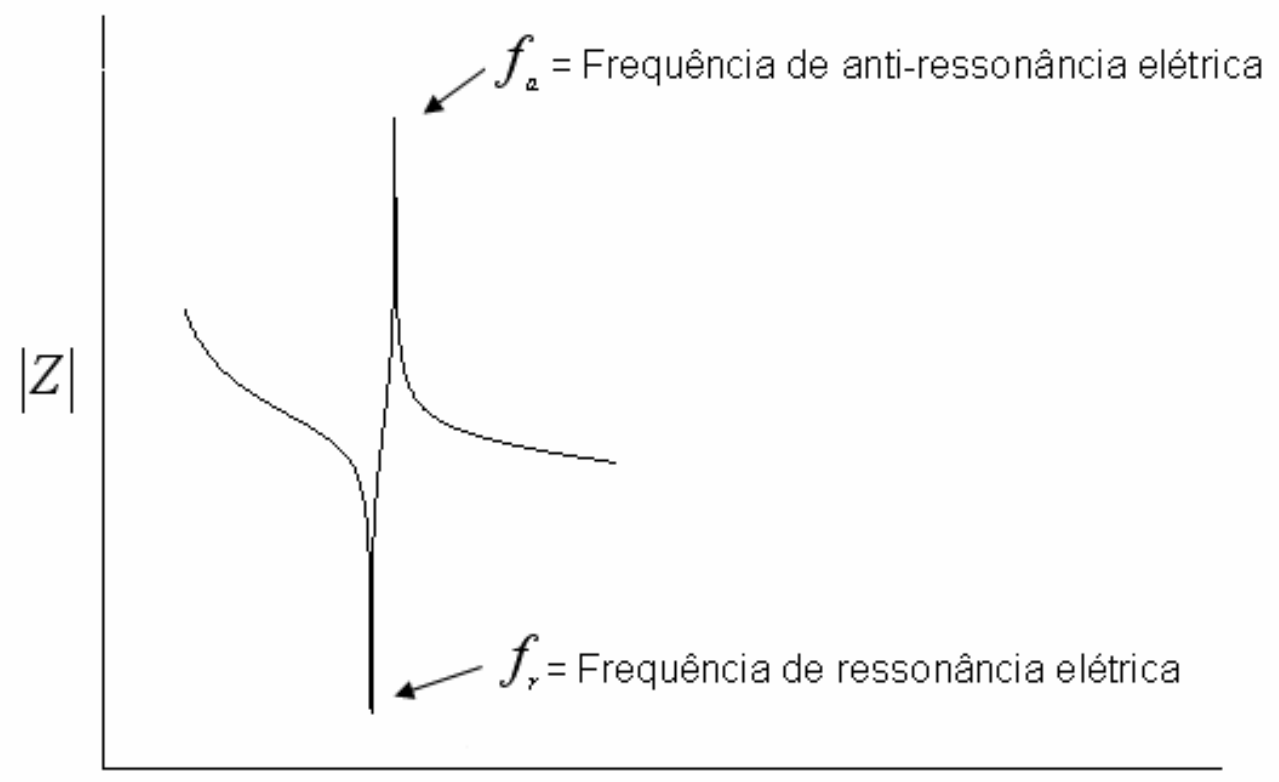

Frequência $(\mathrm{MHz})$

Figura 2.4: Modulo da impedância elétrica em função da frequência para um material piezelétrico no vácuo.

Para frequências maiores que a frequência de ressonância elétrica, a parte mecânica torna-se indutiva devido à reatância $X_{c}$ tender a zero. Na frequência de antiressonância $\left(f_{a}\right)$ a impedância elétrica atinge o valor máximo (condições de circuito aberto), devido à impedância do ramo em série torna-se igual e oposta à impedância de $C_{0}$ e a corrente oposta fluir pelos dois ramos. Assim a frequência de anti-ressonância é denominada frequência de máxima impedância elétrica. Quanto mais afastado estiver as frequências de ressonância e anti-ressonância, maior será o coeficiente de acoplamento eletromecânico $K_{A}$, que indica a eficiência com que num dado modo de vibrar, a energia elétrica é transformada em energia mecânica ou vice versa. 


\subsection{Impedância acústica}

A impedância acústica característica $Z$ é uma propriedade importante para o dimensionamento da camada de retaguarda e da camada de casamento de impedância acústica do transdutor, pois ela determina a amplitude da onda transmitida e refletida nas interfaces entre as camadas do transdutor e entre o transdutor e o meio. A impedância acústica característica é definida como (KINSLER et al.,1982):

$$
Z=\rho c
$$

sendo que $\rho$ =densidade da camada

$c=$ velocidade da onda acústica na camada

As impedâncias acústicas dimensionadas podem ser obtidas variando a fração em volume de misturas. Neste trabalho, será utilizado alumina e epóxi para camada de casamento de impedância acústica e tungstênio e epóxi para a camada de retaguarda.

Os fenômenos de transmissão na interface são representados na figura abaixo:

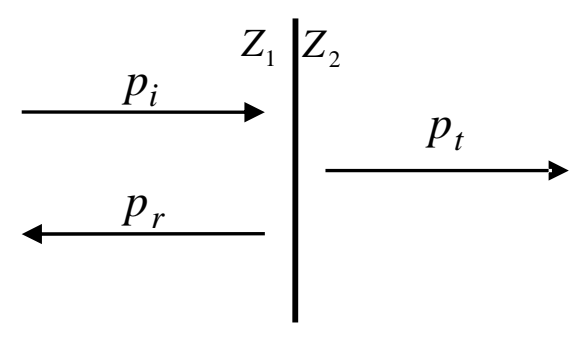

Figura 2.3: Fenômenos de transmissão na interface de dois meios

Sendo $p_{i}$ a amplitude da onda incidente, $p_{r}$ a amplitude da onda refletida e $p_{t}$ a amplitude da onda transmitida. 
Os fenômenos de transmissão são quantificados pelo coeficiente de transmissão $T_{a c}$ (equação 2.12) e pelo coeficiente de reflexão $R_{a c}$ (equação 2.13) :

$$
\begin{array}{ll}
T_{a c}=\frac{p_{t}}{p_{i}} & T_{a c}=\frac{2 Z_{2}}{Z_{1}+Z_{2}} \\
R_{a c}=\frac{p_{r}}{p_{i}} & R_{a c}=\frac{Z_{2}-Z_{1}}{Z_{1}+Z_{2}}
\end{array}
$$

Verifica-se nas equações (2.12) e (2.13) que quando a impedância do meio da onda incidente for igual à impedância do meio em que a onda é transmitida, não ocorre reflexão da onda $\left(R_{a c}=0\right)$ e toda a onda é transmitida $\left(T_{a c}=1\right)$. Também se pode verificar na equação (2.13) que quanto maior a diferença de impedâncias acústicas entre os dois meios, maior será a amplitude da onda refletida. 


\section{METODOLOGIA}

\subsection{Introdução}

Neste capitulo é detalhado, com as devidas alterações iniciais das condições de contorno elasto-elétricas para a cerâmica piezelétrica utilizada neste trabalho, o desenvolvimento do modelo proposto por LAMBERTI, N., Giua, P. E., Pappalardo, M., que tem o título "Modello Matriciale e suo Impiego Nell’Ottimizzazione della Risposta Impulsiva del Trasduttore Multielemento". Este desenvolvimento foi utilizado por tratar da otimização da resposta impulsiva de transdutores de ultrassom e por descrever um modelo simplificado unidimensional, onde esforços e deformações são em função de uma única cordenada, referente ao eixo 3 que é ortogonal as faces dos eletrodos da cerâmica. Esta simplificação pode ser feita devido à hipótese que a cerâmica do transdutor multielemento, em formato de um paralelepípedo recto, não é deformada na direção do seu comprimento (rigidez infinita na direção do eixo ortogonal 2) por este ser bem maior do que as duas outras dimensões, largura (direção do eixo ortogonal 1) e espessura (eixo 3), e para mais uma simplificação, devido à largura ser menor que a espessura pode-se assumir um estado de tensão nulo na direção do eixo 1.

No modelo de transdutor monoelemento desenvolvido neste trabalho, com cerâmica circular, o diâmetro da cerâmica é muito maior do que a sua espessura e assim para a simplificação em um modelo unidimensional temos as hipóteses que as deformações são nulas nas direções do eixo 1 e do eixo 2.

Embora os modelos sejam unidimensionais, devido as diferenças das proporções geométricas da cerâmica piezelétrica do modelo de transdutor multielementos e do modelo de transdutor monoelemento, têm-se diferenças nas condições de contorno elasto-elétricas e por conseqüência nas constantes das equações constitutivas dos materiais piezelétricos. Sendo que as duas equações constitutivas que modelam a cerâmica piezelétrica do transdutor monoelemento, as quais são relacionadas à direção 3 , assumem a forma mais simplificada de modelagem. 
Em relação aos aspectos construtivos é detalhado o processo de fabricação de protótipos de transdutores, o dispositivo de montagem e o desenvolvimento e caracterização dos materiais utilizados para a camada de casamento de impedância acústica e para camada de retaguarda.

São descritas as verificações experimentais de caracterização das cerâmicas e dos transdutores produzidos, efetuando comparações com os resultados teóricos obtidos do modelo e verificando a repetitividade de comportamento dos transdutores através de uma analise estatística. 


\subsection{Modelo matemático do transdutor piezelétrico de ultrassom}

\subsubsection{Descrição do modelo}

Neste trabalho é descrito o modelo matemático de um transdutor piezelétrico de ultrassom monoelemento, que é utilizado para o estudo de otimização dos parâmetros de projeto que determinam a eficiência do transdutor para uma aplicação especifica . É descrito de um ponto de vista analítico o comportamento de um transdutor monoelemento, supondo que ele irá vibrar no que é conhecido como modo de espessura (thickness mode). Em particular, são calculados os modelos matemáticos que descrevem a vibração de um elemento de material cerâmico piezelétrico e de um material não piezelétrico. Utilizando as equações constitutivas dos materiais piezelétricos e a solução da equação de onda, o transdutor é modelado como um produto de matrizes. Essa abordagem matricial permite determinar as relações entre os parâmetros de entrada e de saída do transdutor e com estas definir algumas funções que quantificam a eficiência dos transdutores em determinadas aplicações.

\subsubsection{O modelo da cerâmica piezelétrica}

Considere um elemento típico do transdutor monoelemento, cuja forma é mostrada na Fig.3.1 onde a espessura $\ell$ da cerâmica piezelétrica é muito menor que o seu raio $a(\ell<<a)$.

Para o desenvolvimento do modelo, supõe-se que o material cerâmico piezelétrico é polarizado ao longo do eixo 3, e que o campo elétrico é aplicado ao longo do mesmo eixo, através da metalização mostrada na fig.3.1.

Para estudar as vibrações desse elemento, utilizam-se as equações constitutivas do material piezelétrico; eq. 2.3 e 2.4 nas quais as variáveis independentes são as deformações e o campo elétrico. 


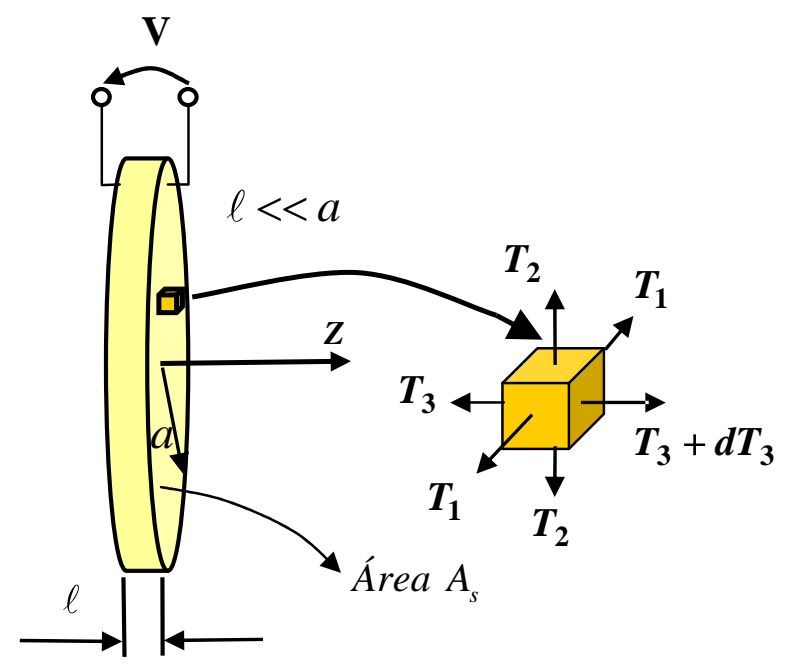

Figura 3.1 - Geometria da cerâmica piezelétrica do transdutor.

O disco cerâmico piezelétrico modelado neste trabalho tem uma alta relação $a / \ell$, ou seja, a espessura do disco é muito menor do que o raio da face do mesmo, assim os modos de vibrar do disco se aproximam dos modos do modelo unidimensional (placa de dimensões infinita). Além disso, considerando que 0 deslocamento $u_{3} \mathrm{e}$ o deslocamento elétrico $D_{3}$ não dependem das coordenadas radiais, têm se:

$$
\begin{aligned}
& S_{1}=S_{2}=S_{4}=S_{5}=S_{6}=0 \text { e } S_{3} \neq 0 \\
& E_{1}=0 \text { e } E_{2}=0
\end{aligned}
$$

Aplicando as hipóteses acima nas equações constitutivas de um material piezelétrico de simetria $6 \mathrm{~mm}$ com polarização na direção 3 obtêm-se:

$$
\begin{aligned}
& T_{3}=c_{33}^{E} S_{3}-e_{33} E_{3} \\
& D_{3}=e_{33} S_{3}+\varepsilon_{33}^{S} E_{3}
\end{aligned}
$$

A partir das equações (3.3) e (3.4), aplicando a segunda lei de Newton e a lei de Gauss obtém-se a equação de onda plana que governa o movimento vibracional da cerâmica na direção $z$ : 


$$
\begin{aligned}
& \rho \frac{\partial^{2} u_{3}}{\partial t^{2}}=\frac{\partial T_{3}}{\partial z} \\
& \rho=\frac{m_{c}}{\left(A_{s} \ell\right)}
\end{aligned}
$$

sendo que $\rho$ é a densidade da cerâmica, $m_{c}$ é a massa cerâmica e $A_{s}$ a área da face circular da cerâmica.

Substituindo $E_{3}$ da equação (3.4) na eq.(3.3) obtém-se:

$$
T_{3}=\left(c_{33}^{E}+\frac{e_{3}{ }^{2}}{\varepsilon_{33}^{S}}\right) \mathrm{S}_{3}-\frac{e_{33}}{\varepsilon_{33}^{S}} D_{3}
$$

que, derivando em z, transforma-se:

$$
\frac{\partial T_{3}}{\partial \mathrm{z}}=c_{33}^{E}\left(1+\frac{e_{33}^{2}}{c_{33}^{E} \varepsilon_{33}^{S}}\right) \frac{\partial \mathrm{S}_{3}}{\partial \mathrm{z}}
$$

Já que ao longo de z não há carga elétrica livre tem-se:

$$
\frac{\partial D_{3}}{\partial z}=0
$$

Substituindo (3.8) em (3.5), e recordando que

$$
S_{3}=\frac{\partial u_{3}}{\partial z}
$$

obtém-se a equação de onda que rege o movimento de vibração do elemento cerâmico:

$$
\rho \frac{\partial^{2} u_{3}}{\partial \mathrm{t}^{2}}=c_{33}^{E} \quad\left(1+\frac{e_{33}^{2}}{c_{33}^{E} \varepsilon_{33}^{S}}\right) \frac{\partial^{2} u_{3}}{\partial \mathrm{z}^{2}}
$$

A velocidade de propagação da onda no meio piezelétrico será:

$$
V_{A}^{D}=\sqrt{\frac{c_{33}^{D}}{\rho}},
$$

sendo que

$$
c_{33}^{D}=c_{33}^{E}+\frac{e_{33}^{2}}{\varepsilon_{33}^{S}}
$$


representa a constante elástica. $O$ sobrescrito $D$ significa que, nesse caso, o deslocamento elétrico é constante na direção de propagação da onda.

Dois outros parâmetros de interesse para caracterizar o comportamento da cerâmica são a sua capacitância estática e o fator de acoplamento eletromecânico. Para determiná-los é necessário integrar a equação de onda.

Assumindo uma excitação do tipo senoidal :

$$
D_{3}(z, t)=D_{0} e^{j \omega t},
$$

procura-se a solução da equação de onda harmônica do tipo

$$
\begin{aligned}
& u_{3}(z, t)=u(z) e^{j \omega t} \\
& u_{3}(z, t)=\left[A \sin \left(\frac{\omega z}{V_{A}^{D}}\right)+B \cos \left(\frac{\omega z}{V_{A}^{D}}\right)\right] e^{j \omega t}
\end{aligned}
$$

As constantes $A$ e $B$ podem ser calculadas pela imposição de condições de contorno. Essas são obtidas impondo que o esforço é nulo na superfície livre da cerâmica:

$$
\begin{gathered}
T_{3}(0)=0 \\
T_{3}(\ell)=0 .
\end{gathered}
$$

Que, sendo substituído na eq. (3.7) fornece:

$$
\begin{aligned}
& \left.c_{33}^{D} \frac{\partial u_{3}}{\partial z}\right|_{z=0}-\frac{e_{33}}{\varepsilon_{33}^{S}} D_{3}=0 \\
& \left.c_{33}^{D} \frac{\partial u_{3}}{\partial z}\right|_{z=\ell}-\frac{e_{33}}{e_{33}^{S}} D_{3}=0
\end{aligned}
$$

Substituindo nas equações (3.19) e (3.20) a expressão de $u_{3}$, obtém-se o sistema de equações a ser resolvido para o cálculo de $A$ e $B$.

$$
\left[c_{33}^{D} \frac{\omega}{V_{A}^{D}} A-\frac{e_{33}}{\varepsilon_{33}^{S}} D_{0}\right] e^{j \omega t}=0
$$




$$
\left[c_{33}^{D} \frac{\omega}{V_{A}^{D}}(A \cos \theta-B \sin \theta)-\frac{e_{33}}{\varepsilon_{33}^{S}} D_{0}\right] e^{j \omega t}=0
$$

com

$$
\theta=\frac{\omega \ell}{V_{A}^{D}}
$$

Resolvendo o sistema de equações, obtêm-se:

$$
\begin{aligned}
& A=\frac{e_{33}}{e_{33}^{S}} \frac{V_{A}^{D}}{\omega} \frac{D_{0}}{c_{33}^{D}} \quad \mathrm{e} \\
& B=-\frac{e_{33}}{\varepsilon_{33}^{S}} \frac{\mathrm{V}_{\mathrm{A}}^{\mathrm{D}}}{\omega} \frac{D_{0}}{c_{33}^{D}} \operatorname{tg} \frac{\theta}{2},
\end{aligned}
$$

que substituídas em (3.15), fornecem a expressão do deslocamento:

$$
u_{3}(z)=\frac{e_{33}}{e_{33}^{S}} \frac{V_{A}^{D}}{\omega c_{33}^{D}}\left[\sin \left(\frac{\omega z}{V_{A}^{D}}\right)-\operatorname{tg} \frac{\theta}{2} \cos \left(\frac{\omega z}{V_{A}^{D}}\right)\right] D_{3}
$$

Substituindo $c_{33}^{D}$ na expressão dada em (3.12) obtém-se :

$$
u_{3}(z)=\frac{e_{33}}{c_{33}^{E} e_{33}^{S}+e_{33}{ }^{2}} \frac{V_{A}^{D}}{\omega}\left[\sin \left(\frac{\omega z}{V_{A}^{D}}\right)-\operatorname{tg} \frac{\theta}{2} \cos \left(\frac{\omega z}{V_{A}^{D}}\right)\right] D_{3}
$$

Assim, com a equação (3.27) que expressa a variação do deslocamento ao longo da direção z, pode-se obter o campo elétrico $E_{3}$ na mesma direção. A partir da eq. (3.4) tem-se:

$$
E_{3}(z)=-\frac{e_{33}}{e_{33}^{S}}\left\{\frac{e_{33}}{c_{33}^{E} e_{33}^{S}+e_{33}^{2}}\left[\cos \left(\frac{\omega z}{V_{A}^{D}}\right)+\operatorname{tg} \frac{\theta}{2} \sin \left(\frac{\omega z}{V_{A}^{D}}\right)\right]\right\} D_{3}+\frac{D_{3}}{e_{33}^{S}}
$$

Ao integrar o campo ao longo de z entre 0 e $\ell$, é possível calcular a tensão entre as faces do transdutor; a relação entre a tensão em suas faces e a corrente que flui fornece a impedância de entrada do elemento piezelétrico considerado

$$
Z_{\text {elétrico }}=\frac{1}{j \omega C_{0}}\left[1-2 \frac{V_{A}^{D} \ell}{\omega} K_{A}^{2} \operatorname{tg} \frac{\theta}{2}\right]
$$


sendo que

$$
C_{0}=\frac{\varepsilon_{33}^{S} A_{s}}{\ell}
$$

é a chamada capacitância e

$$
K_{A}^{2}=\frac{e_{33}{ }^{2}}{c_{33}^{E} \varepsilon_{33}^{S}+e_{33}{ }^{2}}
$$

sendo $K_{A}$ o coeficiente de acoplamento eletromecânico piezelétrico.

$\mathrm{Na}$ análise realizada até agora, assume-se esforços nulos sobre a superfície metalizada do elemento cerâmico: $T_{3}(0)=T_{3}(\ell)=0$,ou seja, ele não troca energia com o exterior, pois o meio em contato é considerado o vácuo.

Para estudar o comportamento da cerâmica em uma situação real, temos que resolver a equação da onda, com diferentes tipos de condições de contorno.

A solução geral da equação diferencial de onda, escrita com a hipótese de unidimensional e de excitação senoidal é mostrada em (3.15).

Ao impor condições de contorno é assumido que a cerâmica transfere energia ao meio externo, de modo que nas faces externas deve-se impor continuidade de velocidade e, em conseqüência, as condições de contorno para $u_{3}$, serão:

$$
\begin{aligned}
& \dot{u_{3}}(0)=v_{1} \\
& \dot{u_{3}}(\ell)=-v_{2}
\end{aligned}
$$

Impondo que a (3.15) satisfaça essas condições, então novos valores para $A$ e $B$ são calculados:

$$
\begin{aligned}
& A=-\frac{1}{j \omega}\left(\frac{v_{2}+v_{1} \cos \theta}{\sin \theta}\right) e^{-j \omega t} \\
& B=\frac{1}{j \omega} v_{1} e^{-j \omega t}
\end{aligned}
$$

que, sendo substituído em (3.15), fornece:

$$
u_{3}(z)=\frac{1}{j \omega}\left[v_{1} \cos \left(\frac{\omega z}{V_{A}^{D}}\right)-\frac{v_{2}+v_{1} \cos \theta}{\sin \theta} \sin \left(\frac{\omega z}{V_{A}^{D}}\right)\right]
$$


Para caracterizar o comportamento externo da cerâmica, temos de extrair as equações que relacionam força e velocidade nas superfícies externas. A ação de forças externas é reduzida nas condições de contorno sobre os esforços desenvolvidos:

$$
\begin{aligned}
& T_{3}=-\frac{F_{1}}{A_{s}} \text { para } z=0 \\
& T_{3}=-\frac{F_{2}}{A_{s}} \text { para } z=\ell
\end{aligned}
$$

Supõe-se que as forças sejam contrárias aos sentidos das velocidades e escolhe-se um sinal negativo para os esforços de compressão.

Utilizando as equações (3.10) e (3.36), a expressão explícita de $S_{3}$ é:

$$
S_{3}=-\frac{1}{j V_{A}^{D}}\left[v_{1} \sin \left(\frac{\omega z}{V_{A}^{D}}\right)+\frac{v_{2}+v_{1} \cos \theta}{\sin \theta} \cos \left(\frac{\omega z}{V_{A}^{D}}\right)\right]
$$

A eq.(3.3) pode ser reescrita como

$$
\frac{F}{A_{s} c_{33}^{E}}+\frac{e_{33}}{c_{33}^{E}} E_{3}=-\frac{1}{j V_{A}^{D}}\left[v_{1} \sin \left(\frac{\omega z}{V_{A}^{D}}\right)+\frac{v_{2}+v_{1} \cos \theta}{\sin \theta} \cos \left(\frac{\omega z}{V_{A}^{D}}\right)\right]
$$

que, calculada em $z=0$ e $z=\ell$ torna-se:

$$
\begin{aligned}
& -\frac{F_{1}}{A_{s} c_{33}^{E}}+\frac{e_{33}}{c_{33}^{E}} E_{3}=-\frac{1}{j V_{A}^{D}} \frac{v_{2}+v_{1} \cos \theta}{\sin \theta} \\
& -\frac{F_{2}}{A_{s} c_{33}^{E}}+\frac{e_{33}}{c_{33}^{E}} E_{3}=-\frac{1}{j V_{A}^{D}}\left(\frac{v_{1}}{\sin \theta}+\frac{v_{2}}{\operatorname{tg} \theta}\right)
\end{aligned}
$$

As equações (3.41) e (3.42) podem ser vistas como as equações de movimento da cerâmica, em que forças externas são funções da velocidade, mas também do campo elétrico. Para eliminar a dependência desse último, pode-se utilizar as equações constitutivas. A partir da eq. (3.4) é obtida

$$
D_{3}=-\frac{e_{33}}{j V_{A}^{D}}\left[v_{1} \sin \left(\frac{\omega z}{V_{A}^{D}}\right)+\frac{v_{2}+v_{1} \cos \theta}{\sin \theta} \cos \left(\frac{\omega z}{V_{A}^{D}}\right)\right]+e_{33}^{S} E_{3}
$$

Utilizando a lei de Gauss para obter a corrente que circula na cerâmica obtém-se:

$$
I_{3}=\frac{d}{d t}\left(D_{3} A_{s}\right)=j \omega A_{s} D_{3}
$$


Sendo

$$
D_{3}=D_{0} e^{j \omega t}
$$

Substituindo (3.43) na (3.44) obtemos a expressão explícita do $I_{3}$

$$
I_{3}=-\frac{\omega A_{s} e_{33}}{V_{A}^{D}}\left[v_{1} \sin \left(\frac{\omega z}{V_{A}^{D}}\right)+\frac{v_{2}+v_{1} \cos \theta}{\sin \theta} \cos \left(\frac{\omega z}{V_{A}^{D}}\right)\right]+j \omega A_{s} e_{33}^{S} E_{3}
$$

de onde se pode obter $E_{3}$ como uma função de $I_{3}$

$$
E_{3}=\frac{I_{3}}{j \omega A_{s} e_{33}^{S}}+\frac{e_{33}}{j e_{33}^{S} V_{A}^{D}}\left[v_{1} \sin \left(\frac{\omega z}{V_{A}^{D}}\right)+\frac{v_{2}+v_{1} \cos \theta}{\sin \theta} \cos \left(\frac{\omega z}{V_{A}^{D}}\right)\right]
$$

Para obter as equações de movimento de oscilação da cerâmica, pode-se calcular $E_{3}$ em 0 e $\ell$ e substituir nas equações (3.41) e (3.42). A essas condições, deve ser acrescentada uma terceira equação para descrever o comportamento da cerâmica, em termos do ponto de vista elétrico. Essa última pode ser obtida através da integração da expressão do campo elétrico entre 0 e $\ell$, calculando assim a tensão entre as superfícies metalizadas.

Assim, as equações obtidas são:

$$
\begin{gathered}
F_{1}=\frac{A_{s} c_{33}^{E}}{j V_{A}^{D}} \frac{1+K^{2}}{\operatorname{tg} \theta} v_{1}+\frac{A_{s} c_{33}^{E}}{j V_{A}^{D}} \frac{1+K^{2}}{\sin \theta} v_{2}+\frac{e_{33}}{j \omega e_{33}^{S}} I_{3} \\
F_{2}=\frac{A_{s} c_{33}^{E}}{j V_{A}^{D}} \frac{1+K^{2}}{\sin \theta} v_{1}+\frac{A_{s} c_{33}^{E}}{j V_{A}^{D}} \frac{1+K^{2}}{\operatorname{tg} \theta} v_{2}+\frac{e_{33}}{j \omega e_{33}^{S}} I_{3} \\
V=\frac{I_{3} \ell}{j \omega A_{s} e_{33}^{S}}+\frac{e_{33}}{j \omega e_{33}^{S}}\left(v_{1}+v_{2}\right) \\
K^{2}=\frac{e_{33}{ }^{2}}{\varepsilon_{33}^{S} c_{33}^{E}}
\end{gathered}
$$

sendo que

Da eq.(3.12) e eq.(3.13) obtém-se:

$$
\rho V_{A}^{D^{2}}=c_{33}^{E}\left(1+K^{2}\right)
$$

e pode-se definir a impedância acústica do elemento de cerâmica como

$$
Z_{A 0}=\rho V_{A}^{D} A_{S}
$$


Recordando também a definição de capacitância do elemento piezelétrico na eq.(3.30), as equações (3.48), (3.49) e (3.50) podem ser reescritas como

$$
\begin{aligned}
& F_{1}=\frac{Z_{A 0}}{j \operatorname{tg} \theta} v_{1}+\frac{Z_{A 0}}{j \sin \theta} v_{2}+\frac{e_{33}}{j \omega e_{33}^{S}} I_{3} \\
& F_{2}=\frac{Z_{A 0}}{j \sin \theta} v_{1}+\frac{Z_{A 0}}{j \operatorname{tg} \theta} v_{2}+\frac{e_{33}}{j \omega e_{33}^{S}} I_{3} \\
& V=\frac{e_{33}}{j \omega \varepsilon_{33}^{S}} v_{1}+\frac{e_{33}}{j \omega \varepsilon_{33}^{S}} v_{2}+\frac{I_{3}}{j \omega C_{0}}
\end{aligned}
$$

Essas são as equações que descrevem o comportamento externo da cerâmica piezelétrica. As variáveis independentes, que derivam diretamente a partir da imposição de condições no contorno, são a velocidade e a corrente.

O elemento piezelétrico pode ser visto como um sistema de três portas, precisamente pelas equações (3.54), (3.55) e (3.56).

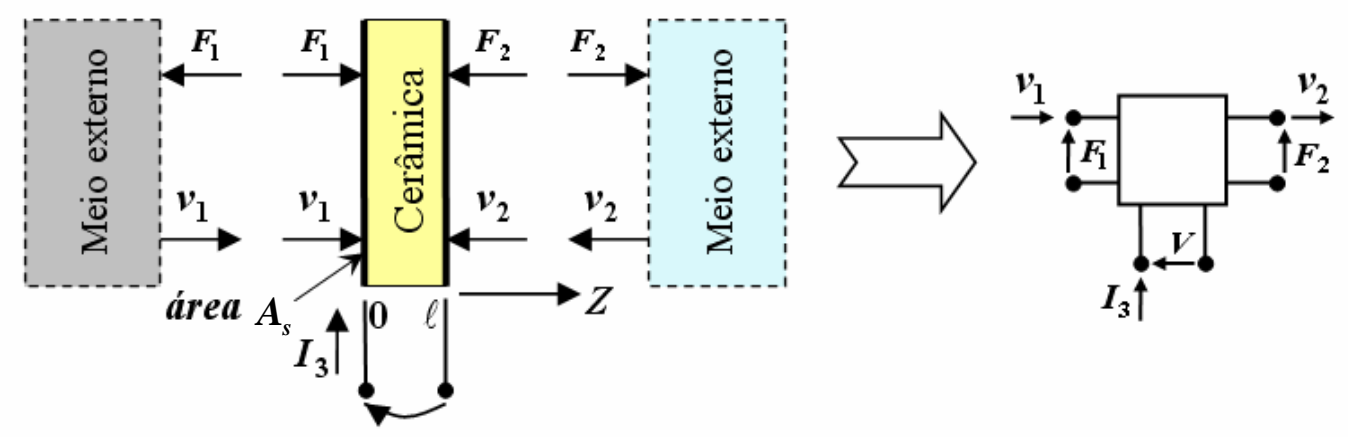

Figura 3.2: Diagrama de bloco da cerâmica piezelétrica.

As três portas são as conexões elétricas e mecânicas com o meio exterior. Para cerâmica é fornecida energia através da porta elétrica e ela irradia na forma mecânica, através das duas portas mecânicas. É consequentemente oportuno ter um modelo que leve em conta à presença dessas portas, ou seja, um modelo em que as variáveis independentes são as grandezas de uma porta mecânica e a corrente elétrica de entrada.

Escolhendo em seguida como variável independente a grandeza mecânica em $z=\ell$, ou seja, a grandeza do que podemos considerar como porta de saída do sistema, 
obtém-se:

$$
\begin{aligned}
& F_{1}=\cos \theta F_{2}-j Z_{A O} \sin \theta v_{2}+\frac{e_{33}}{j \omega e_{33}^{S}}(1-\cos \theta) I_{3} \\
& v_{1}=j \frac{\sin \theta}{Z_{A O}} F_{2}-\cos \theta v_{2}-\frac{e_{33} \sin \theta}{Z_{A O} \omega e_{33}^{S}} I_{3} \\
& V=\frac{e_{33} \sin \theta}{Z_{A O} \omega e_{33}^{S}} F_{2}+\frac{e_{33}}{j \omega e_{33}^{S}}(1-\cos \theta) v_{2}+\frac{1}{j \omega}\left(\frac{1}{C_{o}}-\frac{e_{33}{ }^{2} \sin \theta}{Z_{A O} \omega e_{33}^{S}}\right) I_{3}
\end{aligned}
$$

Conforme figura 3.3, suponhamos que a porta 1 , isto é, em $z=0$, está ligada a uma carga de impedância acústica $Z_{B}$.

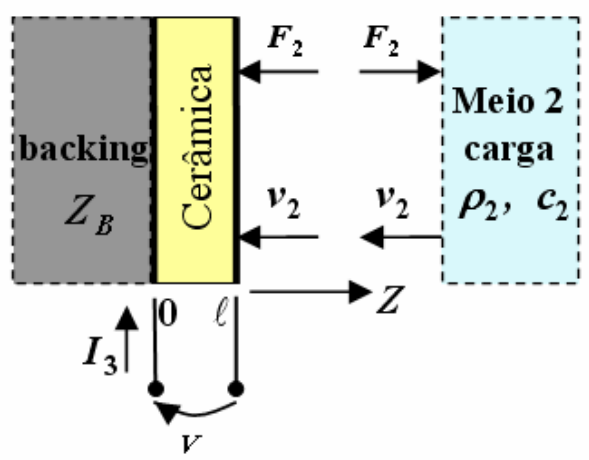

Figura 3.3: Porta 1 fechada com uma carga de impedância acústica $Z_{B}$.

vale portanto a relação

$$
F_{1}=-Z_{B} v_{1}
$$

sendo que o sinal menos é justificado da escolha feita para oposição das forças e velocidades.

Substituindo eq.(3.60) nas equações (3.57), (3.58) e (3.59) e escolhendo como variável independente a grandeza mecânica da porta 2 , obtém-se uma relação do tipo

$$
\left(\begin{array}{l}
V \\
I
\end{array}\right)=\left(\begin{array}{ll}
A_{11} & A_{12} \\
A_{21} & A_{22}
\end{array}\right)\left(\begin{array}{l}
F_{2} \\
V_{2}
\end{array}\right)
$$

sendo que os elementos da matriz são: 


$$
\begin{aligned}
& A_{11}=\frac{e_{33}^{S}}{e_{33} C_{o}} \frac{\cos \theta+j \zeta \sin \theta}{\cos \theta-1+j \zeta \sin \theta}- \\
& -\frac{e_{33}}{\omega e_{33}^{S} Z_{A O}} \frac{\sin \theta}{\cos \theta-1+\zeta \sin \theta} \\
& A_{12}=\frac{e_{33}}{j \omega \varepsilon_{33}^{S}} \frac{2(\cos \theta-1)+j \zeta \sin \theta}{\cos \theta-1+j \zeta \sin \theta}- \\
& -\frac{e_{33}^{S}}{e_{33} C_{o}} \frac{Z_{A O}(\zeta \cos \theta+j \sin \theta)}{\cos \theta-1+j \zeta \sin \theta} \\
& A_{31}=\frac{j \omega \varepsilon_{33}^{S}}{e_{33}} \frac{\cos \theta+j \zeta \sin \theta}{\cos \theta-1+j \zeta \sin \theta} \\
& A_{33}=-\frac{j \omega e_{33}^{S}}{e_{33}} \frac{Z_{A O}(\zeta \cos \theta+j \sin \theta)}{\cos \theta-1+j \zeta \sin \theta} \\
& \zeta=\frac{Z_{B}}{Z_{A O}}
\end{aligned}
$$

\subsubsection{Camadas de casamento de impedância acústica}

Até agora, foi considerado o comportamento vibracional apenas do elemento piezelétrico. O transdutor, porém, não é constituído apenas por isso. Quando em contato com um meio material de dimensão muito maior que o comprimento de onda da radiação, pode-se supor que esse meio é infinito em tamanho, assim, no seu interior não geram ondas refletidas que, dando origem a fenômenos de ressonância irá interferir com a oscilação da cerâmica. Nesses casos, o meio pode ser indicado como uma carga acústica e será simplesmente caracterizado pela sua impedância acústica, que pode ser mais ou menos acoplado com a da cerâmica. 
Diferente é o caso de materiais cuja dimensão, na direção de propagação da onda é comparável com o comprimento de onda. Nesse caso eles irão ser afetados por uma onda que se propaga e interfere de certo modo com a do meio que a gerou. A onda gerada globalmente pelos dois meios em contato terá características diferentes do que a gerada na ausência do segundo meio. Camadas de materiais não piezelétricos destas dimensões podem ser usadas como acopladores de impedância.

Considere uma camada de material não piezelétrico de raio $a$ e espessura $\ell_{m}$, de tal forma que $a \gg \ell_{m}$, como no caso da camada piezelétrica da figura 3.4.

Quando se trata da propagação de onda plana na direção z, o deslocamento nessa direção, será dado pela solução da equação de onda que, neste caso, é unidimensional e por hipótese a excitação é do tipo senoidal, assim o deslocamento será:

$$
u_{3}(z, t)=\left[A \sin \left(\frac{\omega z}{V_{m}}\right)+B \cos \left(\frac{\omega z}{V_{m}}\right)\right] e^{j \omega t}
$$

sendo que $V_{m}$ é a velocidade de propagação da onda, enquanto que $A$ e $B$ são constantes de integração.

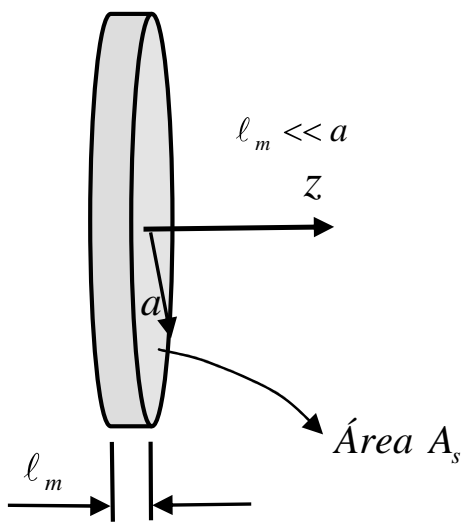

Figura 3.4: Camada de casamento de impedância acústica.

Se a camada não é isolada, mas ocorre o contato sobre as duas faces com o material do meio, a condição de contorno que temos de impor para o cálculo das duas constantes é a condição de continuidade de velocidade: 


$$
\begin{aligned}
& \dot{u}_{3}(0)=v_{1} \\
& \dot{u}_{3}\left(\ell_{m}\right)=-v_{2}
\end{aligned}
$$

Para o cumprimento dessas condições as constantes A e B são, respectivamente, os valores:

$$
\begin{gathered}
A=-\frac{1}{j \omega} \frac{v_{2}+v_{1} \cos \theta_{m}}{\sin \theta_{m}} e^{-j \omega t} \\
B=\frac{1}{j \omega} v_{1} e^{-j \omega t} \\
\theta_{m}=\frac{\omega \ell_{m}}{V_{m}}
\end{gathered}
$$

Substituindo as equações (3.70) e (3.71) na eq. (3.67) obtém-se

$$
u_{3}(z)=-\frac{1}{j \omega} \frac{v_{2}+v_{1} \cos \theta_{m}}{\sin \theta_{m}} \sin \frac{\omega z}{V_{m}}+\frac{1}{j \omega} v_{1} \cos \frac{\omega z}{V_{m}}
$$

Ao impor a continuidade das forças nas faces da camada de acoplamento acústico, obtém-se

$$
\begin{aligned}
& T_{3}(0)=-\frac{F_{1}}{A_{s}} \\
& T_{3}\left(\ell_{m}\right)=-\frac{F_{2}}{A_{s}}
\end{aligned}
$$

sendo as tensões negativas, porque consideramos positivos os esforços de tração. Utilizando as equações da elasticidade, que são obtidas a partir das equações constitutivas (3.3) e (3.4), anulando os parâmetros piezelétricos, podem-se escrever as eqs. (3.74) e (3.75) em termos das deformações:

$$
\begin{aligned}
& c_{11} S_{3}(0)=-\frac{F_{1}}{A_{s}} \\
& c_{11} S_{3}\left(\ell_{m}\right)=-\frac{F_{2}}{A_{s}}
\end{aligned}
$$


Considerando a deformação em $z=0$ e $z=\ell_{\boldsymbol{m}}$ e substituindo nas eqs. (3.76) e (3.77) obtêm-se:

$$
\begin{aligned}
& F_{1}=-j \frac{A_{s} c_{11}}{V_{m}} \frac{\cos \theta_{m}}{\sin \theta_{m}} v_{1}-j \frac{A_{s} c_{11}}{V_{m}} \frac{v_{2}}{\sin \theta_{m}} \\
& F_{2}=-j \frac{A_{s} c_{11}}{V_{m}} \frac{v_{1}}{\sin \theta_{m}}-j \frac{A_{s} c_{11}}{V_{m}} \frac{\cos \theta_{m}}{\sin \theta_{m}} v_{2}
\end{aligned}
$$

Sendo $V_{m}=\sqrt{c_{11} / \rho}$, a partir do qual $\rho V_{m}=c_{11} / V_{m}$ e, recordando a definição de impedância acústica do meio material: $Z_{m}=\rho V_{m} A_{s}$, as eqs.(3.78) e (3.79) podem ser reescritas como:

$$
\begin{gathered}
F_{1}=-j Z_{m} \frac{\cos \theta_{m}}{\sin \theta_{m}} v_{1}-j \frac{Z_{m}}{\sin \theta_{m}} v_{2} \\
F_{2}=-j \frac{Z_{m}}{\sin \theta_{m}} v_{1}-j Z_{m} \frac{\cos \theta_{m}}{\sin \theta_{m}} v_{2}
\end{gathered}
$$

O comportamento externo da camada de casamento de impedância acústica é portanto completamente descrito pelas equações (3.80) e (3.81) que podem ser consideradas como as equações de um quadripolo.

As portas do quadripolo esquematizam as superfícies externas da camada, através da qual ela troca energia com o meio externo. Tal como no caso do elemento piezelétrico, é muito útil uma representação de parâmetros híbridos das eqs. (3.80) e (3.81), na qual as grandezas de uma porta são funções de todas as outras.

Um modelo híbrido desse tipo pode ser obtido escolhendo, por exemplo, como variáveis independentes as grandezas na porta 2 e como variáveis dependentes as grandezas na porta 1.

As equações que são obtidas são:

$$
\begin{gathered}
F_{1}=\cos \theta_{m} F_{2}-j Z_{m} \sin \theta_{m} v_{2} \\
v_{1}=j \frac{\sin \theta_{m}}{Z_{m}} F_{2}-\cos \theta_{m} v_{2}
\end{gathered}
$$




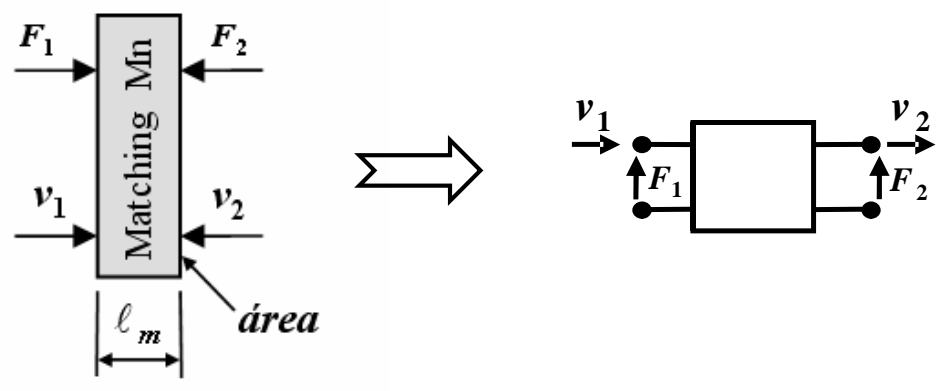

Figura 3.5: Esquema em bloco da camada de casamento de impedância acústica.

Note que os coeficientes de $v_{2}$ são negativos, porque a direção positiva para a velocidade foi escolhida como a direção do eixo z. É fixada a atenção apenas nas equações (3.82) e (3.83), as quais podem ser consideradas como as relações que descrevem o comportamento externo de qualquer sistema em que se encontra relacionado às grandezas de duas portas terminais. Um sistema desse tipo pode ser demonstrado por quadripolo na Fig.3.5. De acordo com o fenômeno físico pode ser definido o novo sistema de referência para as grandezas em questão, em particular, escolhe-se o sentido positivo para velocidade $v_{1}$ que entra, invertendo-se o sentido da velocidade $v_{2}$ da saída. Esse é um processo semelhante ao utilizado em circuitos eletrônicos, quando se escolhe arbitrariamente os sentidos das correntes. Com esse artifício, nas eqs. (3.82) e (3.83), os coeficientes de $v_{2}$ também serão positivos, de modo que a matriz que descreve a ligação de entrada e saída é formada por todos os termos positivos.

Esse procedimento é adequado porque mostra o problema do estudo do comportamento externo do sistema de um quadripolo descrito por equações semelhantes aos dos circuitos no quais as forças são análogas às tensões e os deslocamentos análogos à corrente. A vantagem é que o comportamento de dois quadripolos em cascata é simplesmente descrito pelo produto das duas matrizes. 


\subsection{Algoritmo de cálculo e resultados numéricos}

\subsubsection{Introdução}

Nesta seção explica-se como utilizar os resultados teóricos desenvolvidos no capítulo anterior para obter um simples algoritmo que descreve o comportamento vibracional de um transdutor piezelétrico. Um programa de cálculo é implementado para a simulação numérica, e os resultados obtidos são apresentados em gráficos. Esses resultados podem ser utilizados para prever o comportamento do transdutor e para alterar os parâmetros de projeto.

\subsubsection{Funções características do transdutor}

Como visto na seção 3.2, o comportamento de um elemento vibrante pode ser descrito pelas relações matriciais (3.61) e pelas equações (3.82) e (3.83), dependendo se é piezelétrico ativo ou não.

Essa relação é, a partir de um ponto de vista formal, idêntica à que descreve o comportamento de um duplo bipolo (ver fig.3.6).

Em geral, um transdutor é constituído de mais elementos vibrantes: uma camada de retaguarda, a cerâmica piezelétrica, as camadas de acoplamento acústico à carga, e a carga (ver Fig. 3.7) .

Para descrever o comportamento total do transdutor, deve-se buscar uma relação entre as grandezas de entrada e saída do sistema , isto é, entre a tensão e a corrente elétrica para os terminais do transdutor, e das grandezas mecânicas das faces da carga.

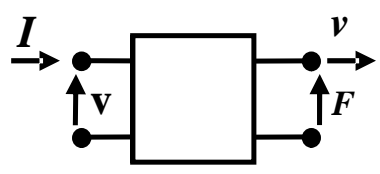

Figura 3.6: Duplo bipolo. 


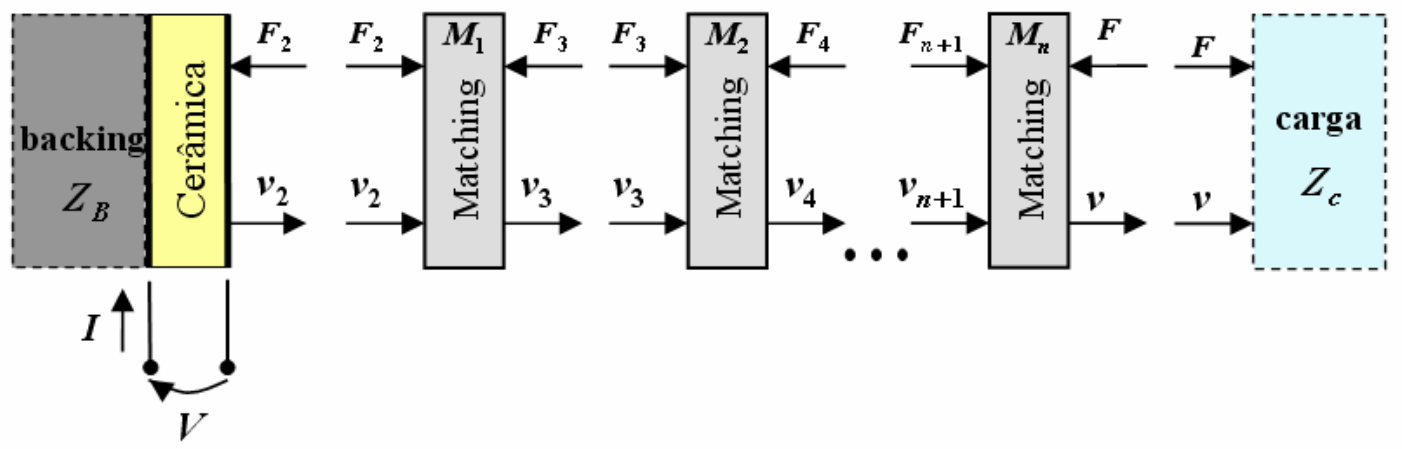

Figura 3.7 - Esquema de um transdutor piezelétrico.

Ainda usando analogia elétrica, a camada de acoplamento acústico e a cerâmica podem ser descritas pelo duplo bipolo, enquanto a camada de retaguarda e a carga simplesmente pela sua impedância acústica. O modelo físico do transdutor da Fig.3.7, pode ser visto como uma cadeia de duplo bipolo, assim como ilustrado na fig. 3.8, onde evidenciamos apenas as grandezas finais de interesse como tensão e corrente de alimentação, força e velocidade sobre a carga.

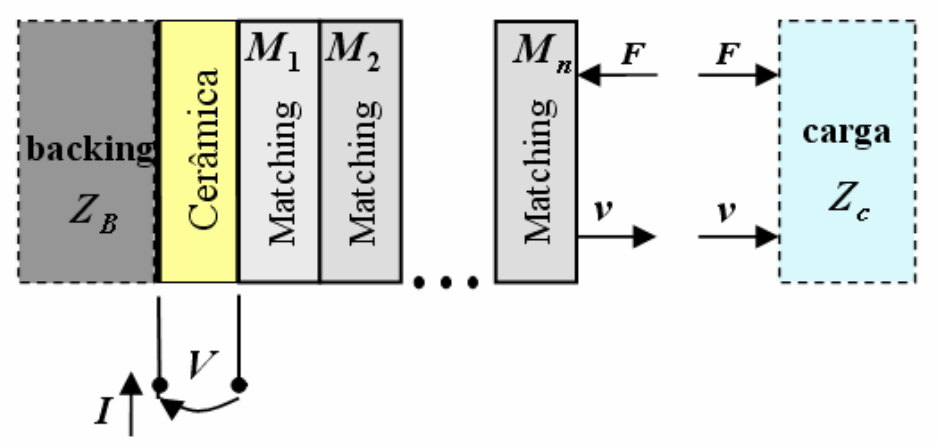

Figura 3.8: Esquema em bloco de um transdutor piezelétrico.

Para encontrar uma relação entre esses dois pares de grandezas, deve-se proceder como no primeiro capítulo, partindo do princípio que a porta acústica da cerâmica piezelétrica, do lado da camada de retaguarda, é fechada com uma impedância acústica $Z_{B}$. 
Para levar em consideração a presença da camada de casamento de impedância acústica à carga basta multiplicar a matriz da eq.(3.61) obtida com $Z_{B}$, a impedância acústica da camada de retaguarda, pelas matrizes que descrevem o comportamento das camadas de casamento acústico, obtendo assim a matriz que leva em conta a presença de todos os elementos do transdutor:

$$
R=\left(\begin{array}{ll}
A & B \\
C & D
\end{array}\right)
$$

Tal como foi construída, esta matriz expressa a ligação da grandeza mecânica de saída e a grandeza elétrica de entrada;

$$
\left(\begin{array}{l}
V \\
I
\end{array}\right)=\left(\begin{array}{ll}
A & B \\
C & D
\end{array}\right)\left(\begin{array}{l}
F \\
v
\end{array}\right)
$$

O transdutor como um todo pode ser descrito como um único duplo bipolo como mostrado na figura 3.9. A parti da equação matricial (3.85) dividindo a tensão elétrica pela corrente elétrica e considerando que a impedância acústica do meio $Z_{c}$ é definida do quociente da força $F$ pela velocidade $v$, obtém-se a impedância elétrica do transdutor $Z_{\text {Trans }}$ dada por:

$$
Z_{\text {Trans }}=\frac{A Z_{c}+B}{C Z_{c}+D}
$$

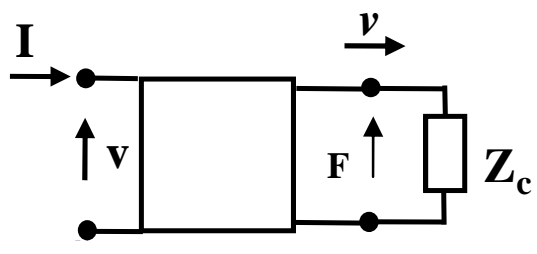

Figura 3.9: Transdutor com carga acústica.

Para descrever o comportamento do transdutor na emissão, pode-se assumir que o mesmo é alimentado por um gerador de tensão $E_{T}$ que tem uma impedância interna $R_{T}$ conforme figura 3.10. Definiu-se como função de transferência na emissão do transdutor (FTE), a seguinte relação

$$
F T E=\frac{F}{E_{T}}
$$




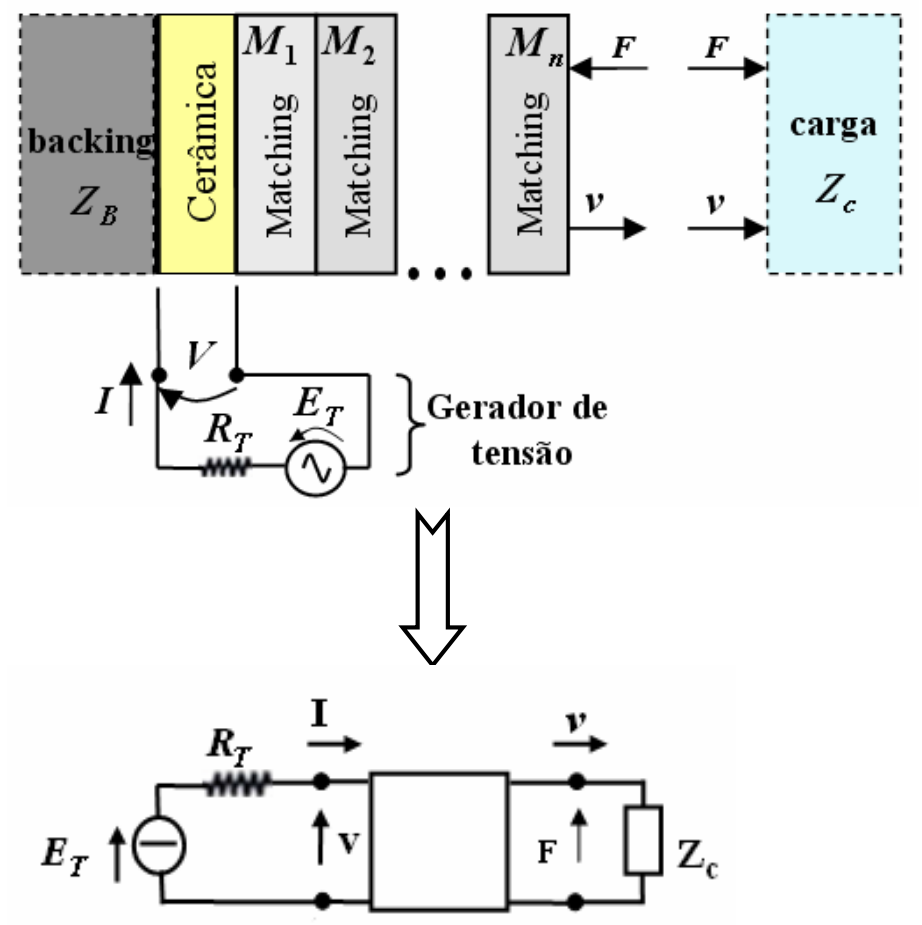

Figura 3.10: Transdutor na emissão.

De um ponto de vista puramente formal, teria sido mais correto descrever o comportamento do transdutor na emissão, definindo a função de transferência em seu terminal, ou seja, a relação entre $F$ e $V$. É freqüente a utilização da fórmula da eq. (3.87), porque, a partir de um ponto de vista experimental, pode-se controlar a tensão no gerador de energia, ao passo que seria muito mais complexo controlar a tensão nas faces do transdutor. Na primeira linha da eq.(3.85) é calculado

$$
\frac{V}{F}=A+\frac{B}{Z_{C}}
$$

A variável $V$ também deve satisfazer o equilíbrio das malhas, de modo que

$$
V=E_{T}-R_{T} I
$$

Substituindo a eq. (3.89) na eq. (3.88) tem-se

$$
\frac{E_{T}}{F}=\frac{A Z_{C}+B}{Z_{C}}+R_{T} \frac{I}{F}
$$


Obtenção de $I / F$ da eq. (4.85) e invertendo a eq.(3.90) obtemos a expressão da $F T E$ :

$$
F T E=\frac{Z_{C}}{A Z_{C}+B+R_{T}\left(C Z_{C}+D\right)}
$$

Como se sabe, o transdutor é um elemento bidirecional, o que significa que ele pode converter um sinal elétrico em acústico, e vice-versa, em este último caso, o transdutor funciona em recepção segundo o esquema da Fig. 3.11, sendo que $R_{R}$ é a resistência interna de um instrumento para medir o sinal elétrico de saída do transdutor. Em comparação com o esquema da figura 3.10 foi mudado o sentido de referência para a velocidade e para a corrente, para indicar que o transdutor está funcionando em recepção, alterando também a matriz $R$ :

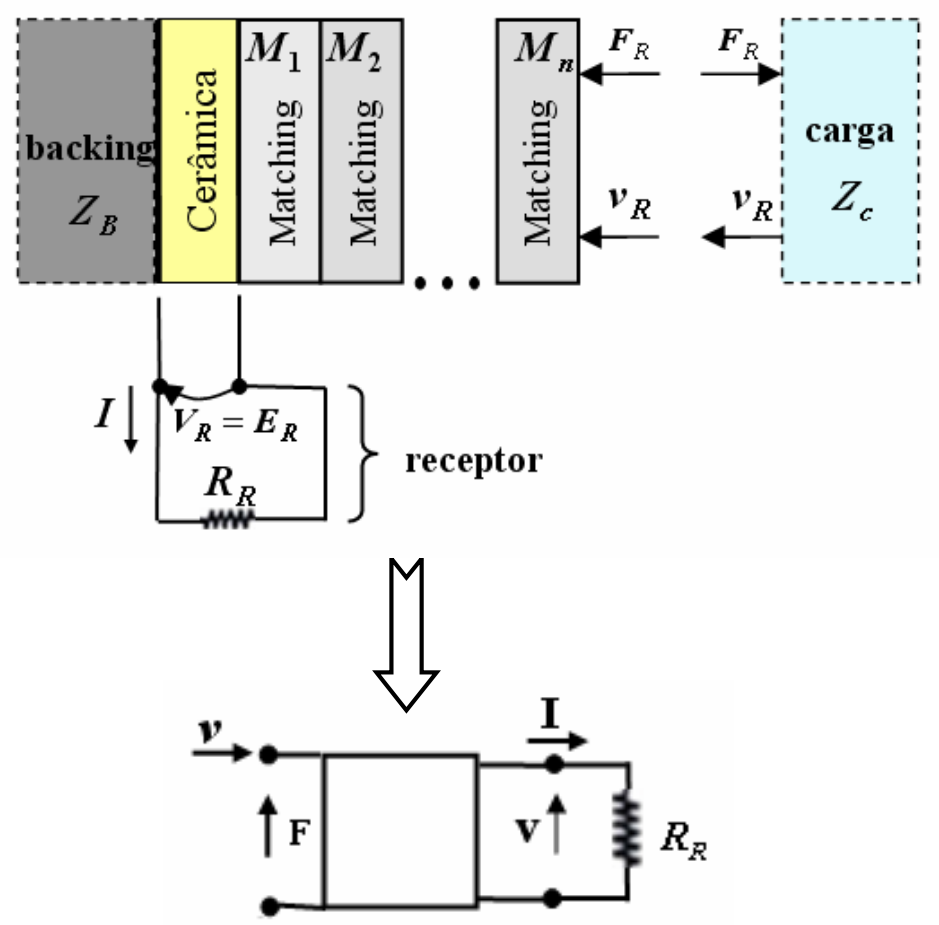

Figura 3.11: Transdutor na recepção. 


$$
\left(\begin{array}{l}
V \\
I
\end{array}\right)=\left(\begin{array}{cc}
A & -B \\
-C & D
\end{array}\right)\left(\begin{array}{l}
F \\
v
\end{array}\right)
$$

O comportamento do transdutor na recepção pode ser descrito pela função de transferência em recepção (FTR), que é definida como a relação

$$
F T R=\frac{V}{F}
$$

Para calcular, deve inverter a relação da eq. (3.92)

$$
\left(\begin{array}{l}
F \\
v
\end{array}\right)=\left(\begin{array}{ll}
D & B \\
C & A
\end{array}\right)\left(\begin{array}{l}
V \\
I
\end{array}\right)
$$

Da eq. (3.94) pode-se então calcular o FTR

$$
F T R=\frac{R_{R}}{R_{R} D+B}
$$

$\mathrm{Na}$ maioria das aplicações, o transdutor é utilizado tanto para gerar uma onda acústica, quanto para recebê-la, transformando-a em tensão elétrica. Assim para caracterizar o transdutor na função de emissão e recepção, normalmente defini-se um tipo de função de transferência conhecida como perda por inserção.

Supondo que o transdutor irradia um pulso no meio, sem perda, que a onda irradiada é uma onda plana e que, por último, ela incida normalmente em uma superfície de descontinuidade, refletindo totalmente. Com essa hipótese a onda incidente não interfere com a onda refletida, o meio pode ser considerado como uma linha de transmissão infinitamente longa e neste transdutor pode ser separada a fase de geração daquela de recepção do sinal. $O$ transdutor pode ser separado em um emissor e um receptor. 


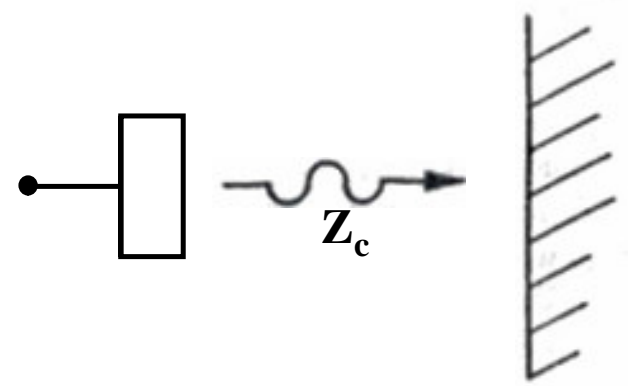

Figura 3.12: Pulso emitido que se propaga na carga acústica.

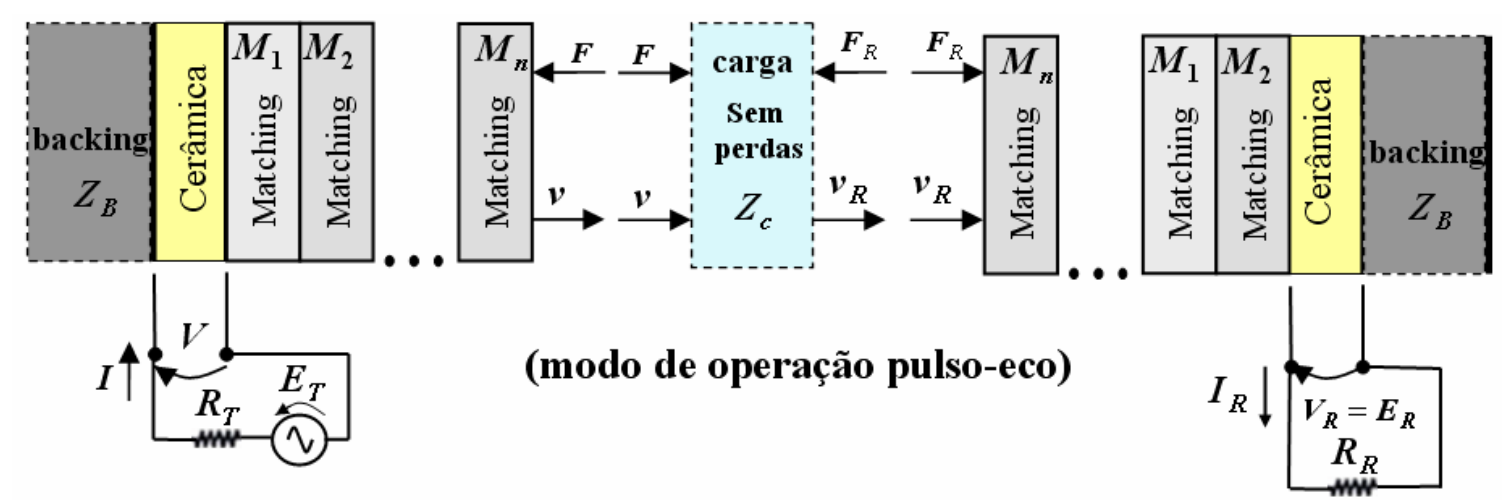

Figura 3.13: Transdutor separado em uma emissão e uma recepção.

O processo de transmissão e recepção do sinal pode ser dividido em três fases:

i. O emissor envia o pulso acústico

ii. O pulso propaga-se no meio material e chega ao receptor, em todas as interfaces parte é transmitida e parte é refletida

iii. A parte que é transmitida é novamente convertida em sinal elétrico.

As hipóteses não são totalmente verificadas na realidade, devido a fenômenos dissipativos e de difração, são simplesmente para ser capaz de definir a perda por inserção $I L$ como a relação entre a tensão elétrica medida no transdutor, comparada com a que the é fornecida pelo gerador. Assim a perda por inserção, ou também conhecida por função característica de transferência de emissão e recepção (FTER) é dada por: 


$$
F T E R=I L=\frac{E_{R}}{E_{T}}
$$

Na Figura 3.13 observa-se que $I L$ pode ser visto como o produto de três funções de transferência:

$$
I L=\frac{F}{E_{T}} \cdot \frac{F_{R}}{F} \cdot \frac{E_{R}}{F_{R}}
$$

Na primeira e na terceira, se reconhece respectivamente, a função de transferência na emissão e a função de transferência na recepção do transdutor, cujas expressões são dadas pelas eqs. (3.91) e (3.95).

$\mathrm{Na}$ hipótese de onda plana e incidência normal sobre a superfície do transdutorreceptor, a onda incidente será parcialmente transmitida e refletida, a parte transmitida será dada por

$$
F_{R}=\frac{2 Z_{R}}{Z_{c}+Z_{R}} F
$$

sendo que $Z_{c}$ é a impedância acústica da carga, enquanto $Z_{R}$ pode ser interpretado como uma espécie de impedância acústica de entrada do transdutor na recepção.

Para o cálculo do $Z_{R}$ refira-se a equação (3.94):

$$
Z_{R}=\frac{D R_{R}+B}{C R_{R}+A}
$$

sendo que $R_{R}$ é a resistência interna do instrumento de medição que é suposto ser ligado aos terminais elétricos do transdutor na recepção.

Substituindo a eq. (3.99) na eq. (3.98) se calcula a função de transferência do meio em que se propaga à onda acústica:

$$
\frac{F_{R}}{F}=\frac{2\left(D R_{R}+B\right)}{A Z_{c}+B+R_{R}\left(C Z_{c}+D\right)}
$$

Finalmente, substituindo na eq. (3.97) as eqs. (3.91), (3.95) e (3.100) obtém-se a expressão explícita da perda por inserção:

$$
F T E R=I L=\frac{Z_{c}}{A Z_{c}+B+R_{T}\left(C Z_{c}+D\right)} \cdot \frac{2 R_{R}}{A Z_{c}+B+R_{R}\left(C Z_{c}+D\right)}
$$




\subsubsection{O programa de cálculo}

Para realizar comparações com os resultados experimentais deste trabalho foi calculada a função característica de transferência de emissão e recepção (FTER) dada pela equação (3.101). Também será considerada a dissipação de energia que ocorre no transdutor através do material piezelétrico como apresentado por (ANDRADE, 2006).

As perdas mecânicas são modeladas considerando-se o fator de qualidade mecânico $Q_{m}$ no modelo de rigidez elástica complexa dado pela equação (3.102) e no modelo de velocidade de propagação complexa dado pela equação (3.103):

$$
\begin{aligned}
& c_{i j}=c_{i j}\left(1+\frac{j}{Q_{m}}\right) \\
& V_{\text {meio }}=V_{\text {meio }}\left(1+\frac{j}{Q_{m}}\right)
\end{aligned}
$$

Da mesma forma as perdas elétricas considera o fator de qualidade elétrica $Q_{e}$ no modelo de permissividade elétrica complexa dado pela expressão:

$$
e_{33}^{S}=e_{33}^{S}\left(1-\frac{j}{Q_{e}}\right)
$$

O algoritmo de cálculo acompanha completamente os passos feitos na definição do modelo do transdutor, considerando apenas uma única camada de casamento de impedância acústica .

Os dados de entrada são os parâmetros característicos de todos os componentes do transdutor. Para a cerâmica, definem-se a impedância acústica , as constantes elásticas, as constantes piezelétricas, a constante dielétrica relativa e, finalmente, as dimensões geométricas. Para a carga e a camada de retaguarda definem-se as suas impedâncias acústicas. Para o circuito excitação define-se a impedância elétrica interna do gerador e para o circuito de medição define-se a resistência elétrica no interior do instrumento de medição. O programa pode simular a 
presença da camada de casamento de impedância acústica que é caracterizada pela impedância acústica, velocidade de propagação no material e espessura.

Para calcular a função de transferência do transdutor, necessita-se previamente determinar a matriz $R$ na eq.(3.85). Inicia-se o cálculo pela matriz da camada de casamento de impedância acústica e pela matriz que caracteriza o meio, observando corretamente a ordem de multiplicação, a fim de obter uma única matriz. Nota-se que com $Z_{B}$ pode calcular a matriz que descreve a cerâmica, e para finalmente chegar em $R$, basta em seguida, fazer os produtos das matrizes características da cerâmica e aqueles relativos à camada de casamento de impedância acústica e a carga.

Com os componentes da matriz $R$, pode-se calcular as diversas funções características do transdutor. Elas são representadas por pontos no domínio da frequência e para o número destes é escolhida uma potência de dois a fim de tornar as funções de transferência facilmente processadas por algoritmos do tipo IFFT (Inverse Fast Fourier Transform) utilizados para obter a resposta do transdutor no domínio do tempo.

A função característica (FTRE) foi calculada no domínio da frequência em um intervalo teórico em torno da frequência de ressonância mecânica dada por:

$$
\begin{array}{r}
f_{m}=\frac{V_{A}^{D}}{2 \ell} \\
f_{m}=\frac{\sqrt{\frac{c_{33}^{D}}{\rho}}}{2 \ell}
\end{array}
$$

sendo que lé a espessura da cerâmica piezelétrica e $V_{A}^{D}$ é a velocidade de propagação dada pela eq. (3.12). 


\subsubsection{Resultados numéricos}

Nesta seção é verificada por simulação a resposta impulsiva do sinal de eco do modelo, dado pela função de transferência (FTRE), em relação às alterações dos parâmetros de entrada. Para uma analise qualitativa dos resultados os parâmetros de entrada foram variados em torno dos valores médios especificados para o lote de transdutores produzidos, em torno de valores obtidos na modelagem, medidos experimentalmente ou fornecidos pela literatura, para verificar quais características do sinal de eco são consideravelmente alteradas e com que intensidades. Uma analise precisa, com parâmetros de entrada específicos para a cerâmica de cada transdutor, será apresentada na seção "Comparação entre o sinal teórico e o experimental".

O material da cerâmica piezelétrica do modelo simulado é o PZ-37 do fabricante Ferroperm Piezoceramics A/S com as seguintes propriedades:

Frequência central: $f_{c}=5 \mathrm{MHz}$

Dimensões da cerâmica: $\phi=10 \mathrm{~mm}$ e $\ell=0,278 \mathrm{~mm}$.

Densidade $\rho=6000 \mathrm{Kg} / \mathrm{m}^{3}$ e Impedância acústica: $Z_{\text {cermica }}=18 \mathrm{MRayl}$. Constantes Elásticas: $c_{33}^{E}=4,3010^{10} \mathrm{~N} / \mathrm{m}^{2}$ e Constante piezelétrica: $e_{33}=10,01 \mathrm{C} / \mathrm{m}^{2}$. Constante de carga piezelétrica : $d_{33}=340 \mathrm{pC} / \mathrm{N}$.

Permissividade dielétrica relativa: $\varepsilon_{33}^{S} / \varepsilon_{0}=627$ sendo $\varepsilon_{0}=8,854210^{-12} \mathrm{~F} / \mathrm{m}$.

Fator de acoplamento piezelétrico: $K_{t}=0,52$ e Velocidade: $V_{A}^{D}=3270 \mathrm{~m} / \mathrm{s}$. Fator de qualidade mecânico: $Q_{m}=50$ e Fator de qualidade elétrico: $Q_{e}=80$.

Para a camada de casamento de impedância acústica foi utilizada uma mistura de epóxi e alumina com as seguintes propriedades:

Impedância acústica: Zmatching = 5,20 MRayl e Fração em volume : $F V=0,22$.

Espessura de um quarto de comprimento de onda: $\ell_{m}=0,125 \mathrm{~mm}$ sendo $V_{m}=2500 \mathrm{~m} / \mathrm{s}$.

Para a camada de retaguarda foi utilizada uma mistura de epóxi e tungstênio com as seguintes propriedades: 
Impedância acústica : Zbacking $=9$ MRayls e Fração em volume: $F V=0,3$. Comprimento: $L \cong 12 \mathrm{~mm}$ (face posterior inclinada).

A carga é a água com as seguintes propriedades:

Densidade: $\rho=1000 \mathrm{Kg} / \mathrm{m}^{3}$, Impedância acústica:Zmeio $=1,5 \mathrm{MRayl}$ Velocidade de propagação: $V_{\text {meio }}=1500 \mathrm{~m} / \mathrm{s}$

As figura (3.14) e (3.15) mostram respectivamente a resposta impulsiva da FTER e seu espectro de amplitude para varias espessuras de camadas de casamentos de impedâncias acústicas. Apesar de uma primeira aproximação dos parâmetros de entrada, pode-se notar que o sinal teórico da resposta impulsiva apresenta uma boa concordância com o sinal experimental, diferenciando apenas na duração do sinal, sendo que o sinal teórico é menos amortecido. Na figura 3.15 pode-se notar que a parti da espessura de 0,16 $\mathrm{mm}$ até a espessura de 0,125mm (correspondente a um quarto do comprimento de onda), ocorre um aumento da largura de banda e a sintonização da frequência central na frequência nominal operacional de $5 \mathrm{MHz}$.

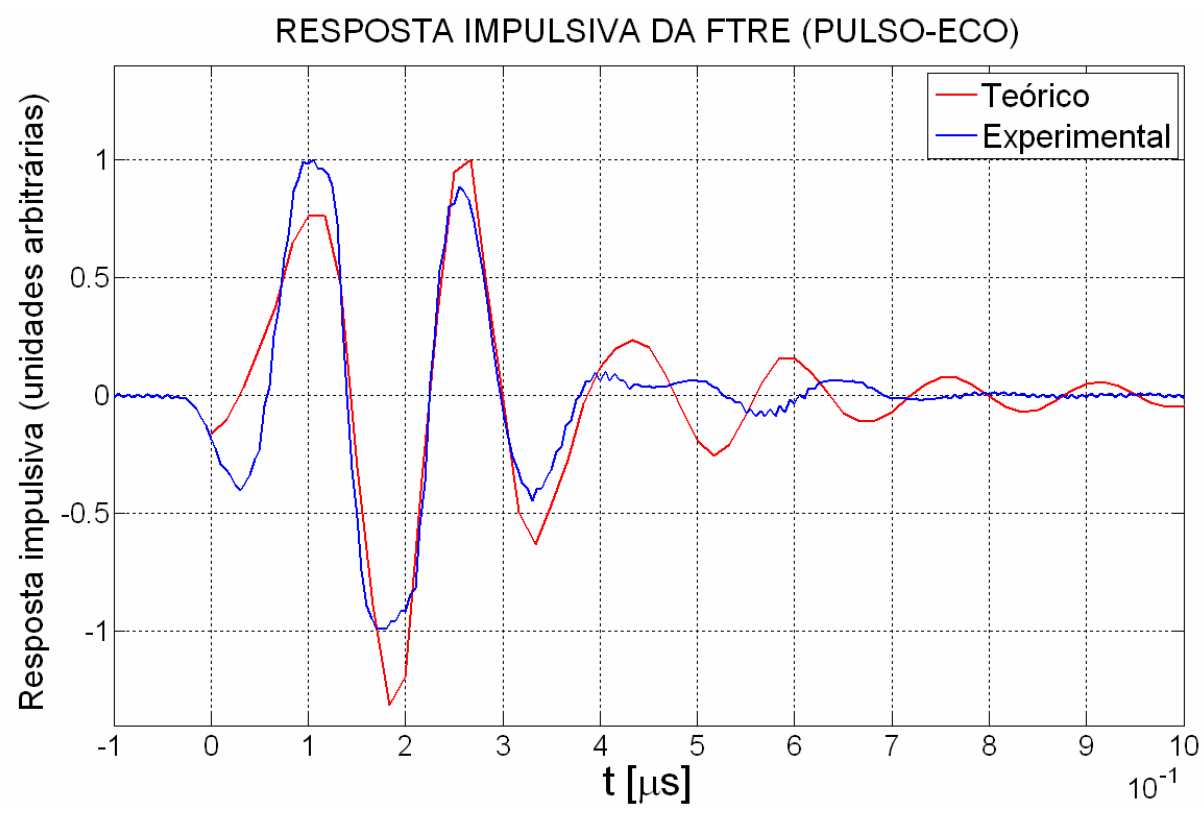

Figura 3.14: Formas das ondas dos sinais de reflexões . 


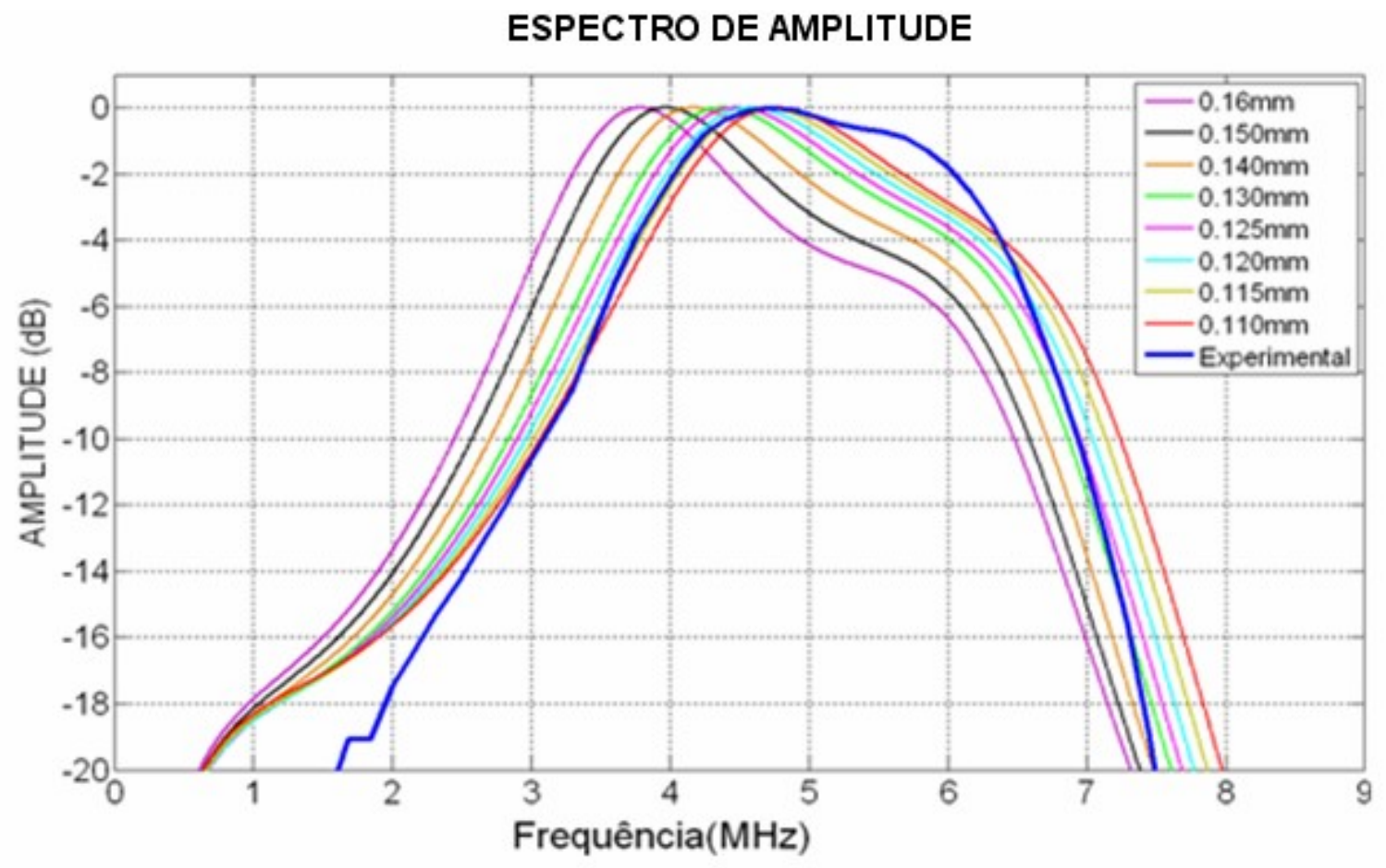

Figura 3.15: Espectros de amplitude dos sinais de reflexões para diferentes espessuras de camadas de casamentos de impedâncias acústicas.

Na figura (3.16) pode-se observar a variação das curvas dos espectros de amplitudes em função da variação da espessura da camada de casamento de impedância acústica. A partir da espessura de $0.16 \mathrm{~mm}$ ocorre um aumento da amplitude e da frequência central até um máximo de amplitude verificado para espessura correspondente a um quarto do comprimento de onda $(0,125 \mathrm{~mm})$. Para valores menores de espessura pode-se notar uma diminuição da amplitude. 


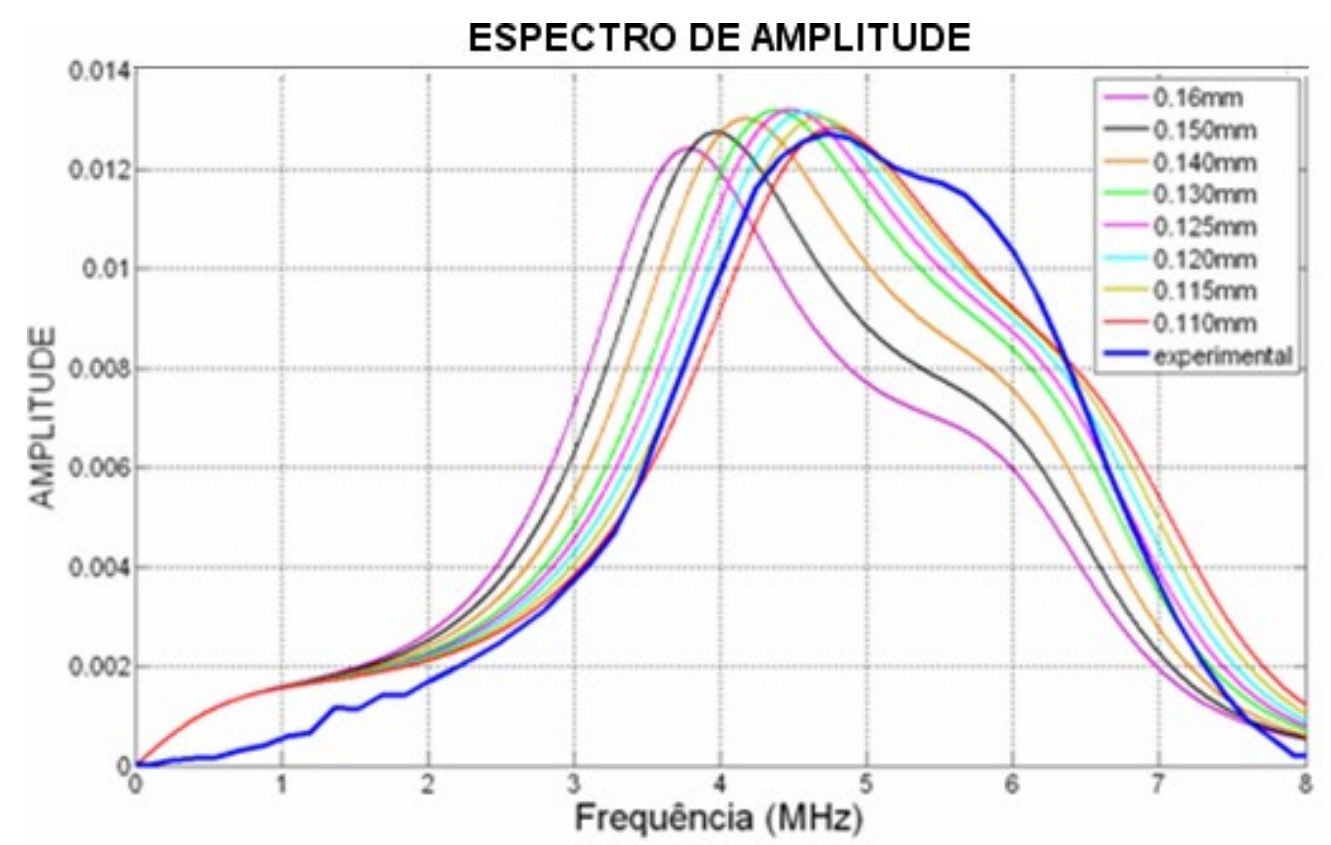

Figura 3.16: Espectros de amplitude dos sinais de reflexões para diferentes espessuras de camadas de casamentos de impedâncias acústicas.

A resposta impulsiva e o espectro de amplitude do sinal de reflexão simulados para dois transdutores que possuem as mesmas espessuras $\left(\ell_{m}=0,125 \mathrm{~mm}\right) \mathrm{e}$ diferentes impedâncias acústicas para suas camadas de casamento de impedância acústica, determinadas pela equações (2.1) e (2.2), podem ser vistas nas figuras (3.17) e (3.18). Nota-se que com a impedância acústica calculada a partir da equação (2.2), $Z_{m b}=3,43 \operatorname{MRayl}\left(F V=0,027\right.$ e $\left.V_{m} \cong 2500 \mathrm{~m} / \mathrm{s}\right)$, obtém-se um sinal de resposta impulsiva ligeiramente mais amortecido e uma tensão de pico-a-pico aproximadamente igual em relação ao transdutor que tem impedância acústica determinada a partir da equação (2.1), $Z_{m}=5,20 \mathrm{MRayl}\left(F V=0,2 e V_{m} \cong 2500 \mathrm{~m} / \mathrm{s}\right)$. Assim, confirma-se que a impedância acústica calculada a partir da equação (2.2) é mais adequada para transdutores de banda larga. Considerando a pequena diferença de amortecimento entre os dois sinais, foi utilizada a impedância da camada de casamento dada pela equação (2.1), que tem uma maior fração de volume de alumina na mistura com epóxi, o que resulta em uma camada mais dura e resistente ao desgaste. 


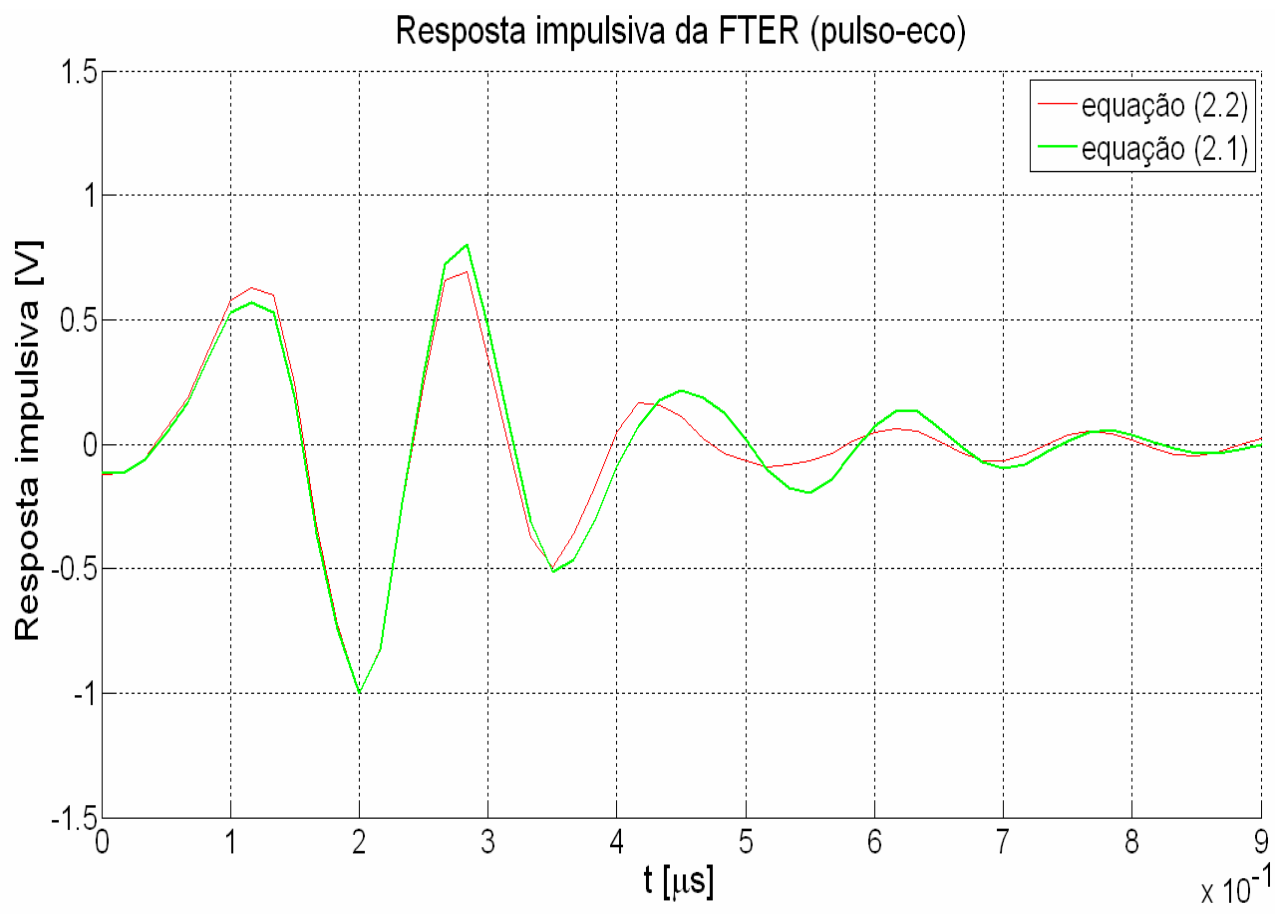

Figura 3.17: Formas das ondas dos sinais de reflexões.

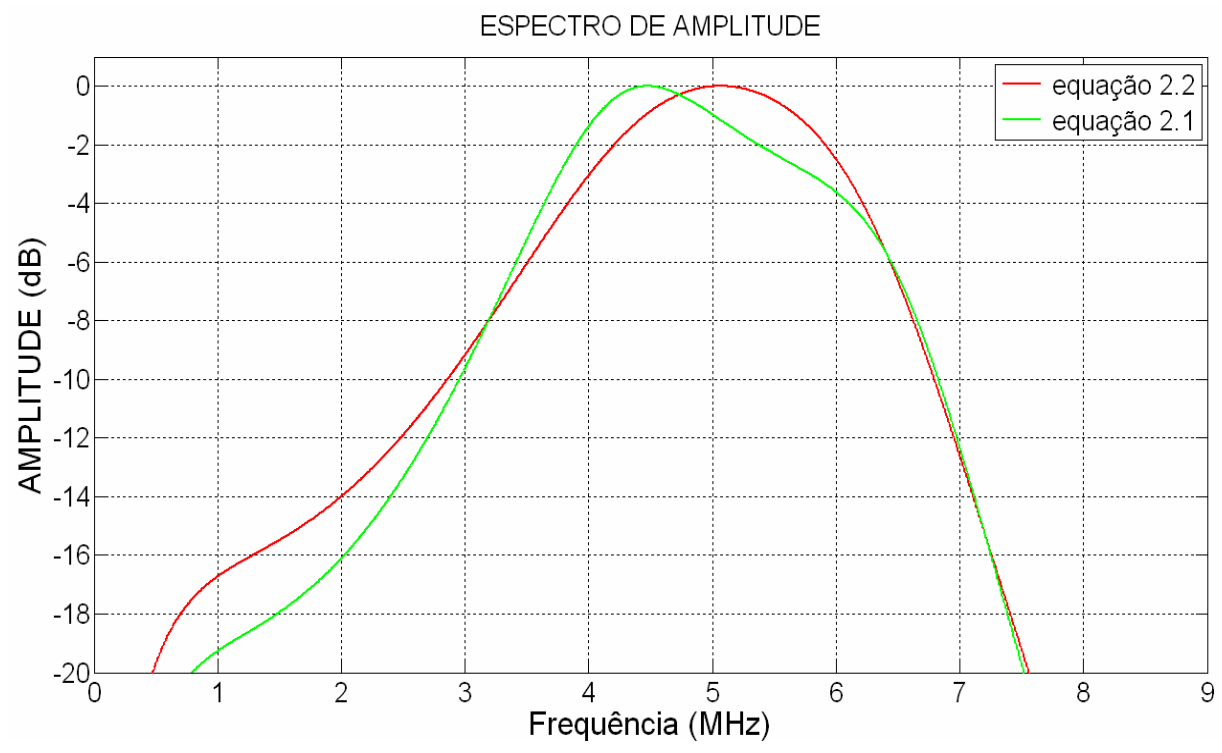

Figura 3.18: Espectros de amplitude dos sinais de reflexões. 


\subsubsection{Analise dos resultados}

Com os resultados obtidos com a simulação do modelo de matriz distribuída podese observar a influência dos parâmetros que caracterizam a cerâmica piezelétrica, a camada de retaguarda e a camada de casamento de impedância acústica, na forma de onda da resposta impulsiva do sinal eco de um transdutor, ou seja, a influência na amplitude do sinal (sensibilidade), comprimento do sinal (largura de banda), frequência central, energia e atenuação.

A largura de banda da função de transferência (FTER), representa um parâmetro muito importante em aplicações onde requer emitir e receber um pulso de curta duração. As variações simuladas da impedância acústica da camada de retaguarda e da espessura da camada de casamento acústico alteraram consideravelmente o valor da largura de banda e da amplitude do sinal de reflexão.

Assim com especificações obtidas através do modelo podem-se selecionar cerâmicas, definir as propriedades e espessuras das camadas passivas para uma aplicação específica de transdutores. 


\subsection{Fabricação de transdutores}

\subsubsection{Processo de fabricação e montagem dos componentes do transdutor}

O corpo do transdutor de ultrassom, mostrado na fig.3.19, tem como matéria prima tubos de Inox $316 \mathrm{~L}$, sem costuras, Polidos (norma ASTM A-269), e possui uma face de referência, perpendicular ao seu eixo central, que é totalmente apoiada na montagem para o correto posicionamento da cerâmica piezelétrica. A guia do cabo coaxial tem um sobre metal que é fundido no corpo do transdutor pelo processo MIG de soldagem e seu material é também de inox $316 \mathrm{~L}$ com a finalidade de não deixar a região soldada suscetível à corrosão devido aos efeitos térmicos da soldagem. Para evitar o sobreaquecimento da cerâmica piezelétrica e por conseqüência sua despolarização, nesta fase é depositado solda de estanho na extremidade da guia para posteriormente realizar as conexões elétricas sem gerar muito calor. Com o intuito de promover adesão é jateado com oxido de alumínio ou granalha de inox a superfície cilíndrica interna do corpo e a externa da guia.

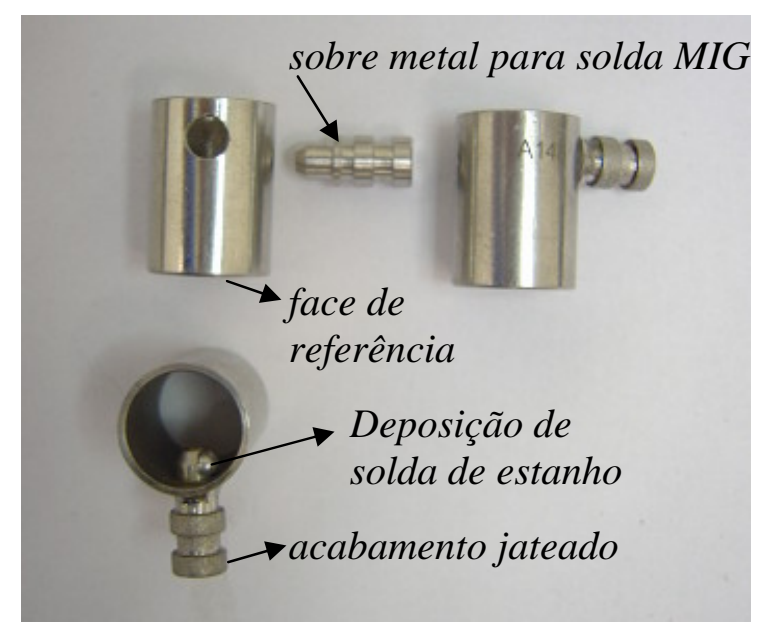

Figura 3.19: Características do corpo do transdutor de ultrassom

$O$ isolante elétrico, mostrado na fig.3.20, tem como matéria prima tubos de $A B S$ extrudados. Para uma boa colagem no corpo do transdutor 0 isolante possui 
externamente uma superfície com acabamento roscado para reter o adesivo e promover adesão. Em sua extremidade o isolante possui um rebaixo também com acabamento roscado, para ancoragem do material da camada de casamento de impedância acústica. Longitudinalmente o isolante possui duas ranhuras para guiar um fio de náilon, que será introduzido entre o corpo e o isolante no processo de colagem, com a finalidade de criar um duto após sua posterior extração, para a passagem dos fios de conexão elétrica.

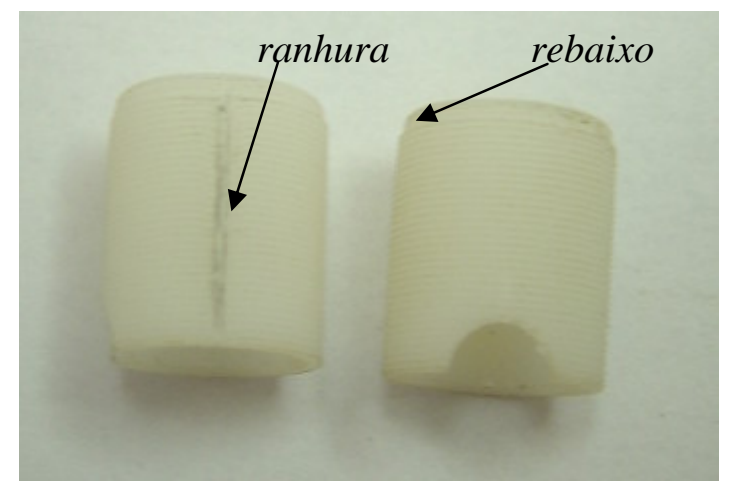

Figura 3.20: Características do isolante elétrico do transdutor de ultrassom.

A fig. 3.21 mostra o posicionamento inicial para efetuar a colagem com adesivo epóxi 24 horas profissional (resina Araldite ${ }^{\circledR}$ AW106 e endurecedor HV $953 \mathrm{U}$ ). O calço que posiciona a face frontal do isolador no corpo do transdutor tem um rebaixo com uma profundidade calculada, para que futuramente na montagem $0,04 \mathrm{~mm}$ da espessura da cerâmica fique para fora do isolante.

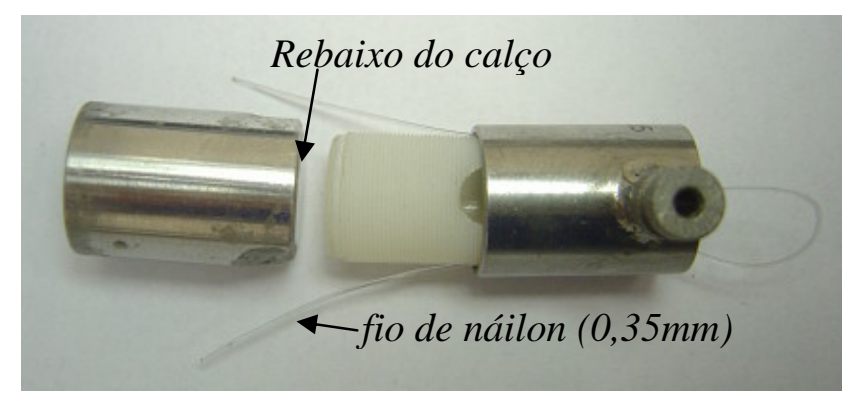

Figura 3.21: Colagem do isolante elétrico no corpo do transdutor de ultrassom. 
O dispositivo de montagem de transdutores pode ser visto na fig. 3.22 e fig.3.23. Foram construídos dez desses dispositivos para produzir lotes de transdutores monoelementos, sendo que a bancada de montagem é mostrada na fig. 3.24.

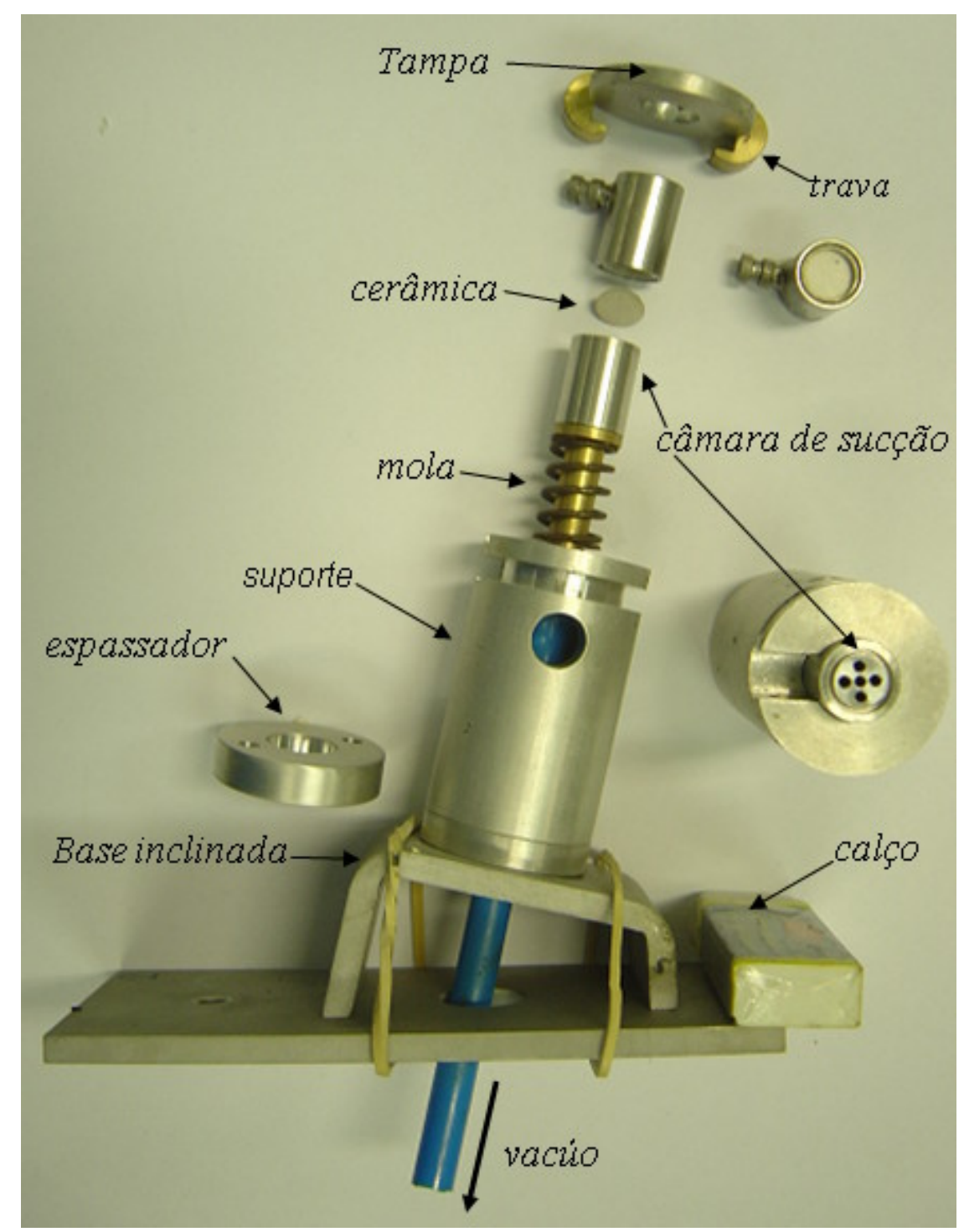

Figura 3.22: Dispositivo de montagem de transdutores de ultrassom.

Esse dispositivo de montagem possibilita, através do rebaixo da câmara de sucção a vácuo, posicionar a cerâmica e colá-la com precisão (dimensional e de paralelismo), fazendo com que a face da cerâmica em relação à face frontal do corpo do transdutor fique a uma distância igual à soma de um quarto de comprimento de onda 
(espessura da camada de casamento de impedância acústica) com mais $0,02 \mathrm{~mm}$ que será utilizado de sobrematerial para os ajustes finais, monitorados com equipamento que medem a forma de onda do sinal de eco da primeira reflexão (pulso-eco) de cada transdutor. Assim é obtido um espaçamento com uma tolerância de posicionamento de 0,01 mm, recomendada por (LAMBERTI, 1987), para a tolerância da espessura da camada de casamento de impedância acústica e também para obter o sinal de banda larga especifico para cada transdutor.
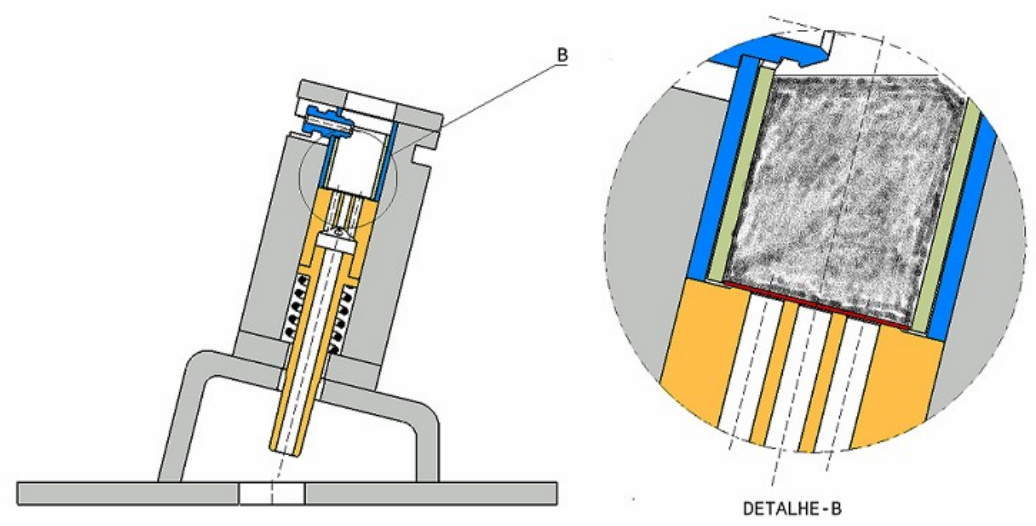

Figura 3.23: Seção transversal em corte do dispositivo de montagem de transdutores.

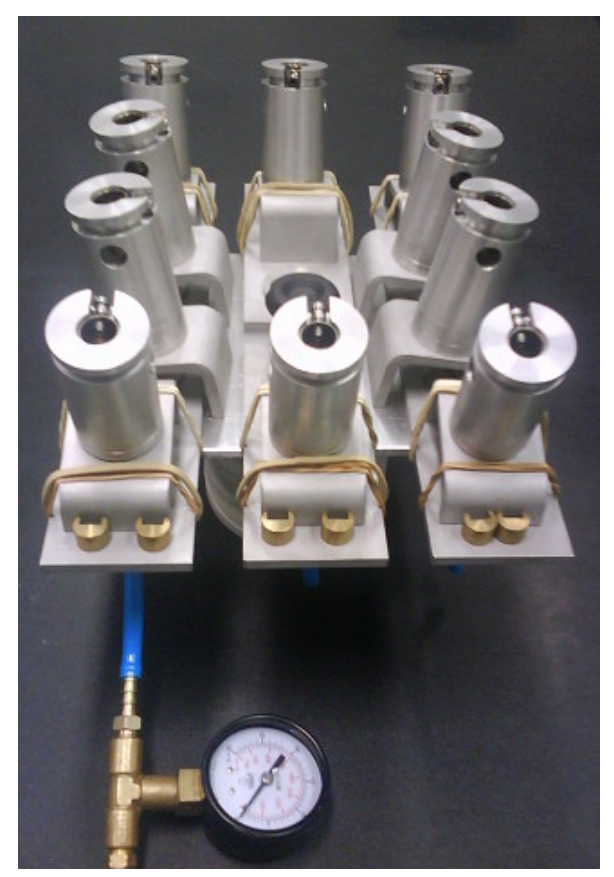

Figura 3.24: Bancada de montagem de transdutores monoelemento. 
Antes de colocar a cerâmica no dispositivo de montagem, deve ser soldado de topo na sua face o fio de conexão elétrica de cobre estanhado, que conduz o sinal elétrico do transdutor. A soldagem é feita a uma distância de aproximadamente $3 \mathrm{~mm}$ do centro da cerâmica conforme fig. 3.25 .

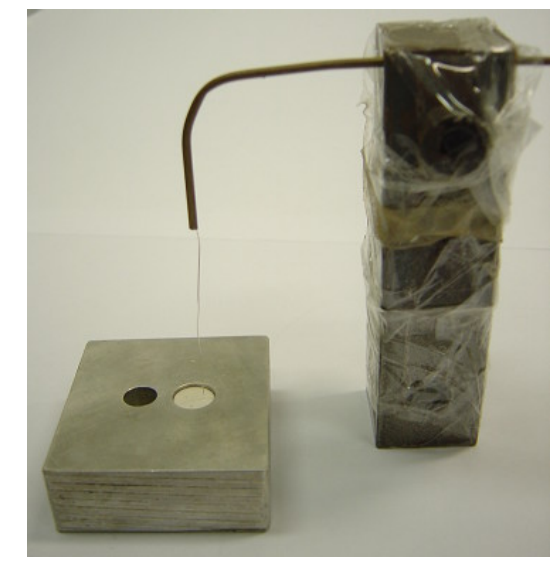

Figura 3.25: Dispositivo de posicionamento para soldagem.

A sequência de montagem no dispositivo é a seguinte:

- Colocar o calço na base inclinada para deixar o dispositivo na vertical.

- Colocar a cerâmica com o fio soldado no interior do isolador elétrico que deve ter seu diâmetro interno 0,03mm maior que o diâmetro externo da cerâmica.

- Empurrar o corpo do transdutor para dentro do suporte contraindo a mola e pressionado o assento do rebaixo da câmara de sucção a vácuo na face frontal de referência do corpo do transdutor.

- Efetuar o fechamento do dispositivo de montagem utilizando a tampa e as suas duas travas.

- Assentar com um pino a cerâmica na face de sucção girando-a se necessário para posicionar o fio de conexão elétrica radialmente oposto à guia do cabo coaxial.

- Acionar o vácuo para fixar a cerâmica.

- Aquecer o dispositivo montado a $70^{\circ} \mathrm{C}$ com um soprador térmico (secador de cabelo profissional de 1700 watts) durante 1 minuto. 
- Para formar a camada de retaguarda e fixar a cerâmica, deve-se introduzir com uma seringa, no interior do isolador elétrico, pelo orifício da tampa do dispositivo, 1,8 gramas de uma mistura de resina epóxi Araldite $^{\circledR}$ AW106, endurecedor HV $953 \mathrm{U}$ e pó de tungstênio (Aldrich ${ }^{\circledR} 12$ microns) na proporção em peso de 1:1:14,7 e aquecer com fluxo de ar quente a $70^{\circ} \mathrm{C}$ durante 1 minuto até que a superfície da mistura fique plana e compactada.

- Repetir o processo de adição da mistura até que a massa total depositada seja de 4 gramas

- Retirar o calço deixando o dispositivo inclinado.

- Repetir o processo de adição da mistura até que a massa total depositada seja de 5,6 gramas

- Colocar o dispositivo montado na estufa a $60^{\circ} \mathrm{C}$ por duas horas e meia .

- Retirar o corpo do transdutor do dispositivo.

O desenho de conjunto do dispositivo montado pode ser visto na fig. 3.23 onde se observa a inclinação da camada de retaguarda devido ao efeito da gravidade. $\mathrm{O}$ corpo do transdutor retirado do dispositivo com o material depositado já endurecido pode ser visto na fig. 3.26.

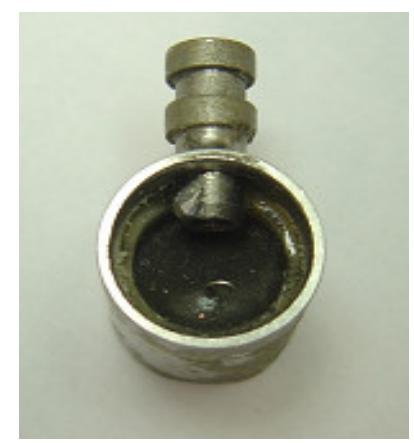

Figura 3.26: Característica do transdutor após ser retirado do dispositivo de montagem. 
A próxima etapa é a de soldagem dos fios das conexões elétricas na cerâmica passado os fios pelas ranhuras externas do isolador elétrico conforme mostrado na fig. 3.27 .

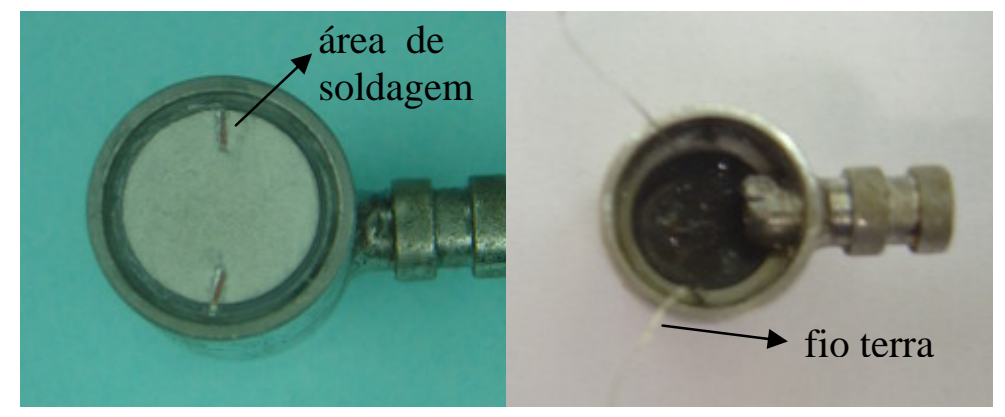

Figura 3.27: Soldagem dos fios das conexões elétricas na cerâmica.

Esses fios possuem secção transversal retangular com espessura de $0,03 \mathrm{~mm} e$ largura de 0,3mm, assim sendo a área de soldagem é retangular com as dimensões da largura do fio que é de $0,3 \mathrm{~mm}$ e do comprimento soldado que é de aproximadamente $1,8 \mathrm{~mm}$.

As etapas da soldagem são:

- Limpar a cerâmica com acetona.

- Adicionar uma camada de 0,1 mm de Solda em Pasta CL-78 (produto da Alpha) (T Fusão $179^{\circ} \mathrm{C}$ ) na área de soldagem da cerâmica.

- Aproximar o fio já aquecido com o ferro de solda regulado a $280 \stackrel{\circ}{\mathrm{C}}$ e absorver a solda fundida pela superfície inferior do fio (o tempo de soldagem deve ser de curta duração até a evaporação do fluxo para não sobreaquecer a liga soldada e despolarizar pontualmente a cerâmica com a queima do eletrodo de prata).

- Controlar o espalhamento da solda para que resulte uma camada de aproximadamente $0,02 \mathrm{~mm}$ de liga soldada sob o fio.

- Limpar o resíduo com acetona ou com Cleaner SC-10E (produto da Alpha).

Após a soldagem é feito o preenchimento das ranhuras externas do isolador elétrico, para blindagem dos fios das conexões elétricas, com resina epóxi (Araldite ${ }^{\circledR}$ AW106, endurecedor HV 953 U), utilizando uma mangueira de silicone encaixada no 
corpo do transdutor (face de referência) para efetuar a sucção a vácuo da resina que será adicionada pela entrada das duas ranhuras.

O próximo processo que é a deposição da camada de casamento de impedância acústica sobre a cerâmica é descrito pelas seguintes etapas abaixo, considerando um processo que envolve três transdutores por ciclo de preparo tem-se:

- Enrolar uma fita crepe na extremidade do corpo do transdutor para aumentar o seu diâmetro para $16 \mathrm{~mm}$.

- Enrolar outra fita deixando 3,5 mm para fora do transdutor para formar um cone por dobragem.

- Aquecer os transdutores na estufa à $70^{\circ} \mathrm{C}$

- Preparar 4g de resina epóxi Araudite ${ }^{\circledR}$ GY 279 BR utilizando 0,44 de endurecedor Aradur HY 951 sem deixar formar bolha de ar.

- Molhar uma microescova com a resina preparada

- Misturar a resina preparada com 3,4g de alumina calcinada TAC SC 25.

- Retirar três transdutores do forno e passar imediatamente uma finíssima camada de resina com a microescova.

- Logo em seguida ir adicionando a mistura com alumina e epóxi simultaneamente nos três transdutores, passando uma agulha nos rebaixos e batendo as faces traseiras dos transdutores num cepo para compactação e penetração do material, até preencher os espaços delimitados pelas fitas.

- Colocar novamente os transdutores na estufa a $70{ }^{\circ} \mathrm{C}$ e assim que a mistura ficar mais fluida, repetir o processo de batimento para afastar da cerâmica algumas pequenas bolhas ainda existes.

- Ainda com a mistura fluida, retirar os três transdutores da estufa posicionando-os equidistantes sobre uma chapa, colocar papéis celofanes sobre as misturas depositadas e apoiar uma chapa sobre os transdutores (que tem sobre ela um peso de 4,5 kg).

- Retornar todo o conjunto para o forno e deixar 3 horas a $60^{\circ} \mathrm{C}$.

- Após obter o material prensado e endurecido conforme apresentado na fig.3.28, tirar as fitas e o excesso, lixando sobre uma superfície plana, até a face frontal de referência do corpo do transdutor. 


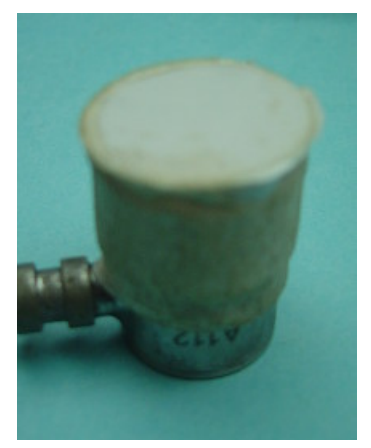

Figura 3.28: Deposição da camada de casamento de impedância

Para finalizar a soldagem das conexões elétricas será soldado a ponta da malha do cabo coaxial na área que foi depositado estanho na guia do cabo conforme fig.3.29. As outras extremidades do fio terra serão soldadas na malha do cabo coaxial e o fio de sinal do transdutor no fio central do cabo coaxial .

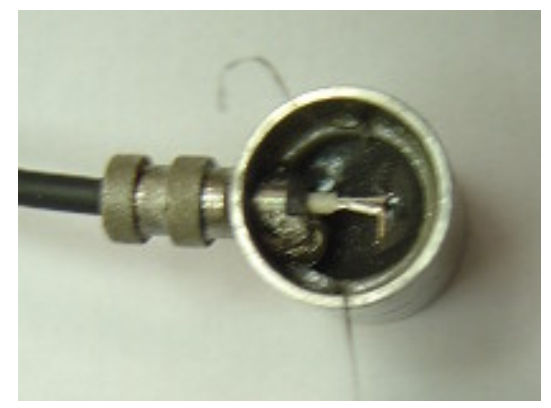

Figura 3.29: Soldagem da malha do cabo coaxial

Para impedir a entrada de resina epóxi de enchimento por dentro do cabo coaxial, será encapsulada sua entrada com uma resina mais viscosa (resina Araldite AW106 e endurecedor HV 953 U) que penetra em um comprimento menor de cabo.

Para finalizar o enchimento do corpo do transdutor, primeiramente será colada a tampa vista na fig. 3.30 no mesmo, utilizando cola condutiva num pequeno setor da colagem e epóxi resina (Araldite AW106 e endurecedor HV 953 U) no restante da colagem. 


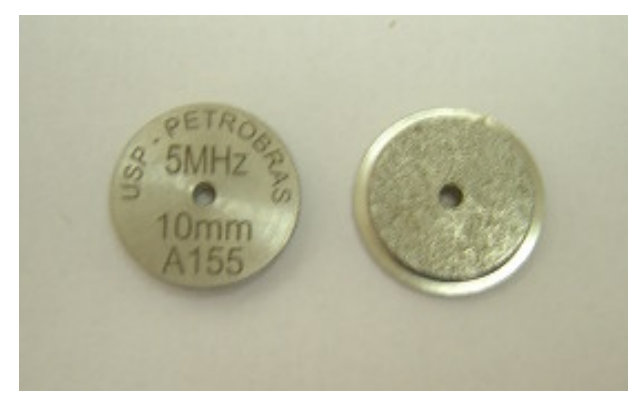

Figura 3.30: Características da tampa

Após colagem da tampa pode-se injetar com uma seringa, pelo orifício visto na figura 3.31 epóxi (Araudite ${ }^{\circledR}$ GY 279 e endurecedor Aradur HY 951) sem deixar formar bolha de ar.

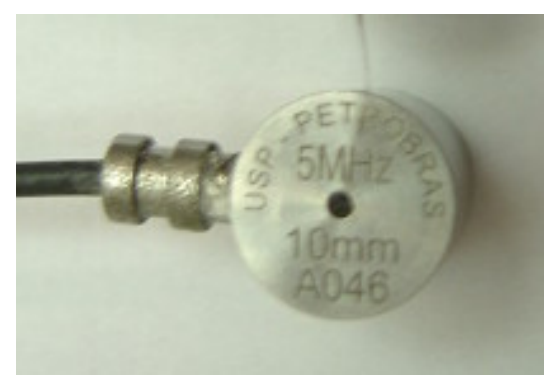

Figura 3.31: Finalização de enchimento e vedação do transdutor.

Para finalizar a vedação aplicar epóxi (Resina Araudite ${ }^{\circledR}$ GY 279 BR Endurecedor Aradur HY 2963) na entrada da guia do cabo coaxial.

Um lote com 133 transdutores testados e produzidos com os processos descritos acima pode ser visto na fig.3.32.

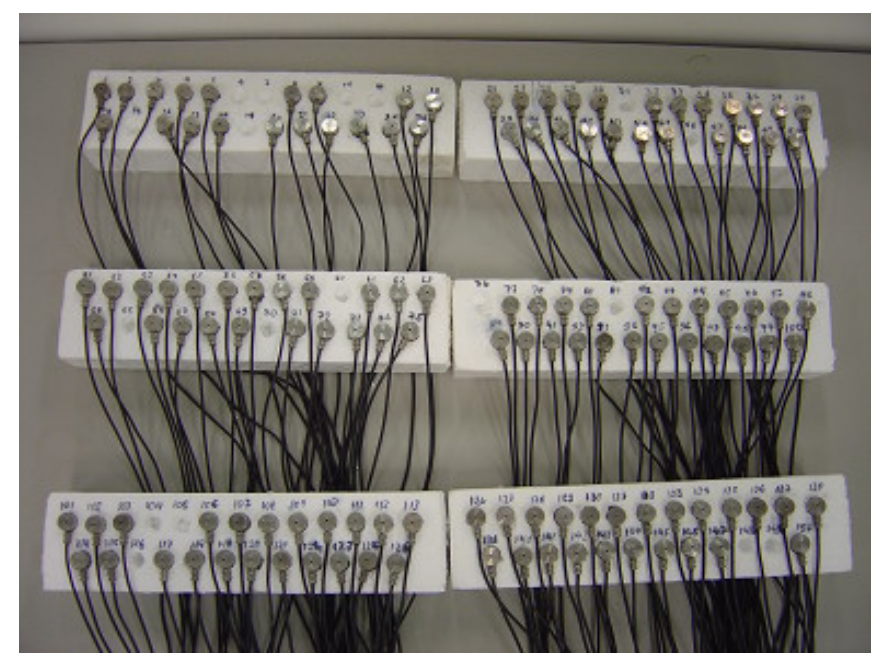

Figura 3.32: Lote de transdutores produzidos. 


\subsubsection{Materiais utilizados para constituição das camadas passivas}

Para poder atender as especificações, outros materiais devem ser pesquisados como, por exemplo, o material da camada de retaguarda que por necessitar ter uma impedância acústica maior para transdutores de banda larga , necessita aumentar sua densidade, aumentando a proporção de tungstênio na mistura o que ocasiona a perda do potencial de adesão na colagem entre os seus próprios componentes e com os outros elementos do transdutor. As características físicas e acústicas da mistura epóxi e tungstênio em função da fração em volume de tungstênio e da mistura epóxi e poliuretano em função da fração em volume de tungstênio, como a densidade, a velocidade de propagação longitudinal, a impedância acústica e a atenuação teóricas e obtidas experimentalmente por (FRANCO et al., 2005) são apresentadas nas figuras (3.33),(3.34),(3.35) e (3.36) respectivamente :

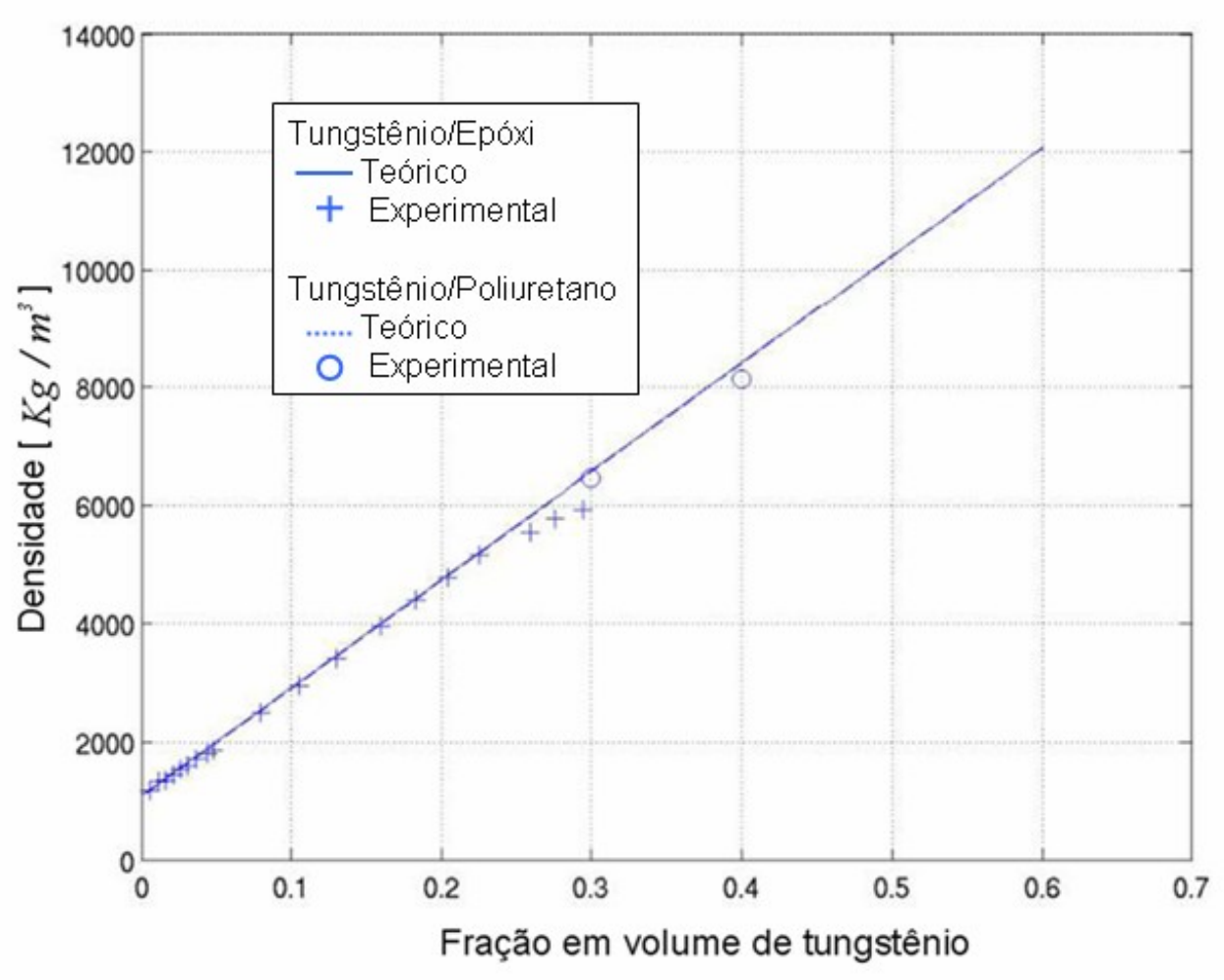

Figura 3.33 : Densidade para a mistura de Tungstênio e epóxi (Modificado de FRANCO et al., 2005) 


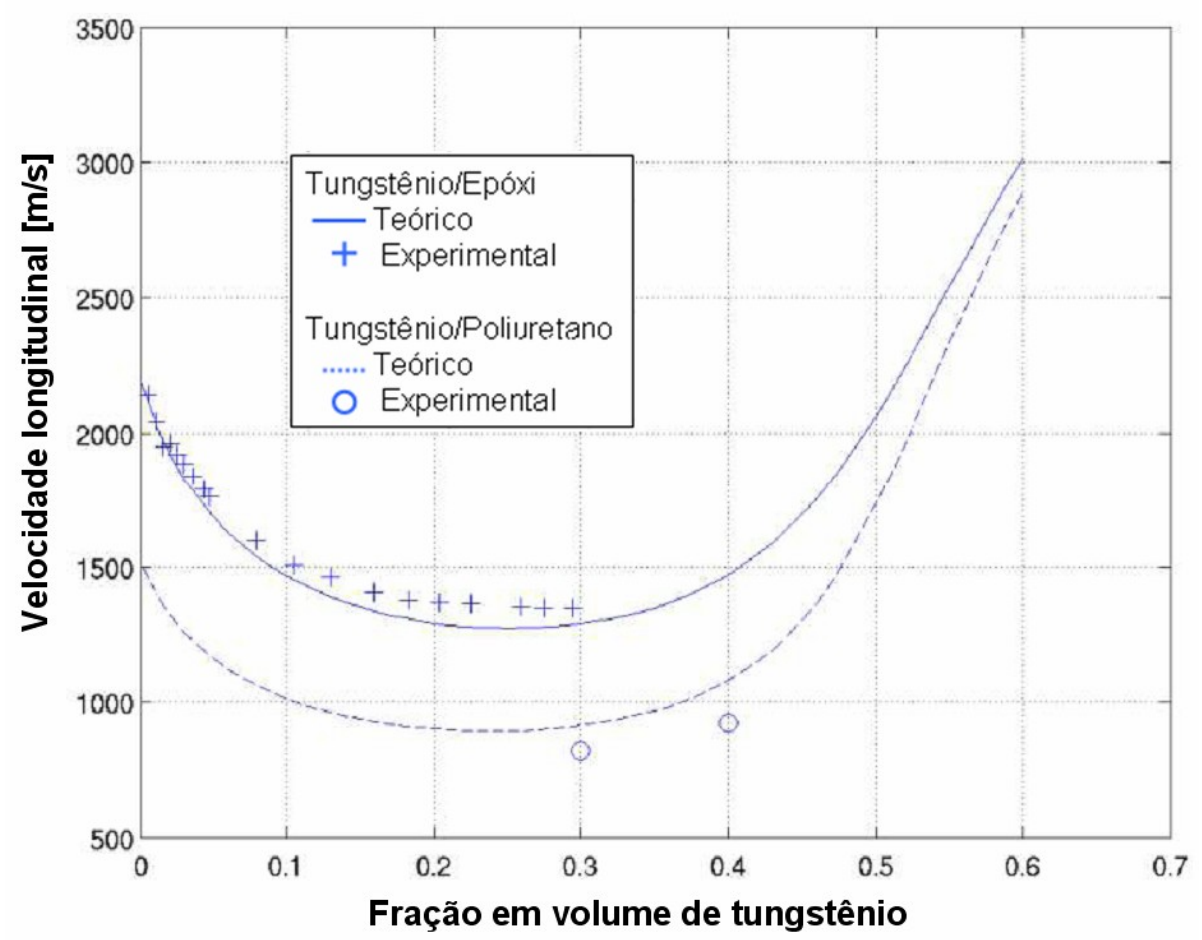

Figura 3.34: Velocidade de propagação para a mistura de Tungstênio e epóxi (Modificado de FRANCO et al., 2005).

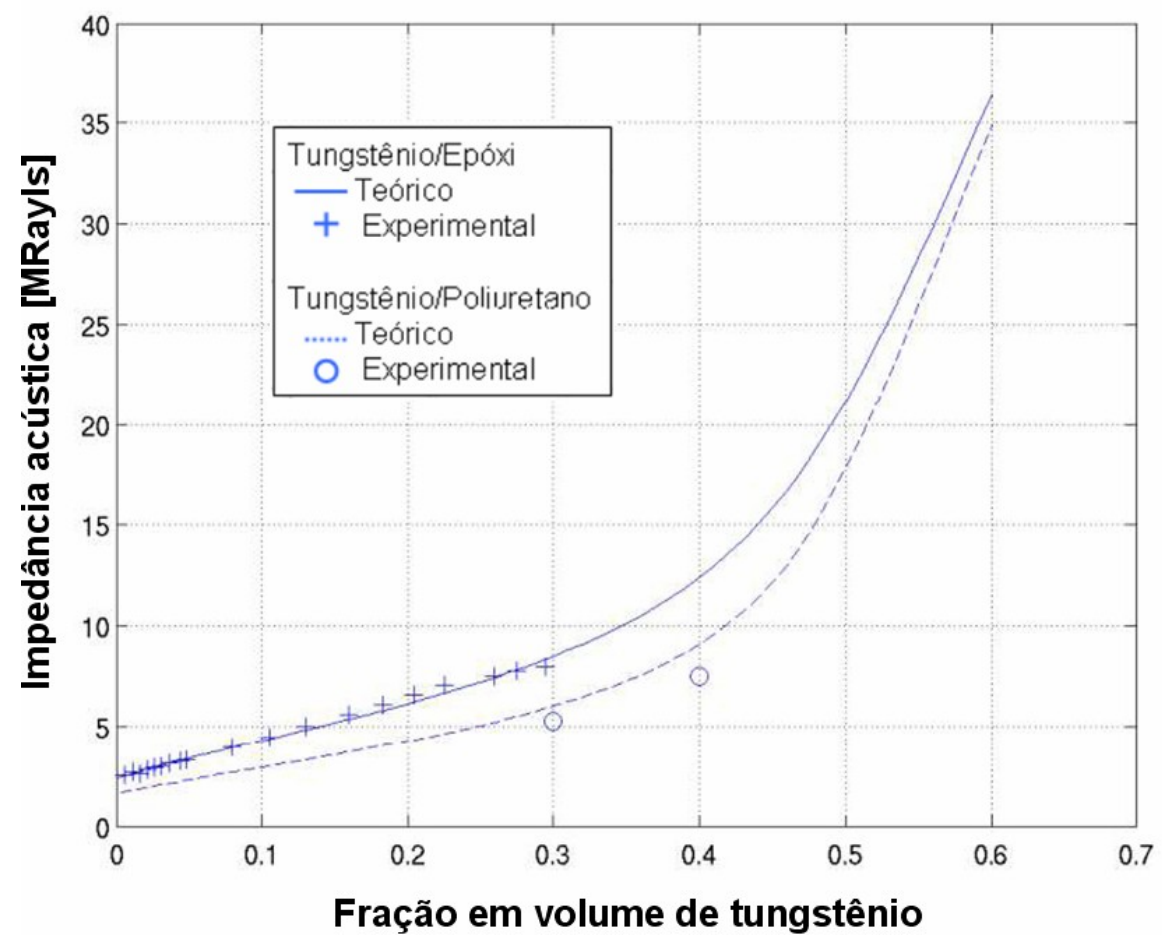

Figura 3.35: Impedância acústica para a mistura de Tungstênio e epóxi (Modificado de FRANCO et al., 2005). 


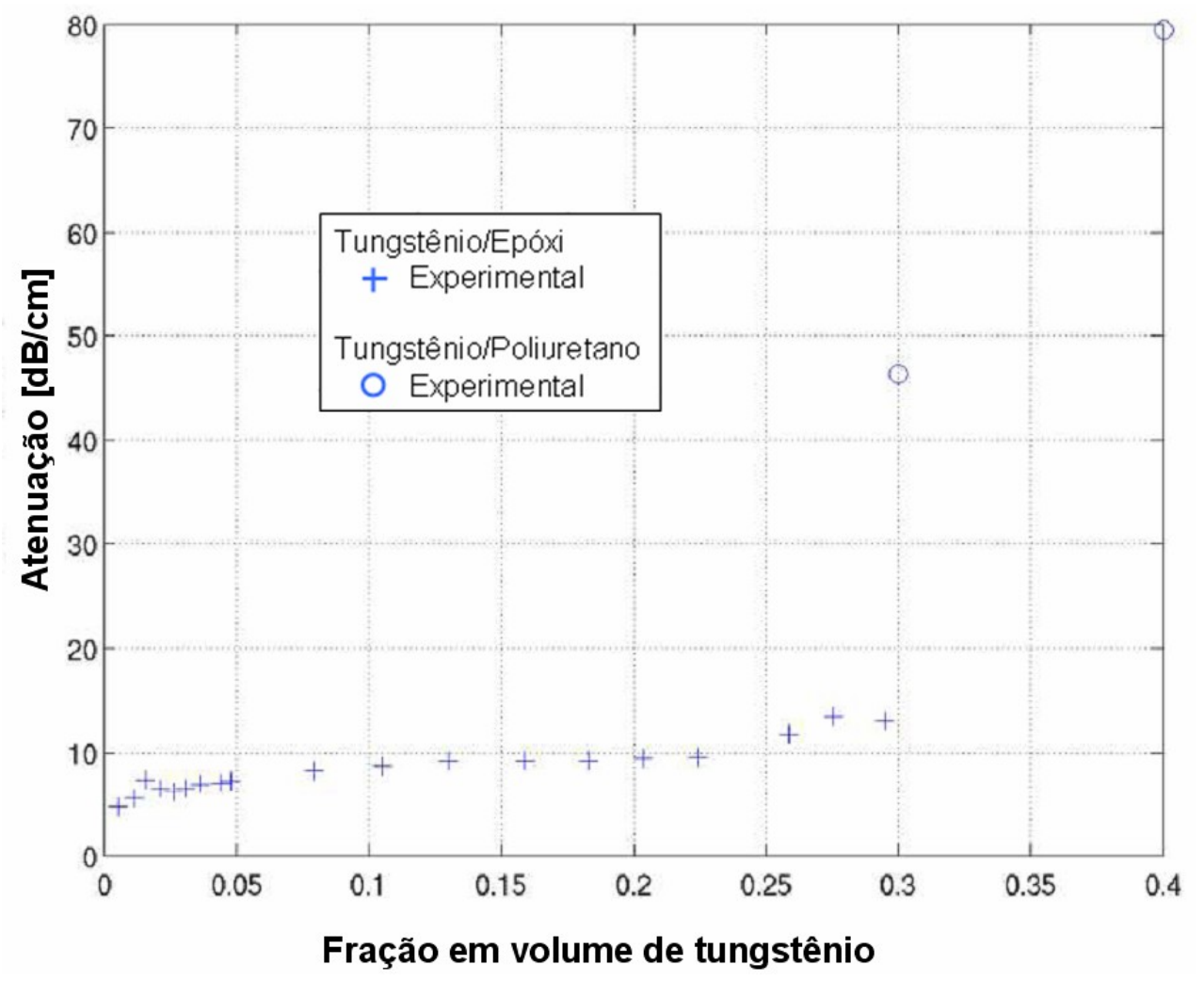

Figura 3.36: Atenuação das amostras de Tungstênio e epóxi obtidas experimentalmente à $1 \mathrm{MHz}$ (Modificado de FRANCO et al., 2005).

Para determinação da espessura da camada de casamento de impedância acústica, inicialmente é calculado o valor da impedância acústica conforme a equação 2.1, com este valor é extraído do gráfico da impedância acústica em função da fração em volume de alumina (MONTERO, 1985) a fração correspondente e com este valor é extraído do gráfico da velocidade de propagação longitudinal da onda acústica em função da fração de volume de alumina o valor da velocidade correspondente. Obtida a velocidade de propagação longitudinal da onda acústica, através da frequência central do transdutor, pode-se calcular o comprimento de onda e, dividindo-o por quatro determina-se a espessura da camada de casamento de impedância acústica. Para valores mais precisos desta espessura convém efetuar a medição da velocidade longitudinal da onda acústica considerando a resina epóxi e a granulação de alumina utilizadas (específicas), conforme método experimental realizado por (FRANCO et al., 2005) para medição da velocidade da mistura de epóxi com tungstênio. 


\subsubsection{Análise do processo de fabricação}

O dispositivo de montagem, além de diminuir o tempo de fabricação, possibilitou uma boa repetitividade de posicionamento da cerâmica piezelétrica nos transdutores, facilitando os ajustes finais de espessura na camada de casamento de impedância acústica, para melhorar a resposta impulsiva de cada transdutor do lote produzido. Para uma maior repetitividade de posicionamento da cerâmica e conseqüentemente da espessura da camada de casamento de impedância acústica, principalmente quando tiver um lote de cerâmicas com comportamentos semelhantes, devem-se evitar pequenos deslocamentos da cerâmica da sua posição correta no transdutor, devido ao deslocamento da camada de retaguarda (contração e deslizamento) ou ao não travamento da cerâmica durante o processo de cura. Assim para melhorar o processo deve-se aumentar o tempo de aplicação de sucção a vácuo na face da cerâmica e simultaneamente manter a temperatura de cura com a colocação de fios de resistências elétricas enrolados em torno dos dispositivos de montagem. Além disso, deve-se aumentar a ancoragem da camada de retaguarda no tubo isolante através de rebaixo, ranhuras ou aumentando a rugosidade da superfície interna do tubo isolante.

Para atender as especificações de projeto e as de construção, outros materiais e métodos de adesão das camadas devem ser testados, pois devido à carga de pó de alumina, à resina e ao endurecedor utilizados, a camada de casamento de impedância acústica não apresentou uma boa aderência no eletrodo de prata da cerâmica e nos tubos de ABS e de inox , necessitando de artifícios como a deposição de uma finíssima camada de resina epóxi menos viscosa sobre a face do eletrodo da cerâmica, que por possuir uma baixa rugosidade necessita de uma interface de adesão; de usinar ranhuras (acabamento serrilhado ou roscado) no tubo isolante de ABS e de jatear com granalha de inox (ou óxido de alumínio) o tubo de inox para obter uma rugosidade que garantisse ancoragem e vedação.

Outros processos como o de deposição a vácuo, sob pressão, compactação por prensagem, vibração e aceleração que não formam bolhas, camadas de ar nas interfaces e que tenham aquecimento simultâneo, os quais propiciam o eficiente contato de adesão das misturas com as superfícies, devem ser implementados e testados, 
principalmente para a camada de casamento de impedância acústica cujo método de deposição por batimento e posterior prensagem mostrou-se trabalhoso e dependente da sensibilidade do operador para manter um padrão de qualidade (pouco repetitivo), pois o operador simultaneamente deve depositar e aquecer no forno a camada (preenchendo todos os espaços e extraindo as bolhas) e controlar (reduzir) o tempo de manipulação da mistura depositada até a prensagem final, para que no processo não ocorra escorregamento (descolamento) desta mistura na face da cerâmica, por ela atingir precocemente uma fase mais consistente. Também para melhorar a adesão deve-se pesquisar outros matérias como resinas (adesivos), cargas de pós diferentes e com menores granulações e verificar a eficácia de depositar nas superfícies um filme fino de resina sem carga de pó para obter uma interface que melhore a adesão sem comprometer a eficiência acústica das camadas.

Outro material a ser pesquisado e testado é o da camada de retaguarda, o qual deve ter impedância acústica e coeficiente de atenuação acústico maiores para transdutores de banda larga. A densidade do material pode ser aumentada pela adição de tungstênio na mistura com a resina epóxi. Tal adição é limitada para não reduzir o potencial de adesão entre os próprios elementos da mistura e da mistura com a cerâmica piezelétrica e com o tubo isolante. Contudo o processo e a mistura utilizados na deposição da camada de retaguarda atenderam às especificações acústicas e de colagem para os transdutores produzidos e testados neste trabalho.

Para pesquisas futuras que visam aumentar eficiência e repetitilidade de processos, devem-se definir métodos de medição que quantifiquem as intensidades de adesões das camadas em ambas as superfícies das cerâmicas e métodos que verifiquem a intensidade, repetitividade e influências acústicas das diferenças de concentração das cargas de pó ao longo das camadas (formadas no processo de deposição por decantação ou flutuação), que determinam as concentrações efetivas (impedâncias acústicas) nas interfaces com a cerâmica.

O processo de soldagem utilizando solda em pasta e fio com seção retangular $(0,25 \mathrm{~mm} \times 0,03 \mathrm{~mm})$ mostrou-se eficiente por apresentar uma baixa altura de perfil soldado (não ultrapassando a superfície da camada de casamento acústico) e uma boa área de contato da solda sob o fio . Não apresentou sobreaquecimento na soldagem 
devido à pequena espessura do fio e a presença do fluxo na solda em pasta, assim otimizou a distribuição de calor, podendo trabalhar com menores temperaturas e tempos de soldagem, sem transmitir muito calor da finíssima camada de prata do eletrodo para a cerâmica, evitando a sua despolarização na área de soldagem. Contudo, a utilização de adesivo condutivo pode ser uma outra solução que pode ser implementada à temperatura ambiente e com a possibilidade de automação para colagem através da utilização de dispensador. 


\subsection{Resultados experimentais}

Para obtenção dos resultados experimentais foi construído um lote de 133 transdutores de $5 \mathrm{MHz}$ e um dispositivo com refletor plano para medição da forma de onda do sinal de eco da primeira reflexão, conforme mostrado na figura 3.37.

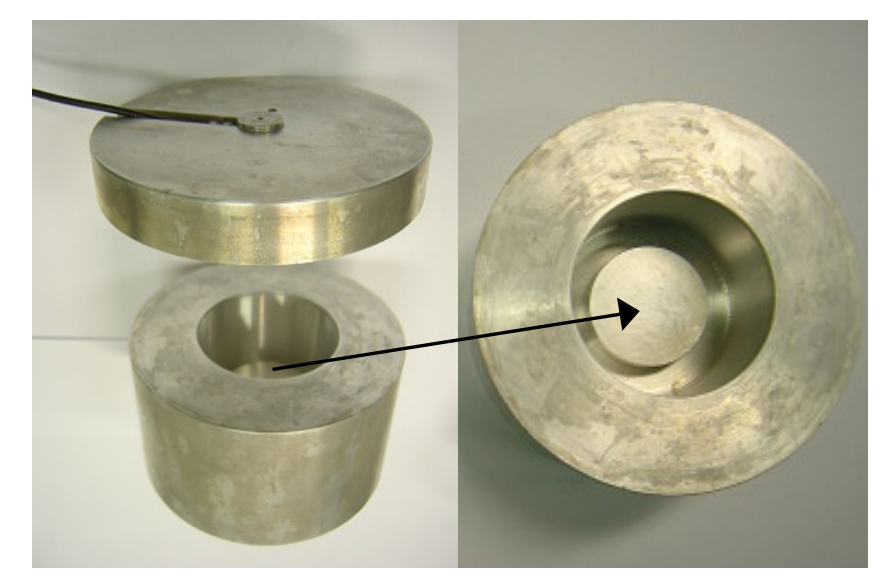

Figura 3.37: Dispositivo com refletor para medição do sinal de eco.

Utilizando o equipamento de teste ultrassônico, US-BOX-S, da Lecoeur Electronique que possui interfase USB, foi montado o aparato experimental conforme mostrado na fig. 3.38. O cabo do transdutor é ligado na conexão de modo pulso-eco do equipamento de teste ultrassônico e a interfase USB no computador. Os dados de excitação do transdutor são ajustados numa interface gráfica feita no MATLAB, como também os dados adquiridos do sinal de eco. Foi ajustada uma amplitude de pulso de excitação de 200 volts, um ganho de $10 \mathrm{~dB}$ e uma frequência de amostragem de $160 \mathrm{MHz}$. Assim, são obtidos os gráficos da forma de onda do sinal de eco de primeira reflexão e o seu respectivo espectros de amplitude. Com os dados adquiridos, também são obtidos a frequência central, a amplitude de pico-a-pico e a largura de banda (medida à $-3 \mathrm{~dB}$ ) do sinal de reflexão. 


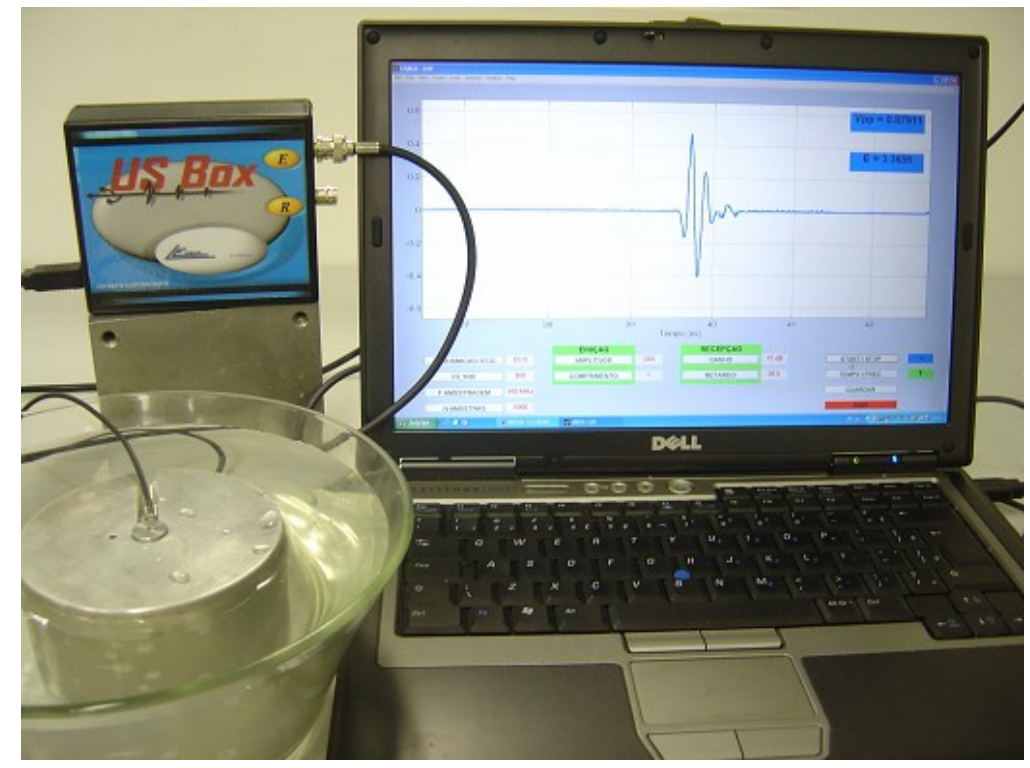

Figura 3.38: Aparato experimental para medições em modo pulso-eco.

As frequências de ressonâncias das cerâmicas obtidas no impedômetro e os dados de alguns transdutores do lote, obtidos no equipamento de teste ultrassônico, US-BOX-S, podem ser vistos na tabela 3.1:

Tabela 3.1 Dados da cerâmica e dos transdutores

\begin{tabular}{|l|l|l|l|l|l|l|l|}
\hline $\begin{array}{l}\text { Numero } \\
\text { de } \\
\text { serie }\end{array}$ & $\begin{array}{l}\text { Diâmetro } \\
\text { da } \\
\text { Cerâmica } \\
{[\mathrm{mm}]}\end{array}$ & $\begin{array}{l}\text { Espessura } \\
\text { da } \\
\text { Cerâmica } \\
{[\mathrm{mm}]}\end{array}$ & $\begin{array}{l}\text { Frequência } \\
\text { da } \\
\text { Cerâmica } \\
{[\mathrm{MHz}]}\end{array}$ & $\begin{array}{l}\text { Espessura } \\
\text { inicial do } \\
\text { Matching } \\
{[\mathrm{mm}]}\end{array}$ & $\begin{array}{l}\text { Frequência } \\
\text { Central do } \\
\text { Transdutor } \\
{[\mathrm{MHz}]}\end{array}$ & $\begin{array}{l}\text { Largura de } \\
\text { Banda do } \\
\text { Transdutor } \\
{[\mathrm{MHz}]}\end{array}$ & $\begin{array}{l}\text { Tensão } \\
\text { Vpp } \\
{[\mathrm{V}]}\end{array}$ \\
\hline 88 & 10,02 & 0,291 & 4,79 & 0,15 & 5,12 & 2,40 & 1,03 \\
\hline 89 & 9,99 & 0,275 & 5,00 & 0,15 & 5,36 & 2,88 & 0,98 \\
\hline 90 & 10,02 & 0,293 & 4,77 & 0,15 & 5,12 & 2,08 & 1,01 \\
\hline 91 & 10,07 & 0,299 & 4,79 & 0,15 & 5,36 & 2,24 & 1,06 \\
\hline 92 & 10,05 & 0,295 & 4,65 & 0,145 & 5,20 & 2,24 & 1,11 \\
\hline 93 & 10,02 & 0,283 & 4,81 & 0,15 & 5,20 & 2,24 & 0,96 \\
\hline 94 & 10,03 & 0,288 & 4,80 & 0,15 & 5,20 & 2,24 & 1,05 \\
\hline 95 & 10,05 & & 4,71 & 0,145 & 5,20 & 1,92 & 1,06 \\
\hline 96 & 10,02 & 0,294 & 4,72 & 0,15 & 5,20 & 1,60 & 0,93 \\
\hline 97 & 10,03 & 0,285 & 4,82 & 0,15 & 5,04 & 2,24 & 1,01 \\
\hline 98 & 10,01 & 0,284 & 4,86 & 0,15 & 5,28 & 2,08 & 1,01 \\
\hline 99 & 10,12 & 0,292 & 4,62 & 0,15 & 5,12 & 2,08 & 1,08 \\
\hline 120 & 10,01 & 0,287 & 4,80 & 0,15 & 5,20 & 2,24 & 1,06 \\
\hline
\end{tabular}


Devido a variações das frequências de vibrações das cerâmicas isoladas (de 4.3 $\mathrm{MHz}$ a $5 \mathrm{MHz}$ ) e pequenas variações de espessuras das camadas de casamentos acústicos (de $+0,003 \mathrm{~mm}$ à $+0,015 \mathrm{~mm}$ em relação a um valor total calculado de 0,125 $\mathrm{mm}$ ), os 133 transdutores inicialmente apresentaram frequências entre $4,5 \mathrm{MHz}$ à 5 $\mathrm{MHz}$, com larguras de bandas entre $1,5 \mathrm{MHz}$ à 2,2 $\mathrm{MHz}$.Para os transdutores que apresentavam baixas frequências, foi necessário uma diminuição das espessuras das camadas de casamento acústico, resultando um aumento das frequências e das larguras de banda dos transdutores e uma pequena diminuição da amplitude de pico-a-pico (sensibilidade) .

As características do lote de 133 transdutores aprovados, após os ajustes finais, são apresentadas na tabela 3.2, através de uma análise estatística dos resultados obtidos pela medição de todos os transdutores :

Tabela 3.2 Análise estatística dos resultados obtidos do lote de 133 transdutores.

\begin{tabular}{|l|c|c|c|}
\hline & $\begin{array}{c}\text { Frequência } \\
\text { Central do } \\
\text { Transdutor } \\
{[\mathrm{MHz}]}\end{array}$ & $\begin{array}{c}\text { Largura de } \\
\text { Banda do } \\
\text { Transdutor } \\
{[\mathrm{MHz}]}\end{array}$ & $\begin{array}{c}\text { Tensão } \\
\text { Vpp } \\
{[\mathrm{V}]}\end{array}$ \\
\hline Média & 5,27 & 2,12 & 1,04 \\
\hline Desvio Padrão & 0,21 & 0,37 & 0,07 \\
\hline Mínimo - Máximo & $5,04-5,68$ & $1,60-2,88$ & $0,93-1,14$ \\
\hline
\end{tabular}

Apenas para uma análise qualitativa que não compara os valores numéricos apresentados na tabela 3.1, uma vez que os resultados a seguir são de um transdutor protótipo que não tem as mesmas características dos transdutores do lote fabricado e que foi testado com outro aparato experimental no início dos trabalhos, será apresentado os resultados obtidos dos sinais de eco nas três etapas de diminuição de espessura da camada de casamento de impedância acústica, os quais podem serem vistos na tabela 3.3 e nas figuras 3.39 e 3.40 , sendo que a etapa 3 é a final com a menor espessura da camada de casamento acústico. 
Tabela 3.3 Resultados obtidos nas três etapas de diminuição da espessura.

\begin{tabular}{|l|l|l|l|}
\hline & Etapa 1 & Etapa 2 & Etapa 3 \\
\hline Frequência [MHz] & 4.1 & 4.3 & 4.5 \\
\hline Energia (normalizada) & 1,00 & 0,81 & 0.67 \\
\hline Tensão pp [V] & 2.14 & 1.98 & 1.88 \\
\hline Largura de banda [MHz] & 1 & 1.2 & 1.4 \\
\hline
\end{tabular}




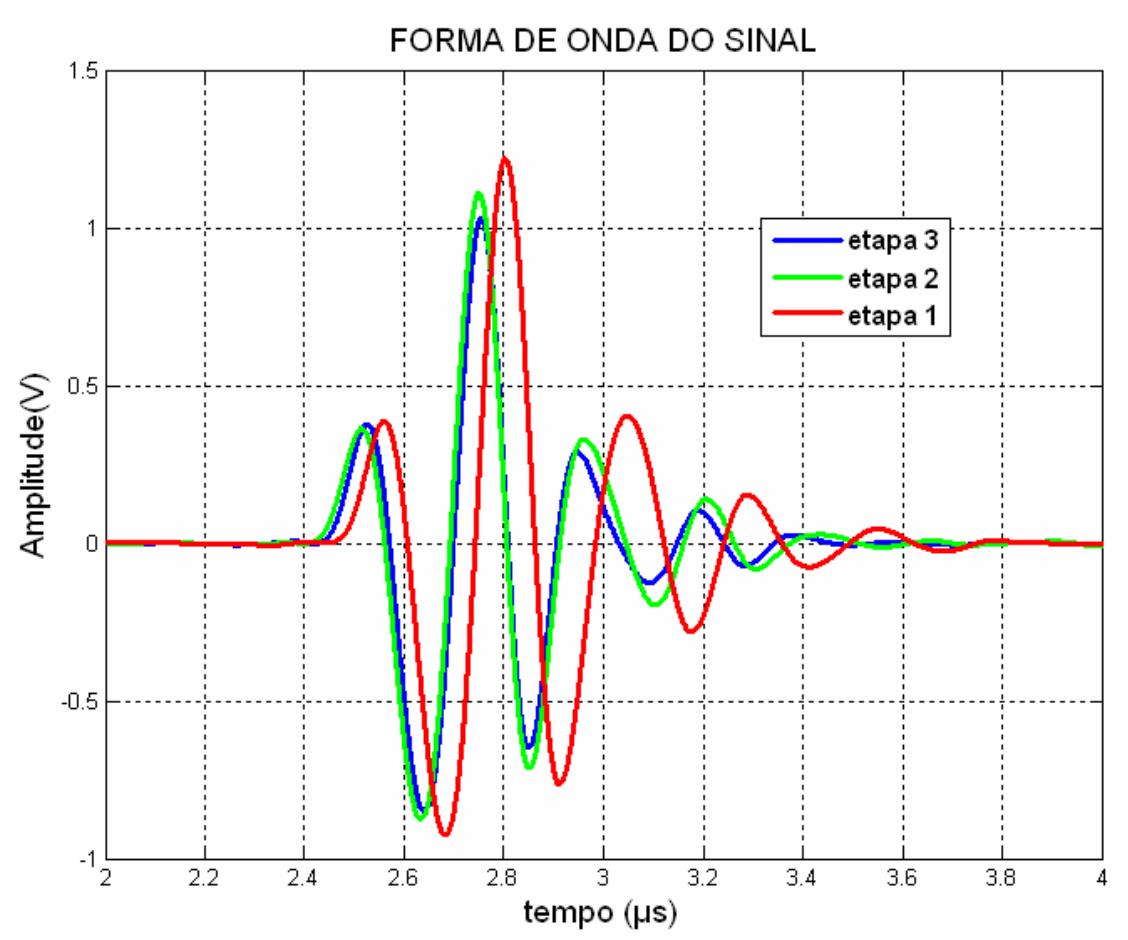

Figura 3.39: Formas de ondas dos sinais de reflexões.

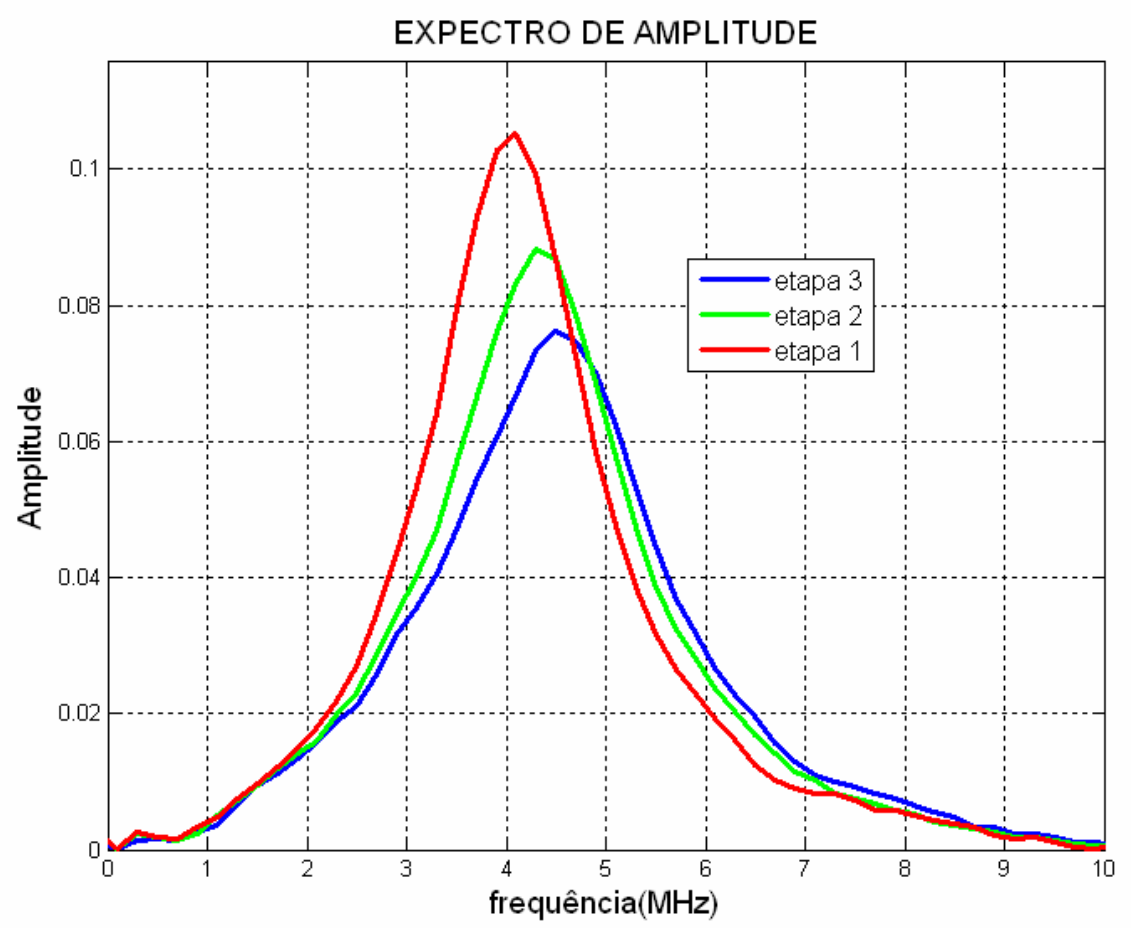

Figura 3.40: Espectros de amplitudes dos sinais de reflexões. 


\subsection{Comparação entre os sinais teórico e experimental}

Para caracterizar e verificar a influência da cerâmica piezelétrica em cada transdutor simulado, antes da montagem foram documentados as medidas geométricas (diâmetros e espessuras) e os gráficos dos módulos e das fases das impedâncias elétricas em função da frequência, obtidos no impedômetro, de todas as cerâmicas utilizadas. As medidas geométricas das cerâmicas dos três transdutores que foram construídos e simulados, identificados com número de serie 89, 91 e 99, podem ser obtidas na tabela 3.1, sendo que da espessura apresentada nesta tabela , para efeito de simulação, deve-se descontar $0,01 \mathrm{~mm}$ referente à soma das espessuras dos dois eletrodos de prata.

Devido ao não fornecimento dos valores da constante elástica $\left(c_{33}^{E}\right)$, piezelétrica $\left(e_{33}\right)$ e dielétrica $\left(\varepsilon_{33}^{S}\right)$ da cerâmica PZ-37 pelo fabricante "Ferroperm Piezoceramics A/S", foi utilizado como parâmetros iniciais de referencia, para realizar as simulações, as constantes de uma das cerâmicas do lote utilizado na montagem dos transdutores, as quais foram determinadas no laboratório de ultrassom, pelo método de identificação de constantes proposto por (Pérez et al.,2010).

As cerâmicas utilizadas nos três transdutores que foram simulados, apresentaram curvas diferentes obtidas no impedômetro, dos módulos e das fases das impedâncias elétricas, mostrando uma grande heterogeneidade das propriedades entre as cerâmicas (a tolerância padrão fornecida pelo fabricante das propriedades elétricas é de $\pm 10 \%$, das propriedades eletromecânicas é de $\pm 5 \%$ e das propriedades mecânicas é de $\pm 2.5 \%$ ). Assim as constantes inicialmente determinadas foram ajustadas conforme tabela (3.4) para cada cerâmica, tendo como referência de ajuste as tolerâncias do fabricante para cada tipo de constante e a minimização das diferenças entre as curvas dos módulos e das fases das impedâncias elétricas obtidas de cada cerâmica no impedômetro e as curvas dos módulos e das fases das impedâncias elétricas correspondentes simuladas. Na tabela (3.4), os valores percentuais mostrados referemse às diferenças entre os valores iniciais das constantes e os respectivos valores ajustados. Considerando a equação (3.61), supondo que para uma cerâmica 
piezelétrica imersa no vácuo, a força de contato é nula $\left(F_{2}=0\right)$ e na determinação dos elementos da matriz, a impedância acústica da camada de retaguarda é igual a zero $\left(Z_{B}=0\right)$, dividindo-se a tesão elétrica pela corrente obtêm-se a impedância elétrica complexa.

Os ajustes das curvas de impedâncias elétricas podem ser vistos na figura (3.41). Para coincidir a frequência de ressonância elétrica $\left(f_{R}\right)$ e de anti-ressonância elétrica $\left(f_{A}\right)$ nas curvas de impedância elétrica, deve-se ajustar simultaneamente a diferença entre elas e os seus valores efetivos.

A impedância elétrica dada na equação (3.29) é descrita em função de $C_{0}, V_{A}^{D}$ e $K_{A}$. O coeficiente de acoplamento piezelétrico $K_{A}$ para o modo de espessura dado na equação (3.31), definido em função de $c_{33}^{D}$ na equação (3.107), é em parte responsável pelo ajuste da diferença entre a frequência de anti-ressonância elétrica e de ressonância elétrica, como pode ser visto na equação (3.108). A velocidade de propagação da onda no meio piezelétrico $V_{A}^{D}$ dado pela equação (3.12) que também é em função de $c_{33}^{D}$ é responsável pelo ajuste do valor efetivo da frequência de antiressonância elétrica que no modo de vibração de espessura e na condição de ressonador de meio comprimento de onda é definida pela equação (3.109). Como as constates $e_{33}, c_{33}^{E}$ ou $\varepsilon_{33}^{S}$ são fatores de $C_{0}, K_{A}$ e de $V_{A}^{D}$ existem valores ótimos para estas constantes que melhor ajusta as curvas de impedâncias elétricas.

$$
\begin{aligned}
& K_{A}^{2}=\frac{e_{33}^{2}}{c_{33}^{D} \varepsilon_{33}^{S}} \\
& K_{A}^{2}=\frac{\pi}{2} \frac{f_{R}}{f_{A}} \operatorname{tg}\left(\frac{\pi}{2} \frac{f_{A}-f_{R}}{f_{R}}\right) \\
& f_{A}=\frac{1}{2 \ell} V_{A}^{D} \quad \ell=\frac{\lambda}{2}
\end{aligned}
$$


Para considerar as perdas mecânicas e elétricas conforme equações (3.102) e (3.104), foi verificado por simulação que diminuindo o valor do fator de qualidade mecânico $Q_{m}$ e o fator qualidade elétrico $Q e$ diminui o módulo do valor da impedância elétrica (principalmente da impedância elétrica referente à frequência de antiressonância elétrica), assim sendo seus valores ajustados para cada cerâmica também são apresentados na tabela (3.4).

Tabela 3.4 Valores ajustados para as constantes que caracterizam as cerâmicas.

\begin{tabular}{|c|c|l|l|l|}
\hline & $\begin{array}{l}\text { Valores de } \\
\text { Referência }\end{array}$ & $\begin{array}{l}\text { Valores } \\
\text { ajustados } \\
\text { Cerâmica (89) }\end{array}$ & $\begin{array}{l}\text { Valores } \\
\text { ajustados } \\
\text { Cerâmica (91) }\end{array}$ & $\begin{array}{l}\text { Valores } \\
\text { ajustados } \\
\text { Cerâmica (99) }\end{array}$ \\
\hline $\begin{array}{c}\text { Densidade da cerâmica } \\
\rho\left(K g / m^{3}\right)\end{array}$ & 6000 & $6350(+6 \%)$ & $6000(+0 \%)$ & $6240(+4 \%)$ \\
\hline $\begin{array}{c}\text { Constante piezelétrica } \\
e_{33}\left(\mathrm{C} / \mathrm{m}^{2}\right)\end{array}$ & 10,0126 & $11,2141(+12 \%)$ & $10,51(+5 \%)$ & $10,26(+2,5 \%)$ \\
\hline $\begin{array}{c}\text { Constante elástica } \\
c_{33}^{E}\left(10^{10} \mathrm{~N} / \mathrm{m}^{2}\right)\end{array}$ & 4,3059 & $4,2628(-1 \%)$ & $4,3920(+2 \%)$ & $4,0470(-6 \%)$ \\
\hline $\begin{array}{l}\text { Permissividade dielétrica } \\
\text { a deformação constante } \\
\varepsilon_{33}^{S}\left(10^{-9} F / m\right)\end{array}$ & 5,5579 & $5,5579(+0 \%)$ & $5,5579(+0 \%)$ & $5,2800(-5 \%)$ \\
\hline $\begin{array}{l}\text { Fator de qualidade } \\
\text { Mecânico : } Q_{m}\end{array}$ & $\begin{array}{l}50 \\
\text { Elétrico : } Q_{e}\end{array}$ & $\begin{array}{l}22,5(-0,55 \%) \\
64(-20 \%)\end{array}$ & $\begin{array}{l}35(-30 \%) \\
64(-20 \%)\end{array}$ & $25(-50 \%)$ \\
80 & & & \\
\hline
\end{tabular}




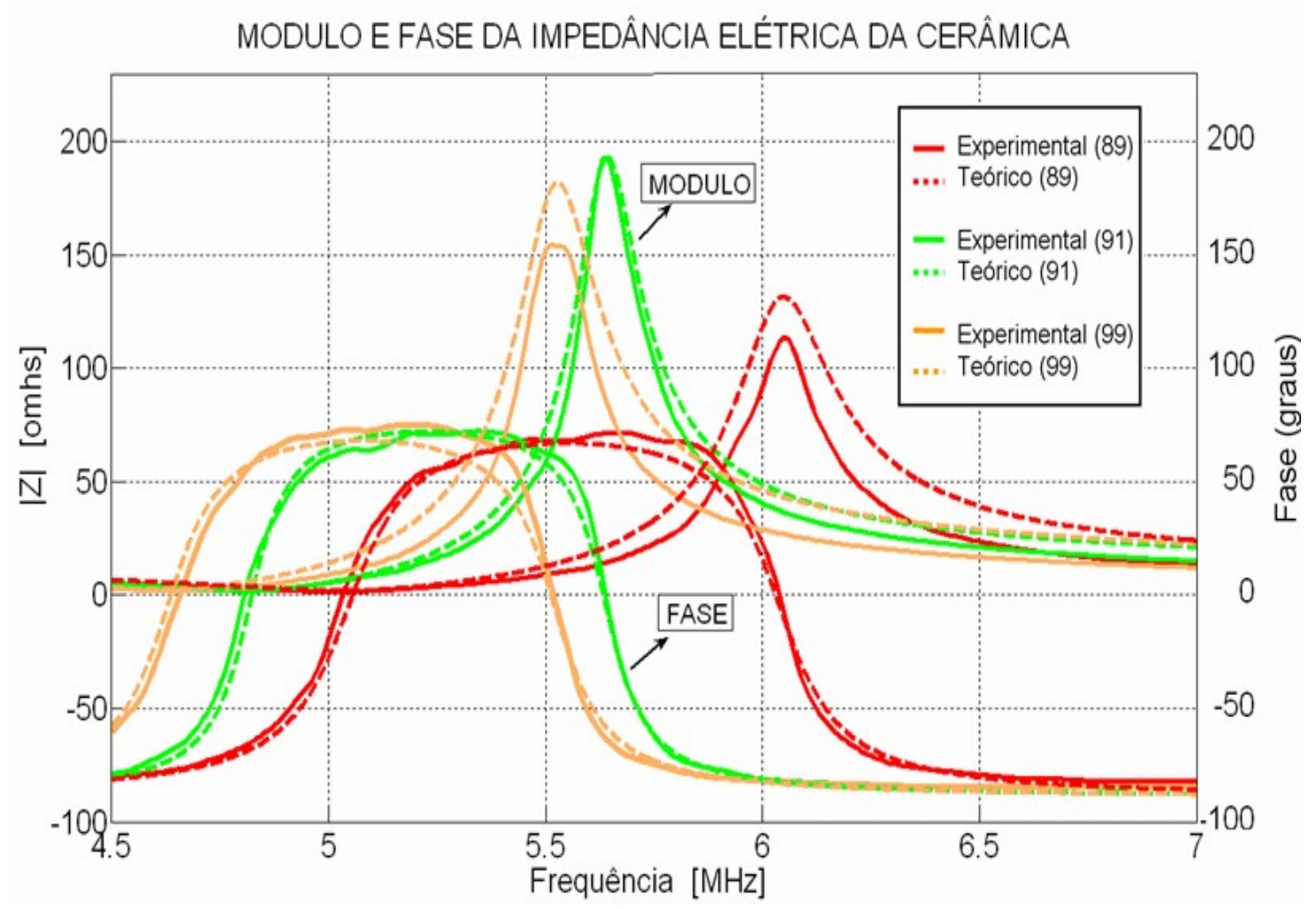

Figura 3.41: Curvas dos módulos e das fases das impedâncias elétricas das cerâmicas.

A partir da determinação das constantes que caracterização as três cerâmicas e das características da camada de casamento de impedância acústica e da camada de retaguarda definidas na seção 3.3.4, foi simulado os transdutores com numero de serie 89, 91 e 99 e obtido as respectivas respostas impulsivas dos sinais de ecos e os seus espectros de amplitudes, para comparação com os resultados experimentais que podem ser vistos nas figuras (3.42), (3.43), (3.44), (3.45) e (3.46). 


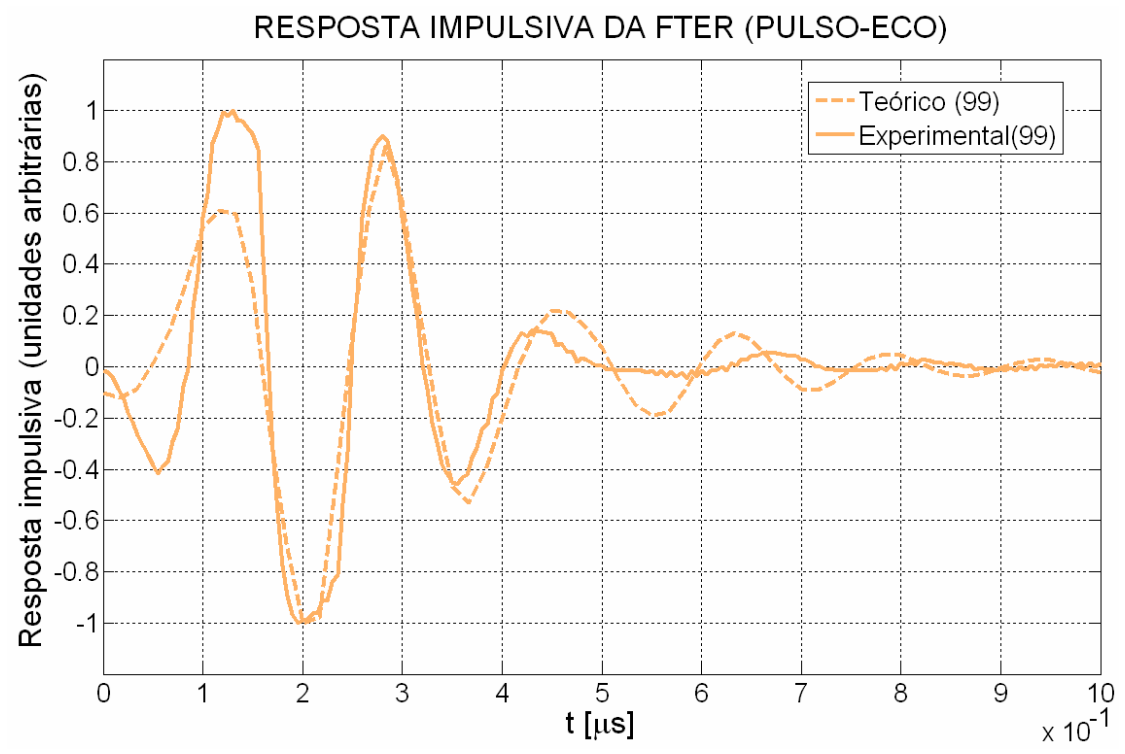

Figura 3.42: Formas das ondas dos sinais de reflexões .

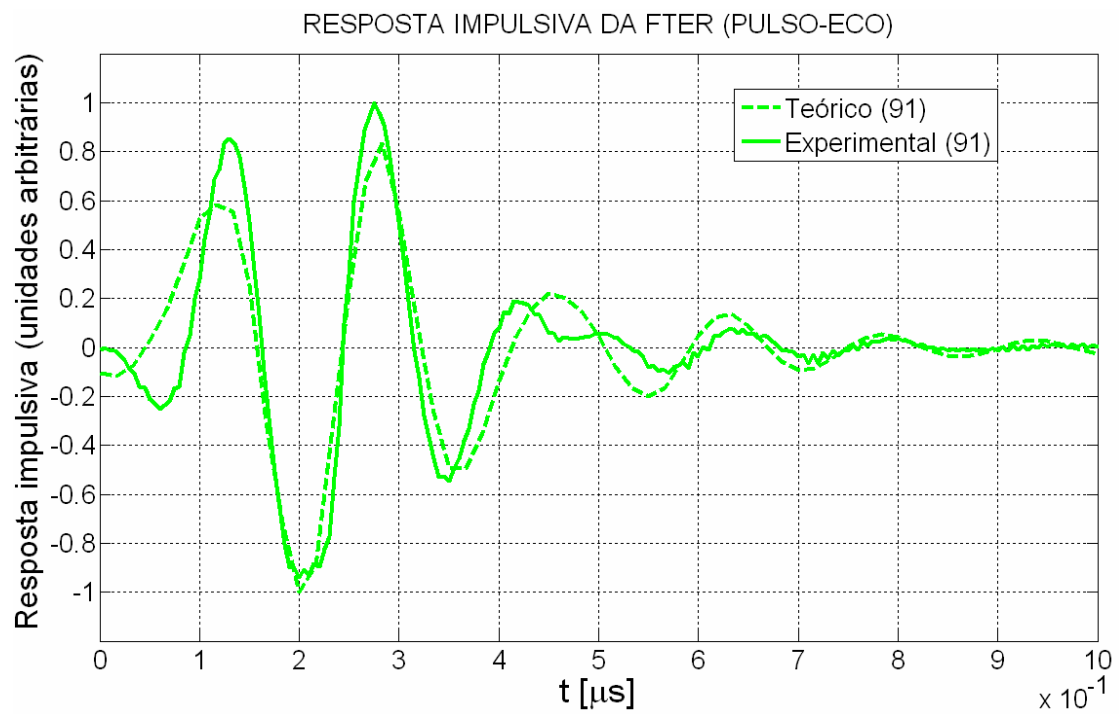

Figura 3.43: Formas das ondas dos sinais de reflexões. 


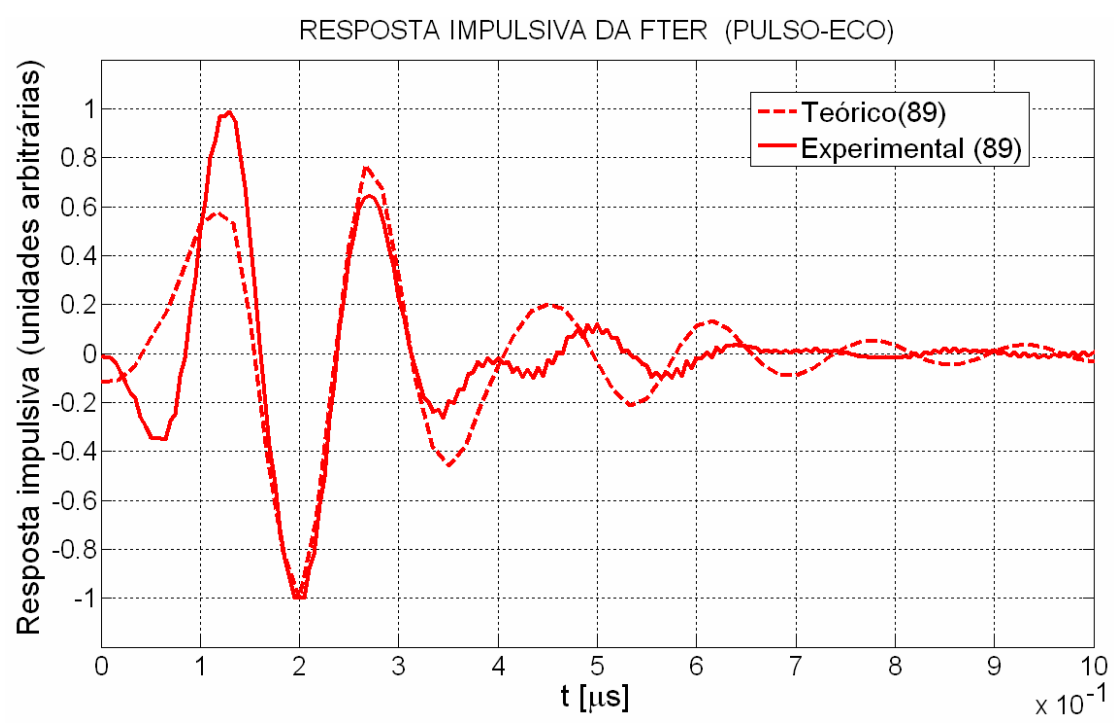

Figura 3.44: Formas das ondas dos sinais de reflexões.

Pode-se verificar na figura (3.41) que entre as três curvas teóricas de impedância elétrica das cerâmicas que foram ajustadas, as curvas identificadas com numero 91 apresentaram a melhor concordância com as curvas experimentais de modulo e fase, e que as constantes que foram determinadas para ajustar estas curvas, vistas na tabela (3.4), estão dentro das tolerâncias fornecidas pelo fabricante. Assim o transdutor identificado pelo numero 91 foi o que apresentou a melhor concordância entre o sinal teórico e simulado da forma de onda da resposta impulsiva do sinal de eco, vista na figura (3.43), e do espectro de amplitude, vistos nas figuras (3.45) e (3.46).

Para uma melhor caracterização da cerâmica e por consequência do transdutor simulado, pode ser implementado um algoritmo para ajustar as curvas teóricas com as curvas experimentais da impedância elétrica, como por exemplo, utilizar o método dos mínimos quadrados. 


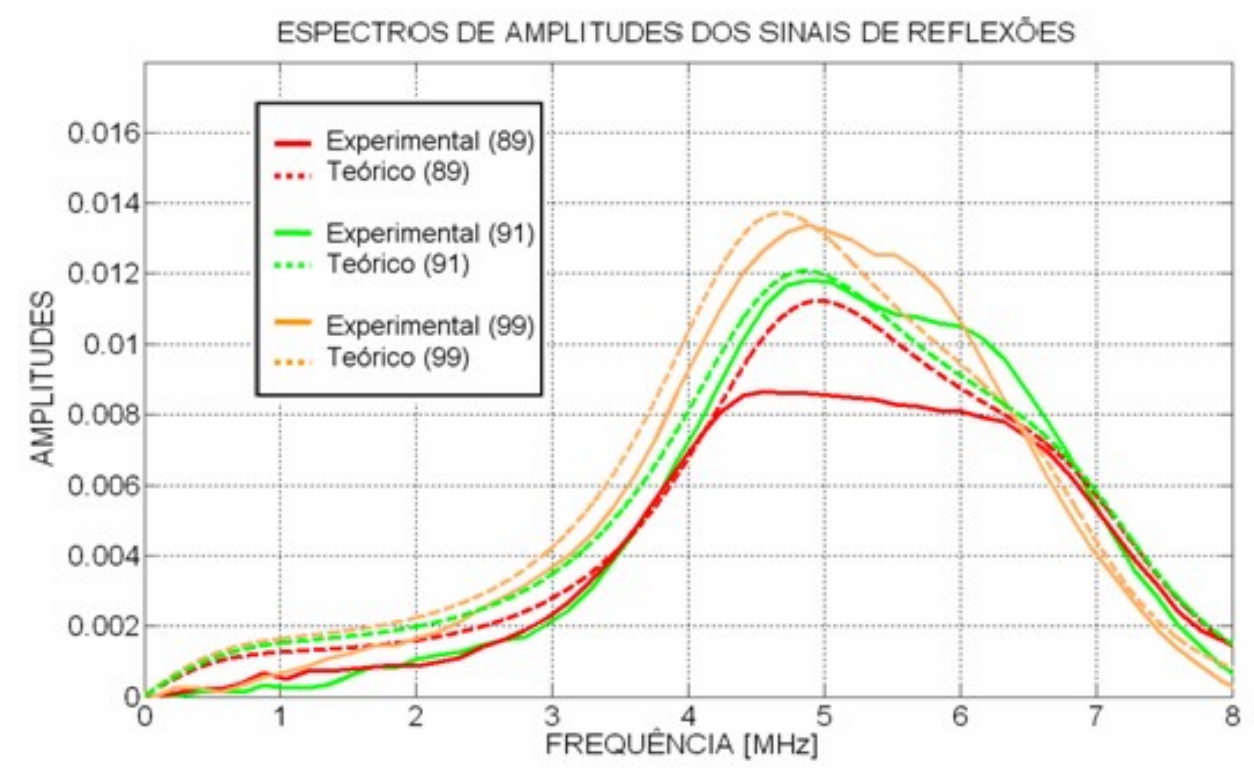

Figura 3.45: Espectros de amplitude dos sinais de reflexões

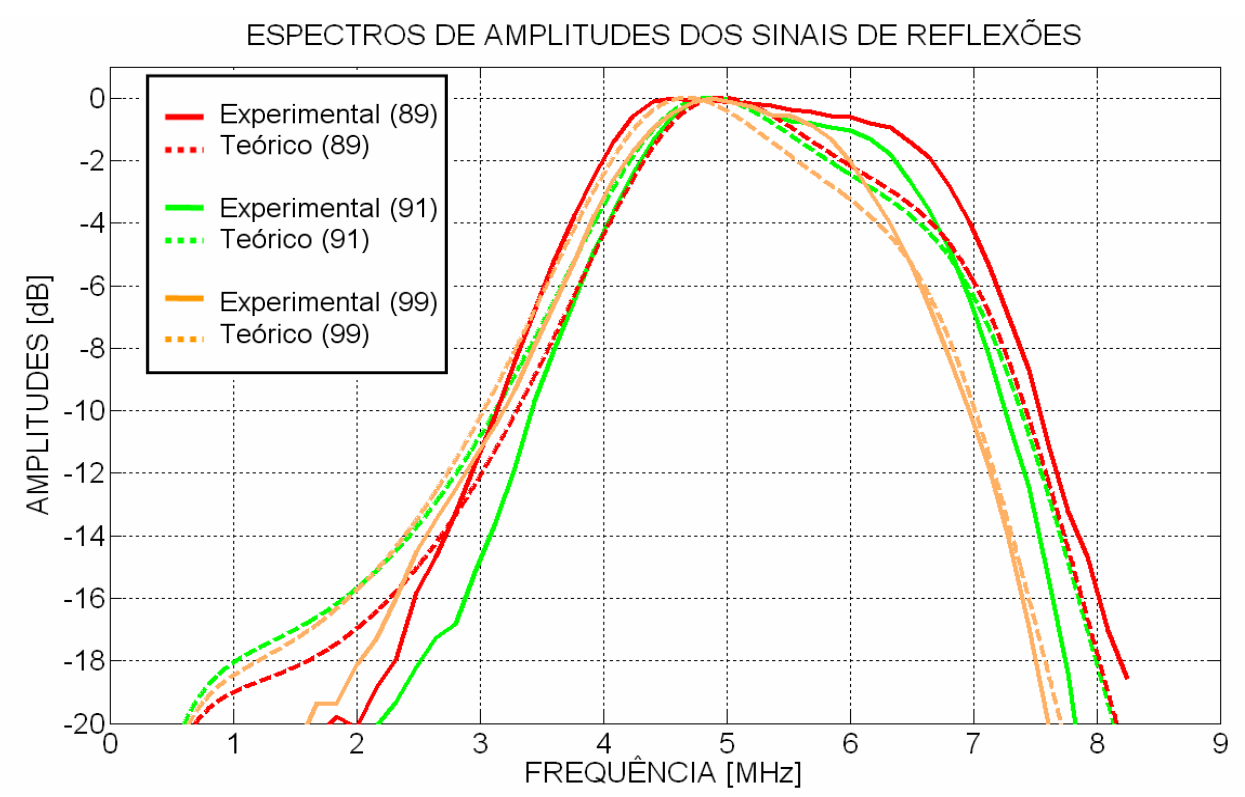

Figura 3.46: Espectros de amplitude dos sinais de reflexões 


\section{CONCLUSÕES}

Os resultados das simulações do transdutor de $5 \mathrm{MHz}$ utilizando o modelo de matriz distribuída foram comparados com resultados experimentais dos protótipos fabricados, mostrando boa concordância. Assim, com especificações prescritas pelo modelo e validadas experimentalmente por protótipos de transdutores foram definidos os materiais passivos das camadas de retaguarda e de casamento de impedância bem como a espessura da camada de casamento de impedância acústica.

Conforme os dados estatísticos do lote de transdutores apresentados na seção referente aos resultados experimentais, pode-se observar uma grande variação percentual da largura de banda do sinal de eco que é acompanhada por uma variação da amplitude de pico-a-pico do sinal de eco dos transdutores, as quais podem ser explicadas em parte pela variação das propriedades da cerâmica, tanto das que estão dentro das tolerâncias ou até mesmo variações em algumas cerâmicas que estão fora das tolerâncias padrões, por variações no processo de fabricação dos transdutores relacionadas ao material, compactação e a colagem das camadas passivas (não permitindo aumentar a largura de banda do transdutor por ele apresentar um sinal de amplitude de pico-a-pico bem inferior ao da média), por erros do operador nos ajustes finais de espessura da camada de casamento de impedância acústica ao aumentar demasiadamente a largura de banda de um transdutor que apresentava em relação à média um sinal de baixa amplitude de pico-a-pico ou por não aumentar a largura de banda de um sinal de alta amplitude de pico-a-pico.

Com relação à produção e ao controle de qualidade de um lote inicial de 143 transdutores, identificados com numero de série para um controle individual, foram aprovados $133(93 \%)$, sendo que $5(3,5 \%)$ foram descartados por baixo desempenho acústico e os $5(3,5 \%)$ restantes não foram totalmente montados por perda das cerâmicas que colaram nos dispositivos de montagem devido aos vazamentos das camadas de retaguarda. Assim pode-se concluir que o processo de fabricação foi satisfatório por manter um padrão de qualidade sem ocasionar muitas perdas. 
Os processos de montagem que envolve posicionamento e fixação da cerâmica, a deposição das camadas de retaguarda e de casamento de impedância acústica, soldagens das conexões elétricas e preenchimento do corpo do transdutor (encapsulamento e vedação) mostraram-se satisfatórios em relação ao tempo de fabricação e confiabilidade de funcionamento dos transdutores. Em relação à repetitividade de processo e repetitividade de comportamento dos transdutores, não considerando a influência das variações nas espessuras das camadas de casamentos de impedâncias acústicas, ocorreram variações significativas da largura de banda do sinal de eco em alguns transdutores, variações que são ocasionadas devido ao lote possuir algumas cerâmicas com propriedades diferentes ou devido à não homogeneidade e qualidade da resina epóxi e endurecedor (para evitar a utilização de produtos sem especificações controladas, na fabricação de um lote de transdutores deve-se utilizar resina epóxi e endurecedor em embalagem industrial e de fornecedores confiáveis). Embora os transdutores testados individualmente obtiveram resultados satisfatórios, os processos continuamente devem ser aprimorados para que haja uma maior uniformização da compactação e adesão das camadas em todos os transdutores de um lote, implementando um processo que a qualidade não dependa demasiadamente dos cuidados, perícia e da percepção do operador do tempo de manipulação das misturas em processo de endurecimento. Assim é desejável uma automatização que envolva redução e maior controle do tempo de deposição, com controle simultâneo da temperatura e pressão, que utilizem dispositivos e métodos padronizados com a finalidade de proporcionar uma maior repetitividade das propriedades especificadas para as camadas e conseqüentemente uma maior repetitividade da eficiência dos transdutores produzidos. 


\section{REFERÊNCIAS BIBLIOGRÁFICAS}

ANDRADE, MARCO AURÉLIO BRIZZOTTI, "Análise de materiais piezelétricos compósitos para aplicações em transdutores de ultrassom", Dissertação de Mestrado, São Paulo - Brasil, Escola Politécnica da Universidade de São Paulo,.2006.

AULD, B. A., "Acoustics Fields and Waves in Solids", vol. 1, EUA, John Wiley \& Sons, $2^{\mathrm{a}}$ ed., 1990 a

FERROPERM PIEZOCERAMICS. "High quality components and materials for the electronic industry", [Online] Available: hittp://Wwww. ferroperm-piezo.com.

FRANCO, E. E., Andrade, M. A., B., Miguel, J. E. S., Buiochi, F., Adamowski, J. C., "Determination of the Acoustic Properties of Tungsten/Epoxy composites using Ultrasonic Transmission Technique." 2005 COBEM - 18th International Congress of Mechanical Engineering November 611, 2005, Ouro Preto, MG.

GALLEGO-JUÁRES, J. A," Piezoelectric ceramics and ultrasonic transducers" ,J. Phys. E: Sci. Instrum. 22 (1989) 804-816

KINO, G. S., "Acoustic Waves: Devices, Imaging, and Analog Signal Processing", New Jersey - EUA, Prentice Hall, 1987.

KINSLER, L. E., Frey, A. R., Coppens, A. B., Sanders, J. V. "Fundamentals of Acoustics", New York - EUA, John Wiley \& Sons, $3^{\text {a }}$ ed., 1982.

LAMBERTI, N., Giua, P. E., Pappalardo, M., "Modello Matriciale e suo Impiego Nell'Ottimizzazione della Risposta Impulsiva del Trasduttore Multielemento", Relatório Técnico, Università di Salerno, 1987.

MONTERO DE ESPINOSA F., "Two-fhase alumina epoxy resin material for multilayer ultrasonic transducers", Proc. Ultrasonic International, p.857-862,1985. 
MOREIRA, DANILO CONTI, "Construção e Caracterização do Campo Acústico de Transdutores Ultrassônicos Piezelétricos de polarização Variável "Dissertação de Mestrado, São Carlos - São Paulo - Brasil, Centro de Ciências Exatas e Tecnológica, Universidade Federal de São Carlos,2008.

OKAMOTO JR, J. ; ADAMOWSKI, J. C.; TSUZUKI, M. S. G.; BUIOCHI, Flavio; CAMERINI, C. . "Autonomous system for oil pipelines inspection. Mechatronics" (Oxford), E.U.A., v. 9, n. 7, p. 731-743, 1999.

PERES, N., M. A. B. Andrade, F. Buiochi, J. C. Adamowski, "Identification of elastic, dielectric and piezoelectric constants in piezoceramic disks", IEEE Transactions on Ultrasonics, Ferroelectics and Frequency Control, (aceito para publicação), 2010.

SHUNG, K. K., Zipparo, M. "Ultrasonic Transducers and Arrays", IEEE Engineering in Medicine and Biology Magazine, v. 15, n. 6, p. 20-30, 1996. 


\section{BIBLIOGRAFIA COMPLEMENTAR}

BERLINCOURT, D., Krueger, H. H. A. "Properties of Morgan Electro Ceramic Ceramics", Relatório Técnico TP-226, Morgan Electro Ceramics, 2000.

BOERI, D. V., 2006, "Caracterização de materiais compostos por ultrassom", Dissertação de Mestrado, São Paulo - Brasil, Escola Politécnica da USP.

DESILETS CS, Frances JD, Kino, S: "The design of efficient broad-band piezoelectric transducers". IEEE Trans. Sonics Ultras.25:115,,1978.

DUARTE, MAURICIO GOMES, "Estudo da Apodização de Cerâmicas Piezoelétricas", Dissertação de Mestrado, Campinas-Brasil, Faculdade de Engenharia Elétrica e de Computação (FEEC), 2003.

EIRAS, J. A., "Cap. 2 - Materiais Piezelétricos", Sensores: Tecnologia e Aplicações, vol. 1, São Paulo, 2004, CD-ROM.

J. SOUQUET. P. DEFRANOULD e J. DESBOIS, "Design of low-loss wide-band, ultrasonic trasducers for noninvasive medical applications", IEEE Trans. on Sonics and ultrasonics vol. SU-26. pp. 75-81, Marzo 1979.

PAPADAKIS, E. P., Oakley, C. G., Selfridge, A. R., Maxfield, B. "Fabrication and Characterization of Transducers", Physical Acoustics, vol. 24, p. 43-134, 1999.

PÉREZ, N., "Dinámica de Estructuras Piezocomposites Complejas: Aplicación a Transductores de ultrasonido", Tesis de Maestria, Uruguay, Universidad de la Republica, 2002. 
This document was created with Win2PDF available at http://www.win2pdf.com.

The unregistered version of Win2PDF is for evaluation or non-commercial use only. This page will not be added after purchasing Win2PDF. 